\title{
SYSTEM IDENTIFICATION OF
}

\section{ADAPTIVE COMPOSITES}

by

Juzer Mohsin Mohammedshah

Thesis submitted to the Faculty of the

Virginia Polytechnic Institute and State University

in partial fulfillment of the requirements for the degree of

Master of Science

in

Mechanical Engineering

APPROVED:

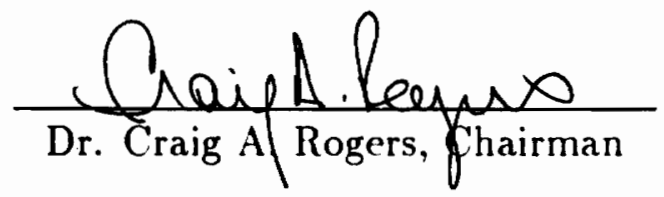

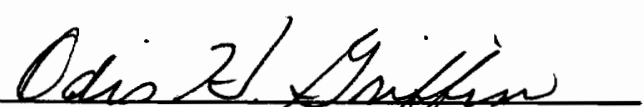

Dr. Odis H. Geithin

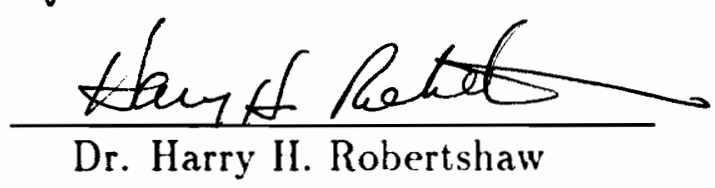

August, 1990

Blacksburg, Virginia 
LD

$$
\begin{aligned}
& 5655 \\
& \sqrt{955} \\
& 1990 \\
& M 453 \\
& \text { C.2 }
\end{aligned}
$$




\title{
System Identification of Adaptive Composites
}

\author{
by \\ Juzer M. Mohammedshah \\ Dr. Craig A. Rogers, Chairman \\ Mechanical Engineering
}

(ABSTRACT)

Modern composites are non-homogeneous materials having high strength fibers embedded in a polymeric or metal matrix, and having directional properties. Shape Memory Alloys (SMAs) such as Nitinol can be embedded in composites for active control of structures. Since the micromechanics of composites in general and adaptive composites in particular are poorly understood, accurate values of material clastic properties and in-plane loads generated are seldom available. It is possible to determine these parameters if natural frequencies of the structure are available. The techniques used to determine these parameteres from the modal response of a structure are generically called 'System Identification'.

This thesis reviews the various System Identification techniques applicable to vibrating structures. Three techniques are then adapted to an orthotropic laminate, and implemented in FORTRAN. These techniques, being iterative in nature, require an initial estimate of the parameters to be identified as input. Because all the techniques discussed here are iterative, they are sensitive to the values of initial estimates. The robustness of these techniques in face of a scatter in the input data is tested using a randomized statistical analysis. The techniques are compared based on certain attributes and recommendations are made. 
to my parents,

for conceiving me,

and much more,

and to Yusuf,

for being there. 


\section{Acknowledgement}

I would like to express my heartfelt gratitude to Dr.Craig Rogers, for playing midwife to this thesis. I hope this thesis is a fair reflection of the many fruitful discussions we had. You have been more than an advisor, Craig. Thank you for your unfailing support during some extremely difficult times. I am also thankful to my committee members, Dr.Robertshaw and Dr.Griffin; Dr.Robertshaw for being around when I needed help, technical and not-so-technical, and Dr.Griffin for teaching me what composites can do, and, more importantly, what they cannot. Nuch of the credit for this thesis also goes to the faculty members of the Mechanical Engineering and the Engineering Science and Mechanics departments, who showed me how interesting course work can be, all those harrowing tests and exams notwithstanding.

Thanks also go to Craig's jolly crew at the Smart Materials Lab., without whose continuous supply of good ideas and bad coffee, this thesis would not have been.

I would also like to acknowledge the financial support provided by the Office of Naval Research.

Finally, this thesis would have been just a dream if my parents had not extended their full support, personally throughout my high school and undergraduate days, and long distance during the graduate studies. 


\section{Contents}

1 Introduction and Literature Review 1

1.1 Introduction . . . . . . . . . . . . . . . . . 1

1.1.1 The Panacea that is Composites . . . . . . . . . . 1

1.1.2 Intelligent Material Systems . . . . . . . . . 2 2

1.1.3 System Identification . . . . . . . . . . . . . . 4

1.2 Motivation ..................... 5

1.3 Literature Review . . . . . . . . . . . . . . . . . 7

1.3.1 Vibration of Plates . . . . . . . . . . . 7

1.3.2 Determination of Elastic Constants . . . . . . . . 12

1.3.3 Intelligent Material Systems and Structures _....... 1.5

1.3.4 System Identification . . . . . . . . . . . . 20

$\begin{array}{llr}2 & \text { Theory } & 29\end{array}$

2.1 Vibration of Plates . . . . . . . . . . . . . . 29

2.1 .1 Kinematic Relations . . . . . . . . . . . . . . 29

2.1 .2 Energy Formulation . . . . . . . . . . . . 30

2.1.3 Rayleigh-Ritz Formulation . . . . . . . . . . . . . . 34

2.2 System Identification . . . . . . . . . . . . . . . 36

2.2 .1 Some Preliminaries . . . . . . . . . . . . . . 36

2.2 .2 Modal Analysis . . . . . . . . . . . . . . 39 
2.2.3 Mode Identification Technique $\ldots \ldots \ldots \ldots \ldots$

2.2.4 Eigenvalue Sensitivity Analysis . . . . . . . . . . 41

2.2.5 Unconstrained Eigenvalue Optimization . . . . . . . . 45

3 FORTRAN Implementation $\quad 49$

3.1 Computer Program SYSID . . . . . . . . . . . . . . . . 49

3.2 Subroutine MODEID . . . . . . . . . . . . . . . . . 54

3.3 Subroutine SENSE . . . . . . . . . . . . . . . 55

3.4 FORTRAN Program OPT $\ldots \ldots \ldots \ldots \ldots \ldots$

4 Discussion and Results $\quad 59$

4.1 Numerical Simulation . . . . . . . . . . . . . . . . 59

4.2 Statistical Analysis . . . . . . . . . . . . . . . . 60

4.3 Statistical Trends . . . . . . . . . . . . . . . . . . 64

4.4 Evaluation of the Three Techniques . . . . . . . . . . 82

5 Conclusions and Recommendations $\quad 87$

5.1 Conclusions . . . . . . . . . . . . . . 87

5.2 Recommendations . . . . . . . . . . . . . . . . 89

$\begin{array}{lr}\text { References } & 91\end{array}$

$\begin{array}{lr}\text { A Beam Eigenvalues and Frequency Parameters } & 98\end{array}$

A.1 Beam Vibration Equations and Boundary Conditions . . . . . . . 98

A.2 Solutions for Beam Equation . . . . . . . . . . . . . . . 99

A.3 Eigenvalues and Frequency Parameters . . . . . . . . . . . . 101

B Listing of Computer Program SYSID 103 
Vita 


\section{List of Figures}

1.1 Shape Recovery of Nitinol . . . . . . . . . . . . . . 16

1.2 Young's Modulus and Yield Stress v. Temperature for Nitinol . . . 19

4.1 Effect of Number of Frequencies on the Mean Values of Stiffnesses for $20 \%$ Bound on Initial Data Using Optimization . . . . . . . . 65

4.2 Effect of Number of Frequencies on the Mean Values of In-plane Loads for $20 \%$ Bound on Initial Data Using Optimization . . . . . . . . 66

4.3 Variation of Mean and Standard Deviation of $E_{x}$ Computed by Mode Identification with Change in Percentage Bound on Initial Estimate

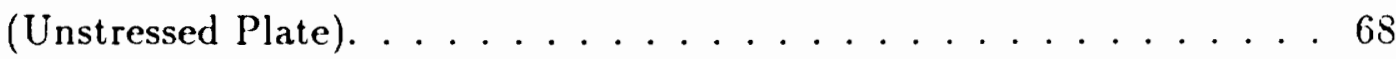

4.4 Variation of Mean and Standard Deviation of $E_{x}$ Computed by Mode Identification with Change in Percentage Bound on Initial Estimate

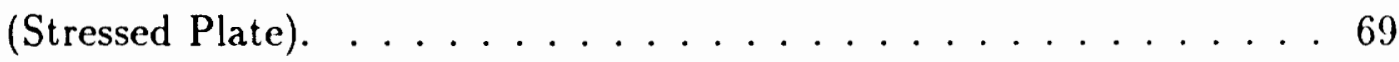

4.5 Variation of Mean and Standard Deviation of $E_{x}$ Computed by Sensitivity Analysis with Change in Percentage Bound on Initial Estimate (Unstressed Plate $) \ldots \ldots \ldots \ldots \ldots \ldots$

4.6 Variation of Mean and Standard Deviation of $E_{y}$ Computed by Mode Identification with Change in Percentage Bound on Initial Estimate

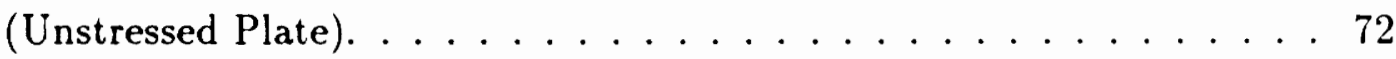


4.7 Variation of Mean and Standard Deviation of $E_{y}$ Computed by Mode Identification with Change in Percentage Bound on Initial Estimate

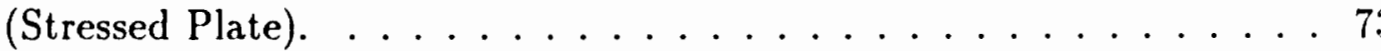

4.8 Variation of Mean and Standard Deviation of $E_{y}$ Computed by Sensitivity Analysis with Change in Percentage Bound on Initial Estimate (Unstressed Plate) . . . . . . . . . . . . . . . . . . 74

4.9 Variation of Mean and Standard Deviation of $G_{x y}$ Computed by Mode Identification with Change in Percentage Bound on Initial Estimate

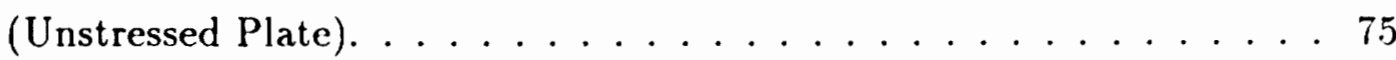

4.10 Variation of Mean and Standard Deviation of $G_{x y}$ Computed by Mode Identification with Change in Percentage Bound on Initial Estimate

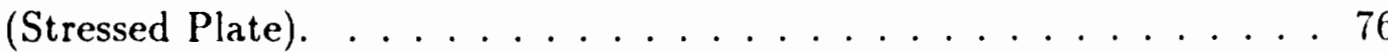

4.11 Variation of Mean and Standard Deviation of $G_{x y}$ Computed by Sensitivity Analysis with Change in Percentage Bound on Initial Estimate

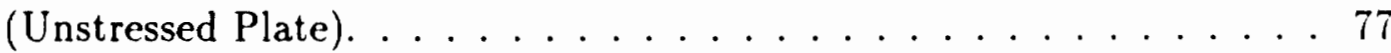

4.12 Variation of Mean and Standard Deviation of $N_{x}$ Computed by Mode Identification with Change in Percentage Bound on Initial Estimate. . 79

4.13 Variation of Mean and Standard Deviation of $N_{y}$ Computed by Mode Identification with Change in Percentage Bound on Initial Estimate. . 80

4.14 Variation of Mean and Standard Deviation of $N_{x y}$ Computed by Mode Identification with Change in Percentage Bound on Initial Estimate. . 81 


\section{List of Tables}

4.1 Physical Properties of the Orthotropic Plate Used for Simulation . . . 63

4.2 First Eight Frequencies of a C-F-C-F Plate . . . . . . . . . 63

4.3 Comparison of the Three Techniques . . . . . . . . . . . 85

A.1 Beam Eigenvalues, $\epsilon_{i} \ldots \ldots \ldots \ldots \ldots$

A.2 Beam Frequency Parameters, $\alpha_{i} \ldots \ldots \ldots \ldots 2 \ldots \ldots$ 


\section{Nomenclature}

$\begin{array}{ll}A_{l}^{(i)} & \text { Eigenvector of length } l \text { corresponding to } i \text { th eigenvalue } \\ A_{m n} & \text { Generalized displacements (in Rayleigh-Ritz series) } \\ a, b & \text { Plate dimensions along } x \text { and } y \text { directions respectively } \\ B_{m n} & \text { Generalized displacements (in Rayleigh-Ritz series) } \\ C_{m n} & \text { Generalized displacements (in Rayleigh-Ritz series) } \\ C_{i j}, C_{i j, m n} & \text { Elements of stiffness matrix } \\ D_{i j} & \text { Bending stiffnesses of laminate } \\ D_{l} & \text { Coefficients of integral matrices } Q_{l, i j} \\ \{d\}^{(k)} & \text { Search direction at } k \text { th iteration (in Optimization) } \\ E_{x}, E_{y} & \text { Young's modulii of the laminate in } x \text { and } y \text { directions respecitvely } \\ F_{r s}^{x} & \text { Values of } a \int_{0}^{a} \Phi_{r} \Phi_{s}^{\prime \prime} d x \\ F_{r s}^{y} & \text { Values of } b \int_{0}^{b} \Theta_{r}^{\prime \prime} \Theta_{s}^{\prime \prime} d y \\ f_{i}^{e} & \text { Experimental resonant frequencies } \\ G_{x y} & \text { In-plane shear modulus } \\ G_{r s}^{x} & \text { Values of } a \int_{0}^{a} \Phi_{r} \Phi_{s}^{\prime} d x \\ G_{r s}^{y} & \text { Values of } b \int_{0}^{b} \Theta_{r} \Theta_{s}^{\prime} d y \\ \{g\}^{(k)} & \text { Gradient of the cost function at } k \text { th iteration } \\ {[H]} & \text { Positive definite approximation of a Hessian } \\ H_{i j} & \text { Solution matrix relating } \lambda_{i}, D_{i} \text { for Mode Identification and } \\ H_{r s}^{x} & \text { Sensitivity matrix for Sensitivity Analysis } \\ H_{r s}^{y} & \text { Values of } a \int_{0}^{a} \Phi_{r}^{\prime} \Phi_{s}^{\prime} d x \\ h & b \int_{0}^{b} \Theta_{r}^{\prime} \Theta_{s}^{\prime} d y \\ & \text { Plate thickness }\end{array}$


Identity matrix

Stiffness matrix

Beam length

Mass matrix

$N_{x}, N_{y}, N_{x y}$

In-plane loads

$p, q$

Values that determine number of terms in the Rayleigh-Ritz solution

$Q_{l, i j}, Q_{l, i j, m n}$

Integral matrices

$T$

$U$

$u^{\circ}$

Kinetic energy of an elastic body

Strain energy of an elastic body

Deflection of plate mid-plane in $\mathrm{x}$-direction

Potential energy due to in-plane loads

Maximum potential energy of a vibrating plate

Deflection of plate mid-plane in $y$-direction

Potential energy due to transverse loads

Transverse deflection of the plate

Generalized displacements

\section{Greek Letters}

$\alpha_{i}, \alpha_{r}$

Frequency parameters of beams

$\beta$

$\delta_{r s}$, etc.

$\epsilon_{j}$, etc.

$\gamma_{x y}$

$\kappa$

$\lambda_{i}$

$\lambda_{i}^{e}$

$\nu_{x y}$

Frequency coefficient

Kronecker delta

Beam eigenvalues or strains (specified in text)

Engineering shear strain in $x-y$ plane

Curvatures

$i$ th eigenvalue from plate vibration model

$i$ th eigenvalue from experimental resonant frequencies

Poisson's ratio 
II

$\rho$

$\sigma_{i}$

$\sigma_{i j}$

$\omega$

$\omega_{s}$

$\Phi_{m}, \Phi_{i}$

$\Theta_{m}, \Theta_{i}$

Subscripts

$x$

$y$

$x y$

$i, j, k, l, m, n, r, s$

Superscripts

$a$

e

$\mathrm{T}$

,

II

\section{$\underline{\text { Special Characters }}$}

First time derivative

Second time derivative
Analytical

Experimental

Transpose

First partial derivative

Second partial derivative
Term in $y$-direction

Cross term

Indices
Material density

Normal stress in $i$ direction

Shear stress in $i j$ plane

Circular frequency

Circular frequency at stationary condition

Assumed X-direction function for Rayleigh-Ritz solution

Assumed Y-direction function for Rayleigh-Ritz solution 
"Well! I've often seen a cat without a grin," thought Alice; "But a grin without a cat! It's the most curious thing I ever saw in all my lifc!" 


\section{Chapter 1}

\section{Introduction and Literature Review}

\section{$1.1 \quad$ Introduction}

In this introduction, we shall take a bird's eye view of the field of composites, intelligent material systems, adaptive materials, and system identification, which will be followed by a detailed exposition of these topics in the Literature Review section.

\subsubsection{The Panacea that is Composites}

Since the early days of plywood, and then fiberglass, the concept of composite materials has come a long way. Composites have totally revolutionized the traditional philosophies of design. Typically, an engineer had little control over the material once the selection had been made based on the design requirements. His job was to optimize cross-sections using the design constraints. It was usually a case of making the best of a not-so-ideal situation. Composites, and advanced composites in particular, permit him to play around with the properties of the material itself, which has come to be known as 'tailoring'. In addition to this 'customizing' ability, modern composites typically have a much higher strength-to-weight ratio as compared to traditional 
materials. As a result, composites have found a wide usage in aerospace, defense, and automotive industries.

By advanced composites we mean the modern composites consisting of high strength fibers embedded in a polymeric or metal matrix. Modern composites are fabricated by consolidating a number of orthotropic layers of a given material to obtain the desired thickness. The designer can obtain a wide range of properties by simply altering the layup scheme, which will, in general, result in an anisotropic structure. However, this has posed a major problem to the structural engineer, because there are so many permutations of materials and layups that it is all but impossible to develop a general guideline for their use. The progress in understanding the mechanics of these materials has not kept up with the breathtaking pace in the field of materials science. This, in turn, has led to what Clarke (1984) calls failure of nerve, and failure of imagination.

Since the engineers are not certain about mechanics of composites, they just try to take advantage of the high strength-to-weight ratio by replacing the traditional materials in existing designs with composites. Most of the time they fail to realize the exotic possibilities offered by the tailorability of the material. A better understanding of the mechanics of composites would go a long way in remedying this unhappy situation. It is hoped that the current work will contribute to this understanding in some measure.

\subsubsection{Intelligent Material Systems}

"Smart", "Intelligent", "Sense-able", and "Adaptive" have all been used to describe structures with the ability to respond or react to a certain stimuli or input in a desired fashion. There is a lot of anthropomorphic chauvinism involved in the definition of 
various terms used above. No consensus exists as to the standard definition of these special class of materials. However, one can get some flavor of the new science by the definitions presented above. One of the most prominent class of adaptive materials is the so-called shape memory alloys (SMAs). In the current work, we shall be concerned with these materials only.

Adaptive structures, as the name implies, are structures with a built in capability of changing physical configuration and/or properties. Though there are a lot of mechanical devices that fit this category, the only structures that are germane to this thesis are the SMA hybrid composites. These are fabricated by incorporating the SMA fibers in the matrix during the curing of composites, thereby forming an integrated structure. This structure is then capable of sensing internal and external stimuli, and responding to it in a predictable manner. According to Barker (1989), the common features that should be included in any definition of smart or intelligent structures are:

Sensors Smart structures have embedded or intrinsic sensor(s) which recognize and measure the intensity of stimulus which could be force-like, displacement-like, thermal, electric, magnetic, chemical, etc.

Actuators Smart structures have embedded or intrinsic actuator(s) to respond to the stimulus.

Control Mechanism Smart structures have the ability to control the response to the stimulus according to a predetermined relationship. The control mechanism must be capable of selecting response if more than one option is available.

Time and Nature of Response Smart materials have fast response in relation to 
stimulus. The system returns to its original state when the stimulus is removed.

\subsubsection{System Identification}

At the heart of modern scientific and engineering enterprise is the process called mathematical modelling. A mathematical model is a limited representation of reality, based on the scientist's domain of interest. A mathematical model consists of relational statements regarding the physical parameters of the system under consideration, inputs to the system, external forces operating on the system, and the output or response of the system to these various stimuli. Nature, however, being as fickle as it is, does not lend itself very well to a holistic treatment. Typically, the modeller will isolate the phenomena of interest, taking account of some, but not all, of the external agents affecting the system, based on certain assumption that he thinks are valid.

The next step is to validate the model by comparing analytical results with experimental data. Due to the various assumptions built into the model, these will rarely match. Hence the scientist then goes back to the model and tweaks certain constants here and there to make the analytical results agree with experimental data. The generic term 'System Identification' is used in this context. It refers to a host of techniques developed over the years to deal with the inverse problem of determining fundamental properties of a system from the observed behavior of a system. Some of these will be considered later in this chapter.

As far as the current work is concerned, the mathematical model used is the one developed by application of Rayleigh-Ritz energy technique, and the experimental data in question are the eigenvalues and modal vectors obtained by performing modal analysis on the structure. The flexural deformations of an elastic structure are gov- 
erned by material elastic constants and external loads. Specifically, for a laminated orthotropic plate, these are the four bending stiffnesses, $D_{11}, D_{12}, D_{22}$, and $D_{66}$, and the three force resultants, $N_{x}, N_{y}$, and $N_{x y}$. In 1979, Wolf and Carne showed that if four natural frequencies of a panel are available, they can be used in conjunction with a Rayleigh-Ritz type of analysis to determine the bending stiffnesses in absence of in-plane loads. In the present work we shall consider the determination of in-plane loads as well. The details shall be presented in Chapter 2 .

\subsection{Motivation}

Modern composites are fabricated by laying up a number of plies of 'pre-pregs', which consist of some high strength fibers like graphite or boron embedded in a polymeric matrix, to obtain the desired thickness and section properties. The properties of the 'laminate' as a whole depend upon the angle that the high strength fibers in various plies make with some reference coordinate system. These properties obviously depend on the properties of individual plies too. This is where the problem arises. Typically, certain assumptions are made regarding the kinematics of the fibers in matrix, and the so-called micromechanics models are developed to predict the gross properties of a given ply, in terms of the fiber and matrix properties.

The various parameters needed for implementing these models, such as fiber volume fraction, are seldom accurately known, given the variations inherent in any manufacturing system. Hence the transition from local properties in a generally inhomogeneous material to global properties may oftentimes give unwarranted values of material constants such as stiffnesses and gross density. If these values of material constants are to be used for validation of any given mathematical model, the ana- 
lytical results obtained may not match well with experimental results, even if the model deserves some merit. The current project aims at remedying precisely this discrepancy.

Composites are typically manufactured by thermal curing of laid up laminates in autoclaves or by the use of hot presses. Depending upon the heating and cooling cycles employed, as well as the thermal behavior of the material, there might be local and global expansions or contractions during the curing process. This results in laminates with residual stresses, giving rise to net in-plane loads. The presence of in-plane loads have a significant effect on the mechanical behavior of structures. At times, these in-plane loads may be deliberately induced to obtain certain control characteristics, such as those induced by employing shape memory alloy fibers embedded in the composite substructure. In this case, some of the force is balanced by the interaction between fiber and matrix, thus giving net in-plane loads significantly different from those calculated using the constitutive relationships for the material. The techniques presented here may then be used to determine the net in-plane loads experienced by the structure.

Finally, as pointed out by Deobald and Gibson (1988), to obtain one complete set of material constants, two tensile test specimens and one shear test specimen must be fabricated and tested. One disadvantage of these tests is that the resulting strains are measured by strain gages at a point (well, not strictly, as strain gages have finite size, and so they measure strain smeared over the gage area), thus giving the localized value of stiffnesses. In addition, these tests require destruction of the original specimen. Obviously, such an approach cannot be used for the purposes of quality control as every specimen is different from each other due to differences inherent in 
any manufacturing system, and testing every specimen to destruction would not leave the manufacturer with any product at all! The technique outlined here requires just one test to obtain all the four material constants and three in-plane loads, and is non-destructive in nature.

\subsection{Literature Review}

In this section we shall take a look at certain classical and contemporary publications which have either a direct bearing on the matter at hand or which can supplement the theory presented in later chapters. For the convenience of organization, the review is divided into four major sections dealing with a general description of various plate vibration theories, determination of elastic constants of plates using Rayleigh-Ritz technique, a brief description of shape memory alloys, and system identification.

\subsubsection{Vibration of Plates}

All the formulations used in the various plate theories start with the classical equations of 2-D or 3-D elasticity. From that point on, various simplifying assumptions are made regarding the kinematics of deformation, which give rise to the different types of plate theories. Much of the work done in the field of composite materials deals with anisotropic plate theories, since, by its very nature, a laminate consisting of an arbitrary layup gives rise to an anisotropic medium. A number of excellent texts are available on the theory of anisotropic plates such as the works of Lekhnitskii (1968), and Abartsumyan (1970).

In the case of a so-called thin plate, or classical laminated plate theory (CLPT), 
the standard Kirchoff assumption, which says that normals to the mid-plane before bending remain straight, normal, and unstretched after bending are applicable. This reduces the three dimensional problem to an equivalent two dimensional one.

The above assumptions lead to the following kinematic relations, given in Whitney (1987) and elsewhere:

$$
\begin{gathered}
\epsilon_{x}=\epsilon_{x}^{0}+z \kappa_{x} \\
\epsilon_{y}=\epsilon_{y}^{0}+z \kappa_{y} \\
\gamma_{x y}=\gamma_{x y}^{0}+z \kappa_{x y}
\end{gathered}
$$

where $z$ is the out of plane axis, the $\epsilon$ 's are in-plane strains, and the $\kappa$ 's are curvatures. The governing equations for vibration are then obtained by substituting these relations into the equilibrium equations obtained from classical theory of elasticity.

The second class of plate theories are the so-called von Kármán type theories which take into account the higher order strain tensors, leading to non-linear equations of motion, and are generally used for analysis of stability problems. An excellent exposition of the von Kármán type theories as applied to composites can be found in Chia $(1980)$.

Finally there are the thick-plate or shear deformation theories. In cases where the ratio of the thickness of plate to the smallest in-plane dimension is sufficiently high (what counts for 'sufficiently high' depends very much on application and material 
properties), and/or the ratio of in-plane modulus to the transverse shear modulus is appreciable, the classical Kirchoff assumptions are no longer valid, and the kinematic relations used for displacements need to take account of that. Depending on the degree of terms used in these kinematic assumptions, a number of higher order shear deformation theories have been proposed in recent years (Noor and Burton, 1989). Noor and Burton (1989), and Kapania and Raciti (1989a, 1989b) present an excellent overview of these higher order theories. Comparisons are carried out between various higher order theories and the classical theory as well as some three dimensional elasticity solutions. All the shear deformation theories give frequencies lower than the CLPT, as in the CLPT the plate is effectively considered to possess infinite shear modulus in the transverse planes. Hence by using the classical theory we may obtain an upper bound on the actual frequencies of the plate, the deviation from actual frequency increasing with higher modes.

The governing equations obtained in most of these theories yield closed form solutions only for very simple boundary conditions. For plates having simply supported end conditions, solutions can be easily obtained by the the Navier techniques and if at least two opposite edges are simply supported, solutions can be obtained by the standard Levy technique (Timoshenko and Woinowsky-Krieger, 19:59). For all the other types of boundary conditions, solutions are generally obtained in terms of some infinite series of trigonometric and/or hyperbolic functions.

The phrase "variational methods" refers to methods that make use of variational principles, such as the principle of virtual displacements to determine approximate displacements as continuous functions of position in a body (Reddy, 1984). Variational statements of physical problems form a powerful basis for obtaining solutions to many 
physical problems, many of which are intractable otherwise. They can be utilized to determine the governing equations of problems that are posed in terms of determining maxima or minima of a functional. Variational principles can be used to formulate energy equations which can then be used to apply the Rayleigh Ritz technique. The Ritz method provides a convenient tool for obtaining approximate solutions to boundary value problems (Whitney, 1987). The problem is formulated in terms of an energy functional as follows:

$$
\Pi\left(u^{\circ}, v^{\circ}, w\right)=\text { stationary value }
$$

where, for the free vibration case,

$$
\Pi=U+W+V-T
$$

where,

$U=$ strain energy of an elastic body

$W=$ potential energy due to transverse loads

$V=$ potential energy due to in-plane loads, and

$T=$ kinetic energy of the elastic body

In the Ritz method, a solution is sought in the series form,

$$
u^{o}=\sum_{m=1}^{M_{1}} \sum_{n=1}^{N_{1}} A_{m n} U_{m n}(x, y)
$$




$$
\begin{aligned}
& v^{\circ}=\sum_{m=1}^{M_{2}} \sum_{n=1}^{N_{2}} B_{m n} V_{m n}(x, y) \\
& w=\sum_{m=1}^{M_{3}} \sum_{n=1}^{N_{3}} C_{m n} W_{m n}(x, y)
\end{aligned}
$$

where $A_{m n}, B_{m n}$, and $C_{m n}$ are generalized displacements. The functions $U_{m n}, V_{m n}$, and $W_{m n}$ are known and usually chosen in the variables separable form $X_{m}(x) Y_{n}(y)$. These functions must satisfy the so-called essential, or geometric, boundary conditions. For the solution of plate problems, following the approach proposed by Young (1950), characteristic equations of vibrating beams having boundary conditions similar to the plate boundary conditions are used as the assumed functions $X_{m}(x)$ and $Y_{n}(y)$. Substituting Eq. 1.4 into the energy condition expressed by Eq. 1.2 leads to a minimization problem relative to the unknown generalized displacements. In particular, $\Pi$ is a function of $A_{m n}, B_{m n}$, and $C_{m n}$ only and the conditions given by Eq. 1.2 reduce to the equations:

$$
\begin{array}{ll}
\frac{\partial \Pi}{\partial A_{m n}}=0 & \left\{\begin{array}{l}
m=1,2, \ldots, M_{1} \\
n=1,2, \ldots, N_{1}
\end{array}\right. \\
\frac{\partial \Pi}{\partial C_{m n}}=0 \quad\left\{\begin{array}{l}
m=1,2, \ldots, M_{2} \\
n=1,2, \ldots, N_{2}
\end{array}\right. \\
\frac{\partial \Pi}{\partial C_{m n}}=0 \quad\left\{\begin{array}{l}
m=1,2, \ldots, M_{3} \\
n=1,2, \ldots, N_{3}
\end{array}\right.
\end{array}
$$


For the classical plate theory formulations, $\Pi$ is always quadratic in the generalized displacements. Thus, the conditions expressed by Eq. 1.5 lead to a $\sum_{i=1}^{3} M_{i} \times N_{i}$ set of linear simultaneous equations. For the free vibration problems, this leads to the standard eigenvalue problem. A more detailed presentation of this technique is given in the following chapter.

\subsubsection{Determination of Elastic Constants}

Unlike determination of elastic constants from modal analysis of beams, very few references exist for the plate problem. One of the earlier papers discussing the determination of dynamic elastic constants of an isotropic circular plate was by Zelenev and Elektrova (1973). The paper considered polymer plates having boundary conditions of clamped and free edges. A notable work on orthotropic plates by Caldersmith and Rossing (1984) discussed a method of determining Poisson's ratio. The authors took advantage of frequency split of degenerate mode pairs caused by coupling between longitudinal and transverse strains. By designing plates with certain specific aspect ratios, the Poisson's ratio can be determined from the frequency ratios of the modes. In 1979, Wolf and Carne published the seminal paper which is the direct progenitor of this current research program. They developed empirical equations for the elastic modulii of a rectangular isotropic plate. They began by using the frequency equations determined by Leissa using the Rayleigh-Ritz technique (Leissa, 1973).

$$
\omega_{m n}=\frac{\lambda_{m n}(\nu, a / b)}{a^{2}} \sqrt{\frac{D}{\rho h}}
$$

Using finite element analysis, they developed empirical equations for $\lambda_{22}$ and $\lambda_{31}$. Us- 
ing empirical results, approximate values of the shear modulus and Young's modulus could be determined.

$$
G=\frac{4.2 \rho a^{4} \omega_{22}^{2}}{\hat{\lambda}_{22}^{2} h^{2}} \quad E=\frac{10.92 \rho a^{4} \omega_{31}^{2}}{\hat{\lambda}_{31}^{2} h^{2}}
$$

where,

$$
\begin{aligned}
& \hat{\lambda}_{22}=\lambda_{22}(\nu=0.3) \sqrt{\frac{1-\nu}{0.7}} \\
& \hat{\lambda}_{31}=\lambda_{31}(\nu=0.3) \sqrt{\frac{1-\nu^{2}}{0.91}}
\end{aligned}
$$

$$
0.2 \leq \nu \leq 0.44
$$

Wolf and Carne (1979) used an impact vibration test with a Fast Fourier Transform analyzer to determine resonant frequencies of panels having all edges free. They obtained results for a 6061-T6 aluminum plate and isotropic random chopped-fiber composite plates.

Similar kind of work on orthotropic plates has been done quite recently. In 1984 , DeWilde, et al., published a paper, where they first use the classical plate theory to formulate the equilibrium equations. Then the Rayleigh-Ritz method is applied for which the authors resort to the variational or weak formulation. As discussed in a 
previous section, this then yields the standard eigenvalue problem

$$
\left(\left[K^{\prime}\right]-\lambda[M]\right)\{A\}=\{0\}
$$

The authors then use the orthogonality of eigenmodes and write the eigenvalues as follows:

$$
\lambda_{i}=A_{i}\left(\frac{D_{11}}{a^{4}}+\frac{D_{22}}{b^{4}}\right)+B_{i} \frac{D_{12}}{a^{2} b^{2}}+C_{i} \frac{D_{66}}{a^{2} b^{2}}
$$

where $A_{i}, B_{i}$, and $C_{i}$ are parameters depending on the eigenfrequency, Poisson's ratio, and plate geometry. The values of these parameters for different values of Poisson's ratio and plate aspect ratio were determined using a finite element code. Once these values have been established, they are available for future use in determination of elastic constants. The process is as follows:

1. An initial estimate of Poisson's ratio is obtained either from literature or the rule of mixtures.

2. A series of experimental tests is carried out on the lamina using different aspect ratios and the previously established tables are used to find the appropriate coefficients A, B, and C.

3. The values of the four elastic constants $D_{11}, D_{12}, D_{22}$, and $D_{66}$ can then be calculated using Eq. 1.9

4. The value of ratio $D_{11} / D_{22}$ is used to estimate a better value of Poisson's ratio, 
which can now be used in an iterative process, giving more accurate values of the stiffnesses.

In a later paper published in 1986, DeWilde, et al.(1986), proposed an extension on the previous technique by introducing Lagrange interpolation functions as trial functions in the Rayleigh-Ritz formulation. Also, the formulation used was for a general orthotropic plate rather than special orthotropic plate (i.e. all the plies need not be either $0^{\circ}$ or $90^{\circ}$, but may be a combination of the two). They also generated a sensitivity matrix relating the elastic constants to the eigenfrequencies.

Lastly, we mention the work carried out by Deobald (1985), and Deobald and Gibson (1988). This will not be described in detail here as it forms the backbone of this thesis and will be presented in detail in Section (2.2.3).

\subsubsection{Intelligent Material Systems and Structures}

Most of the material in this section has been presented elsewhere (Rogers, et al., 1988a; Rogers, et al., 1988b; Rogers and Robertshaw, 1988; Barker, 1989), hence only a brief summary highlighting the major features and important papers shall be presented here. Here, we consider just one class of adaptive materials, namely shape memory alloys (SMA). An SMA has the inherent ability to 'remember' a specific memorized shape. The shape memory effect is basically a phenomenon in which an object in the low temperature martensitic condition, when plastically deformed and the external stresses removed will regain its original - 'memorized' - shape when heated (see Figure (1.1)). This is the result of martensitic transformation taking place during heating. A great deal has been learned about the characteristic properties of this class of materials in the past twenty years or so (Cross, et al., 1969; Wayman and 


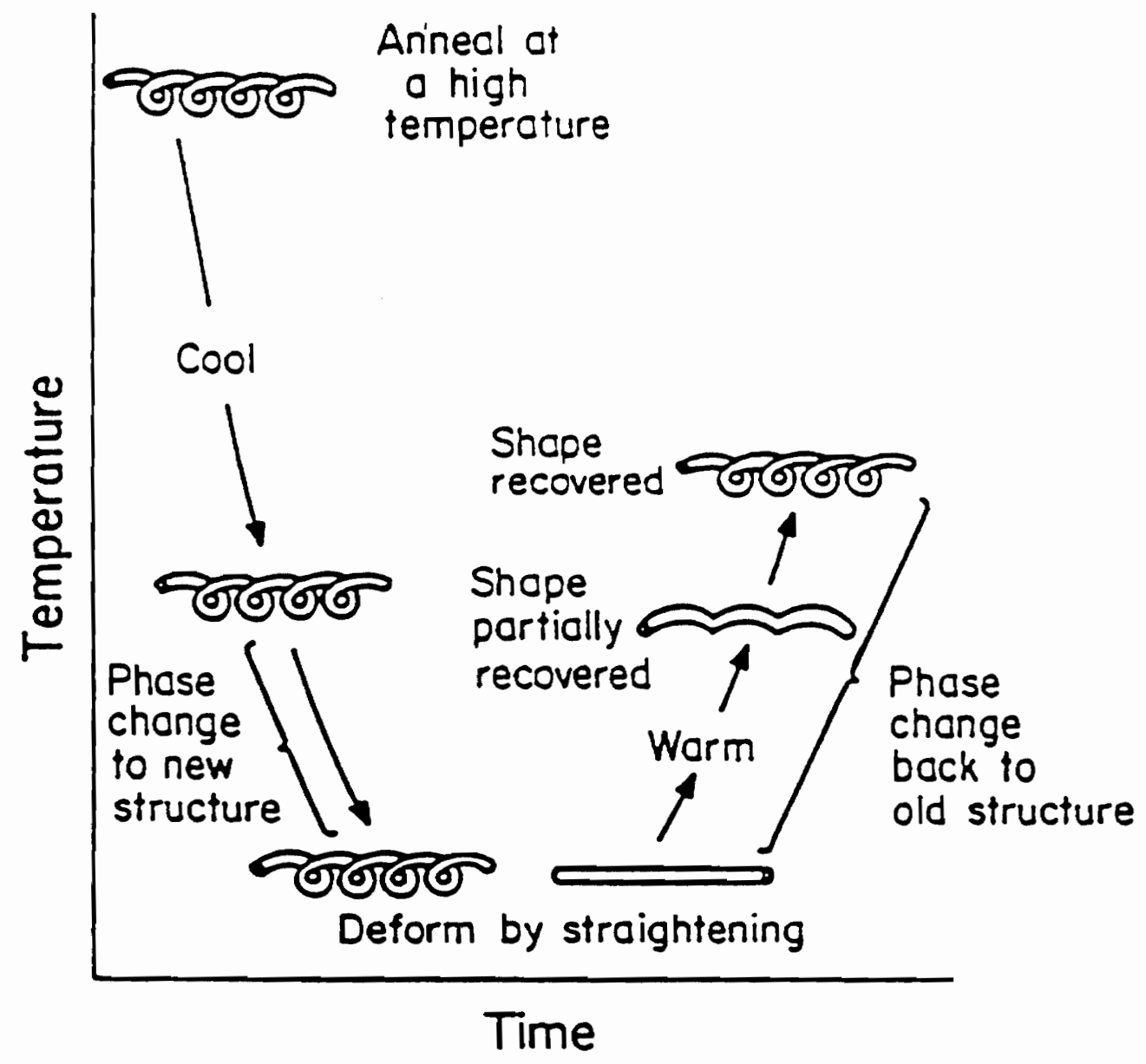

Figure 1.1: Shape Recovery of Nitinol (Perkins, 19i5). 
Shimizu, 1972; Jackson, et al., 1972; Delaey, et al., 1974; Perkins, 1975; Goldstein, 1978; Schetky, 1979; Saburi and Wayman, 1979) even though the exact mechanism by which the shape recovery takes place is a matter of conjecture and controversy.

One specific case of SMA is a series of Nickel-Titanium alloys, generically called 55Nitinol. In 1965, Buehler and Wiley of the U.S. Naval Ordnance Laboratory received a United States patent on the Nitinol group of alloys (Buehler and Wiley, 196.5). Rogers (19S8) has developed a new class of adaptive materials incorporating Nitinol actuators. Some very interesting control features can be obtained when the SMA fibers are imbedded in a composite material and heated to various degrees (for instance, by applying a current to the fibers). There are many possible configurations for imbedding the SMA fibers (Rogers, et al., 1988). In one scenario, these fibers are imbedded at an offset on either side of the neutral axis in agonist-antagonist pairs after plastically elongating them. These fibers are constrained from contracting to their 'memorized' length during the curing process. Thus, after fabrication, the plastically deformed SMA fibers become integral with the structure. When the fibers are heated, generally by passing a current through them, the fibers 'try' to contract to their 'normal' or 'memorized' length, thereby generating a uniformly distributed shear load along the entire length of the fibers, the magnitude of this load being a function of the degree of activation. The shear load offset from the neutral axis will cause the structure to bend in a known and predictable manner, accompanied by a change in its effective stiffness. But for this, the magnitude of the net in-plane load generated has to be known to a good degree of accuracy. The current project was basically carried out with this purpose in mind.

From a structural point of view, one of the two most important characteristics of 
Nitinol is the large change in Young's modulus when the material transforms from the austenite to the martensite phase. The second one, as outlined above, is the characteristic shape recovery effect, which manifests itself in a remarkable restoring force and/or recovery of a tremendous amount of plastic strain. From these two basic material characteristics, it is possible to classify the structural schemes which rely on embedded SMA fiber actuators or reinforcement as:

- Active Properties Tuning (APT) (Liang, et al., 1989a, 1989b)

- Active Strain Energy Tuning (ASET) (Liang, et al., 1989a, 1989b)

The modal response of a structure or mechanical component can be tuned or modified by simply heating the SMA fibers or lamina to change the stiffness of all or portions of the structure. When Nitinol is heated to cause the material transformation from the martensitic phase to the austenitic phase, the Young's modulus increases by a factor of approximately four as shown in Figure (1.2). Not only is the stiffness increased by a factor of four but the yield strength also increases by a factor of ten. These changes in material properties occur because of a phase transformation and do not result in any appreciable force and do not need to be initiated by any plastic deformation (Rogers, et al., 1988).

In ASET, the SMA fibers are placed in or on the structure in such a way that when activated, there is no resulting deflection but instead the structure is placed in a 'residual' state of strain. The resulting stored strain energy changes the energy balance of the structure and modifies the modal response much like tuning a guitar string.

There are two configurations of the composite material generally used for active strain energy tuning (Rogers, et al., 1988). One of these, where the S.MA fibers are imbedded 


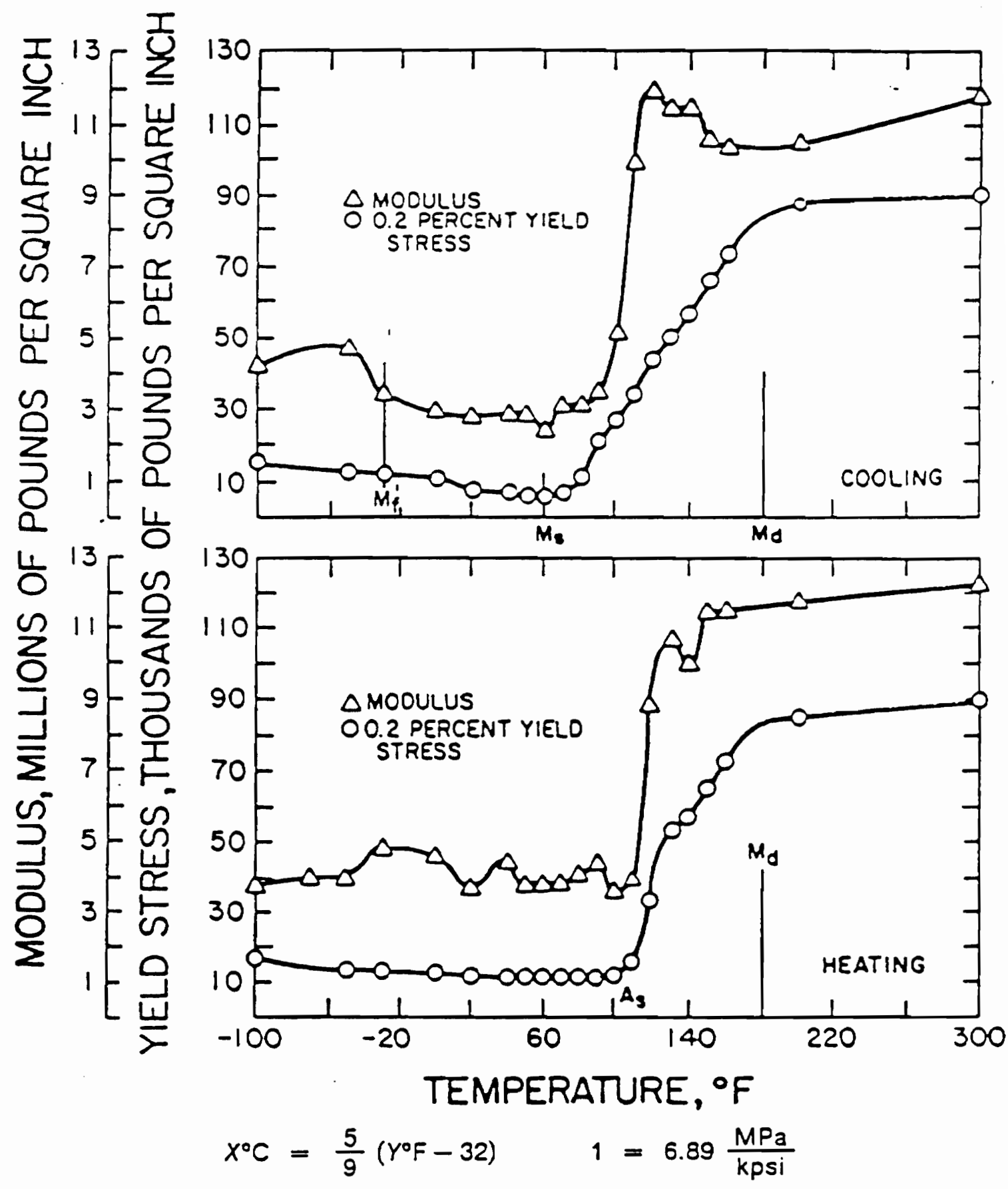

Figure 1.2: Young's Modulus and Yield Stress v. Temeperature for Nitinol (Cross, et al., 1969). 
in the composite matrix in an integral way, has been described earlier. The second configuration consists of creating 'sleeves' within the composite laminate in which the plastically elongated shape memory alloy can be inserted and then clamped at both the ends. When the SMA is heated, the fibers try to contract in the same fashion as explained above. The fibers in a sleeve will exert a concentrated force on the clamped end of the structure. The difference between epoxied fibers and the fibers in a sleeve is that in the first case, the force of SMA is distributed over the length of the fiber whereas in the later case the force is concentrated at the end of the structure and is used to resist transverse motion. Activating SMA fibers that have been placed in a sleeve tunes the stiffness of the fibers and creates a large tensile stress in the fibers that will resist transverse motion of the structure. This technique can be simulated as a beam in parallel with a number of nonlinear-tunable springs.

\subsubsection{System Identification}

System Identification is a very generic term, applied to the inverse problem of determining fundamental properties of any system from observed behavior of that system. The inverse problem arises in many fields such as celestial mechanics, radiative transfer, neutron transport, wave propagation, geometrical optics, nonlinear filtering, and physiology (Kagiwada, 1974). The techniques used for parameter estimation may vary greatly with the type of problem, as well as the type of mathematical model used to represent a system. There are publications dealing with general system identification theory (see, for example, Eykhoff (1979)). However, generality introduces a lot of mathematical jargon that a specialist in a given field may not find particularly comprehensible. Here we shall take a look at system identification literature only from the point of view of a modal analyst. 
Depending upon the amount of data available and the type of mathematical construct used to model the dynamic system, the system of equations might be over-constrained or under-constrained. If all the elements of the mass and stiffness matrices are considered as unknown, then the number of equations available to evaluate them will be less than the number of unknowns. Similar problems may arise when the experimental data available is not sufficient. On the other hand, if the number of unknown parameters is less than the number of equations available, some redundancy is introduced in the system of equations. These differences, and how they are interpreted, define the basis for different sub-classes of System Identification methods.

A review of System Identification techniques as applied to various fields is given by Jain and Dobcek (1979). There have been many publications in the literature which review a certain class of methods, or present extensive bibliographies; Sage and Melsa (1971), Pilkey and Cohen (1972), Berman (1975), Pakstys (1982), Heylen and Sas (1986), and Ibrahim and Saafan (1986). Berman (1975) gives a brief description of mathematical formulations of a a vibrating structure, and various categories of parameter identification. He also surveys related works published in past and presents comprehensive references on relevant fields.

Pakstys (1982) discusses integration of the computer aided analysis methods with computer based experimental techniques. Unlike most of the authors who assume the test data to give 'real life' representation of a system, he stresses the necessity of validating both analytical as well as test data. The main limitations of present experimental modal analysis procedures are outlined and compared to finite element analysis capabilities. Projections are made of what the future holds in store when 
expert system hardware and software may be able to perform automatically the correlation process, and derive important structural dynamics parameters as well as optimized mathematical models of the complete structural system.

Heylen and Sas (1986) discuss the accuracy and compatibility of analytical and experimental input data. They also present two groups of optimization techniques, the first group of methods being one-step procedures based upon the equations of motion and the orthogonality conditions, the second one being a group of iterative procedures making use of some kind of sensitivities in an incomplete Taylor's series expansion. Finally, they combine the two methods, making use of the advantageous features from both sets of methods.

Ibrahim and Saafan (1986) present a review of the problem of dynamic modelling of structures and existing approaches for updating them. Some of the limitations of present methods are summarized, and recommendations for future work are presented. A review of concepts and classifications of system identification as applied to vibrating structures is presented by Berman (1975). Berman divides System Identification into three groups: verification, modification, and direct identification.

Stiles (1988) has summarized these three classes based on the definitions available in the literature. Verification belongs to the classical domain, where the analyst, based on his experience, may either vary the system parameters intuitively or use some systematic method of varying parameters to make the analytical model agree with reality, based upon the experimental data. The various modification techniques deal with altering the components of the global mass and stiffness matrices, utilizing certain constraints. Direct identification deals with generating an analytical model 
directly from experimental data.

An analytical method basically consists of setting up the so-called eigenvalue problem where the mass and stiffness matrices depend on the mathematical model chosen, while the eigenvalues and eigenvectors are obtained experimentally. The common time domain discrete formulation of the equation of motion of a linear vibrating structure is

$$
[M]\left\{\ddot{x}_{i}\right\}+[C]\left\{\dot{x}_{i}\right\}+[K]\left\{x_{i}\right\}=\left\{f_{i}\right\}
$$

If the forcing function is assumed to be sinusoidal at a frequency $\omega$, the equations may be transformed to the frequency domain as

$$
\left[-\omega^{2}[M]+i \omega[C]+\left[K^{i}\right]\right]\left\{x_{i}\right\}=\left\{f_{\omega i}\right\}
$$

The coefficient of $\left\{x_{i}\right\}$ is an impedence type matrix. Each element of its inverse, the mobility matrix, is a transfer function, and is measurable, representing the response of each point on the structure to a sinusoidal force at each point. Finally, by setting the $\left\{f_{i}\right\}$ and $[C]$ in Eq. 1.10 to zero, we obtain the standard eigenvalue problem (Eq. 1.9). Typically, the mass and stiffness matrices are generated analytically, based on the mathematical model used, and the normal modes and frequencies are measured from the actual structure. The analytical mass and stiffness matrices are used to generate eigenvalues and eigenvectors which are then compared to the experimental values and necessary changes are made to the mass and stiffness matrices to bring 
them in accord with the experimental data. This is where the various methods differ.

The verification method is one of the earliest methods used in this field, as it is the simplest and most straightforward of all. A basic approach is to calculate the sensitivity of the response of the structure with respect to design variables, and then modify the structure accordingly, using various error minimization techniques such as the least squares method (Hall, et al., 1970). Some researchers, such as Collins, et al. (1974), have used a truncated Taylor's series expansion to generate linear estimators which would model the structural parameters. Yet another group has used the perturbation technique, assuming that the two initial models are close and an iteratively updated model would give better approximations (Chen and Garba, 1980). Another technique is to use the Bayesian parameter estimation where the confidence level in the obtained data is used to avoid unrealistic parameter estimation (Blakely and Walton, 1983).

The modification method is by far the most sophisticated, and a very widely used, technique. It is feasible to treat each component of the analytically generated matrices as separate variables in this method, in which case the problem becomes underconstrained as the number of variables would exceed the number of independent equations. The difference in various modification methods stems from this fact. Some methods minimize the change to each component of the matrices. Baruch and Itzhak (1978) describe a technique by which measured modes, which usually do not satisfy the theoretical requirement of weighted orthogonality, are forced to satisfy this condition in an optimal way. The modes corrected in such a fashion are closest to the measured ones in a weighted Euclidean sense. The authors also discuss direct and iterative methods for computing the corrected modes. 
In most of the cases, the correction to be applied for updating the stiffnesses is additive in nature. Due to this, non-zero terms might be introduced in the stiffness matrix which were originally zero. In effect, this introduces non-existent load paths in the system equations. To obviate this, some authors have attempted to keep the connectivity of the matrices the same as in the original matrices. One of these methods, introduced by Kabe (1985), utilizes a constraint relationship which effectively implies that the matrix coefficients that were originally zero, remain zero in the final updated matrices. Such a constraint is achieved by defining a modification matrix which is a term-to-term multiplier rather than the standard difference matrix. This method minimizes the percent change in the coefficients of the stiffness matrix. The method assumes that the mass matrix is reasonably correct, as mass is something that can be directly measured. Hence it is more important to modify the stiffness matrix. Kabe's formulation (1985) assumes that the modes are orthogonal. However, results can be obtained even if they are not. Kabe utilizes Lagrange multipliers to minimize an error function comprised of relative changes to the original stiffness matrix, while adhering to certain constraints. The technique, as outlined here, yields a closed form solution and does not require any initial eigensolution. The only thing needed is formulation of the analytical system matrices and the experimental data in the form of eigenvalues and modal vectors.

Some authors have used finite element models of the physical system, where a combination of modification and verification is used. For instance Chen and Wang (1988) have developed an approach where they generate the so-called residual force vector and try to pinpoint the elements which contribute to this residual forces and make necessary changes to obtain updated matrices. This method is based on the finite 
element concept of expressing the product of the stiffness matrix with the generalized displacement vector to be equal to the generalized force vector. If the analytical models of the stiffness and mass matrix represent the reality exactly, a standard eigenvalue problem can be formulated using these in conjunction with experimental eigenvalues and modal vectors, with a null vector on the right hand side of the equation. However, since the analytical matrices just represent some mathematical model of reality, the right hand side of the equation, in general, will not be a null vector. Any non-zero entries in this vector is termed the 'residual force'. It is then possible to examine this vector and pinpoint the elements which contribute to it. In this way the exact location of the parameters that need updating can be found. From then on, any of the previously described methods may be used to actually update these values. The authors themselves have used the orthogonality approach where they assume the actual mass and stiffness matrices to be the sum of the analytical matrices and some difference quantities, which can be easily determined by forcing the orthogonality relations.

Another major technique in the modification class uses the orthogonal properties of the eigenfunctions and symmetry properties of the stiffness matrices (Berman, 1983). Mass matrices can be modified in such a way as to orthogonalize the experimentally determined modal vectors with respect to them. Then the stiffness matrices can be modified by forcing orthogonality on the modal vectors themselves. In cases where the analytical matrices are larger than the amount of data generated, techniques like Guyan reduction are used to make the experimental and analytical matrices dimensionally compatible. Lagrange multipliers are also widely used in most of these techniques. Finally, some authors have even used flexibility matrices instead of stiffness matrices for the purpose of modification (Dobson, 1983). 
If sufficient high quality data is available, then direct identification, which deals with generating an analytical model directly from the experimental data, would be an ideal system identification tool. However, a large amount of accurate data is rarely available. The direct identification methods use various curve-fitting algorithms and certain other techniques to estimate the system parameters (for example Shye and Richardson (1986)). But these techniques are not very widely used. 
"You may call it 'nonsense' if you like," she said, "but I've heard nonsense, compared with which that should be as sensible as a dictionary!" 


\section{Chapter 2}

\section{Theory}

In this chapter we shall first discuss derivation of the basic plate equations used for mathematical modelling of vibrating plates. Then we recast these equations in a form suitable for extraction of elastic constants and in-plane loads using an iterative scheme.

\subsection{Vibration of Plates}

\subsubsection{Kinematic Relations}

The plate model used for the current work is the so-called classical lamination theory. The classical lamination theory is based on the standard Kirchoff assumptions:

1. Straight lines normal to the middle surface before deformation remain straight and normal to the deformed middle surface

2. The length of a normal remains unchanged

3. The effects of the out-of-plane stresses are small and can be neglected in comparison with in-plane stresses except in regions of high normal loads 
4. Displacement gradients are small (i.e. higher order terms in the strain tensor are neglected)

In addition to this, it is also assumed that rotary inertia terms and body forces are negligible.

The use of Kirchoff assumptions allows us to reduce a three-dimensional problem to an equivalent two-dimensional one, and the following kinematic relations result:

$$
\begin{aligned}
\epsilon_{x} & =\epsilon_{x}^{o}+z \kappa_{x} \\
\epsilon_{y} & =\epsilon_{y}^{o}+z \kappa_{y} \\
\gamma_{x y} & =\gamma_{x y}^{o}+z \kappa_{x y}
\end{aligned}
$$

where,

$$
\begin{gathered}
\epsilon_{x}^{o}=\frac{\partial u^{o}}{\partial x} \quad \epsilon_{y}^{o}=\frac{\partial v^{o}}{\partial y} \quad \gamma_{x y}^{o}=\frac{\partial u^{o}}{\partial y}+\frac{\partial v^{o}}{\partial x} \\
\kappa_{x}=-\frac{\partial^{2} w}{\partial x^{2}} \quad \kappa_{y}=-\frac{\partial^{2} w}{\partial y^{2}} \quad \kappa_{x y}=-2 \frac{\partial^{2} w}{\partial x \partial y}
\end{gathered}
$$

\subsubsection{Energy Formulation}

It is very common to use energy methods for solution of equations arising in the dynamic analysis of structures. The energy formulation offers certain advantages over classical formulation techniques. For one, the boundary conditions are obtained as a natural consequence of the formulation itself. Secondly, it also provides the basis for the development of approximate solution methods. In particular, we shall develop 
the Ritz method for later use in system identification.

As a take-off point, we reiterate the preliminary steps of the Ritz analysis, which involves formulation of an energy functional:

$$
\Pi\left(u^{\circ}, v^{o}, w\right)=\text { stationary value }
$$

where, for the free vibration case,

$$
\Pi=U+W+V-T
$$

We shall derive all the four quantities in the above functional for a specially orthotropic plate, that is, a laminated plate having all its layers oriented such that the fibers are lined up in either $\mathrm{x}$, or $\mathrm{y}$ direction, and having symmetric material and geometric properties about the mid-plane.

1. The strain energy of an elastic body in terms of an $x, y, z$ coordinate system is given by

$$
U=\frac{1}{2} \iiint\left(\sigma_{x} \epsilon_{x}+\sigma_{y} \epsilon_{y}+\sigma_{z} \epsilon_{z}+\sigma_{x z} \epsilon_{x z}+\sigma_{y z} \epsilon_{y z}+\sigma_{x y} \epsilon_{x y}\right) d x d y d z
$$

Taking into account the strain-displacement relations of Eq. 2.1, and using the constitutive relations for a specially orthotropic plate, the above equation 
reduces, for a rectangular plate, to (Whitney, 1987)

$$
\begin{aligned}
U= & \frac{1}{2} \int_{0}^{b} \int_{0}^{a}\left[D_{11}\left(\frac{\partial^{2} w}{\partial x^{2}}\right)^{2}+2 D_{12} \frac{\partial^{2} w}{\partial x^{2}} \frac{\partial^{2} w}{\partial y^{2}}+D_{22}\left(\frac{\partial^{2} w}{\partial y^{2}}\right)^{2}\right. \\
& \left.+4 D_{66}\left(\frac{\partial^{2} w}{\partial x \partial y}\right)^{2}\right] d x d y
\end{aligned}
$$

where, for a specially orthotropic plate,

$$
\begin{aligned}
& D_{11}=\frac{E_{x} h^{3}}{12\left(1-\nu_{x y} \nu_{y x}\right)} \\
& D_{22}=\frac{E_{y} h^{3}}{12\left(1-\nu_{x y} \nu_{y x}\right)} \\
& D_{12}=\frac{\nu_{y x} E_{x} h^{3}}{12\left(1-\nu_{x y} \nu_{y x}\right)} \\
& D_{66}=\frac{G_{x y} h^{3}}{12} \\
& \nu_{x y} E_{y}=\nu_{y x} E_{x}
\end{aligned}
$$

2. In this study, the effect of transverse loads will not be considered, since comparison of analytical results have to be made with only the results of an impact type of test. Hence, for the purposes of this work,

$$
W=0
$$

3. The potential energy of in-plane loads, $V$, due to transverse deflection $w$, is 
given by

$$
V=\int_{0}^{b} \int_{0}^{a}\left(N_{x} \epsilon_{x}^{\prime}+N_{y} \epsilon_{y}^{\prime}+N_{x y} \epsilon_{x y}^{\prime}\right) d x d y
$$

where $\epsilon_{x}^{\prime}, \epsilon_{y}^{\prime}, \epsilon_{x y}^{\prime}$ are simply von Kármán type strains. Consequently, the final form of the potential energy is

$$
V=\frac{1}{2} \int_{0}^{b} \int_{0}^{a}\left[N_{x}\left(\frac{\partial w}{\partial x}\right)^{2}+N_{y}\left(\frac{\partial w}{\partial y}\right)^{2}+2 N_{x y} \frac{\partial w}{\partial x} \frac{\partial w}{\partial y}\right] d x d y
$$

4. The kinetic energy of an elastic body is given by

$$
T=\frac{1}{2} \iiint \rho_{o}\left[\left(\frac{\partial u}{\partial t}\right)^{2}+\left(\frac{\partial v}{\partial t}\right)^{2}+\left(\frac{\partial w}{\partial t}\right)^{2}\right] d x d y d z
$$

Once again making use of the strain-displacement relations, Eq. 2.1, and recognizing that for a symmetric laminate, the in-plane and out-of-plane effects are totally decoupled, we get the final form of kinetic energy for transverse vibrations of a rectangular plate

$$
T=\frac{1}{2} \int_{0}^{b} \int_{0}^{a} \rho\left[\left(\frac{\partial w}{\partial t}\right)^{2}\right] d x d y
$$


where,

$$
\rho=\int_{-h / 2}^{h / 2} \rho_{o} d z
$$

Hence the total energy functional of the plate in question is expressed as

$$
\begin{gathered}
\Pi=\frac{1}{2} \int_{0}^{b} \int_{0}^{a}\left[D_{11}\left(\frac{\partial^{2} w}{\partial x^{2}}\right)^{2}+2 D_{12} \frac{\partial^{2} w}{\partial x^{2}} \frac{\partial^{2} w}{\partial y^{2}}+D_{22}\left(\frac{\partial^{2} w}{\partial y^{2}}\right)^{2}+4 D_{66}\left(\frac{\partial^{2} w}{\partial x \partial y}\right)^{2}+\right. \\
\left.N_{x}\left(\frac{\partial w}{\partial x}\right)^{2}+N_{y}\left(\frac{\partial w}{\partial y}\right)^{2}+2 N_{x y} \frac{\partial w}{\partial x} \frac{\partial w}{\partial y}-\rho\left(\frac{\partial w}{\partial t}\right)^{2}\right] d x d y
\end{gathered}
$$

\subsubsection{Rayleigh-Ritz Formulation}

In the Ritz method, a solution is sought in the series form,

$$
w=\sum_{m=1}^{p} \sum_{n=1}^{q} A_{m n} W_{m n}(x, y)
$$

where $A_{m n}$ are undetermined coefficients, and the functions $W_{m n}$ are known and usually chosen in the variables separable form $\Phi_{m}(x) \Theta_{n}(y)$ such that the geometric boundary conditions are satisfied. Hence we shall make the following substitution in the Eq. 2.13

$$
w=\sum_{m=1}^{p} \sum_{n=1}^{q} A_{m n} \Phi_{m}(x) \Theta_{n}(y)
$$


In accordance with the Ritz principle, this leads to a minimization problem relative to the unknown generalized displacements. In particular, $\Pi$ is a function of $A_{m n}$ only and the conditions given by Eq. 2.4 reduce to the equations

$$
\frac{\partial \Pi}{\partial A_{m n}}=0 \quad\left\{\begin{array}{l}
m=1,2, \ldots, p \\
n=1,2, \ldots, q
\end{array}\right.
$$

Application of conditions expressed by Eq. 2.17 then lead to

$$
\begin{gathered}
\sum_{m=1}^{p} \sum_{n=1}^{q}\left\{D_{11}\left[\int_{0}^{a} \Phi_{m}^{\prime \prime} \Phi_{i}^{\prime \prime} d x \int_{0}^{b} \Theta_{n} \Theta_{j} d y\right]+D_{22}\left[\int_{0}^{a} \Phi_{m} \Phi_{i} d x \int_{0}^{b} \Theta_{n}^{\prime \prime} \Theta_{j}^{\prime \prime} d y\right]\right. \\
+D_{12}\left[\int_{0}^{a} \Phi_{m}^{\prime \prime} \Phi_{i} d x \int_{0}^{b} \Theta_{n} \Theta_{j}^{\prime \prime} d y+\int_{0}^{a} \Phi_{m} \Phi_{i}^{\prime \prime} d x \int_{0}^{b} \Theta_{n}^{\prime \prime} \Theta_{j} d y\right] \\
+4 D_{66}\left[\int_{0}^{a} \Phi_{m}^{\prime} \Phi_{i}^{\prime} d x \int_{0}^{b} \Theta_{n}^{\prime} \Theta_{j}^{\prime} d y\right] \\
+N_{x}\left[\int_{0}^{a} \Phi_{m}^{\prime} \Phi_{i}^{\prime} d x \int_{0}^{b} \Theta_{n} \Theta_{j} d y\right]+N_{y}\left[\int_{0}^{a} \Phi_{m} \Phi_{i} d x \int_{0}^{b} \Theta_{n}^{\prime} \Theta_{j}^{\prime} d y\right] \\
+N_{x y}\left[\int_{0}^{a} \Phi_{m}^{\prime} \Phi_{i}^{\prime} d x \int_{0}^{b} \Theta_{n} \Theta_{j} d y+\int_{0}^{a} \Phi_{m} \Phi_{i} d x \int_{0}^{b} \Theta_{n}^{\prime} \Theta_{j}^{\prime} d y\right] \\
\left.-\rho h \omega_{s}^{2}\left[\int_{0}^{a} \Phi_{m} \Phi_{i} d x \int_{0}^{b} \Theta_{n} \Theta_{j} d y\right]\right\} A_{m n}=0
\end{gathered}
$$

One member of each pair of the following two quantities need to be specified as the boundary conditions

$$
\frac{\partial w}{\partial n} ; M_{n} w ;\left(\frac{\partial M_{n}}{\partial n}+2 \frac{\partial M_{n s}}{\partial s}+N_{n} \frac{\partial w}{\partial n}+N_{n s} \frac{\partial w}{\partial s}\right)
$$

These boundary conditions can be satisfied by using the shape functions of EulerBernoulli beams having boundary conditions similar to the plate boundary conditions 
(Young, 1950). This is where the convenience of expressing the assumed solution in a variables separable form becomes apparent. The function $\Phi_{m}(x)$ can be chosen to satisfy the plate boundary conditions on the edges parallel to the $\mathrm{x}$-axis and the

function $\Theta_{n}(y)$ can be chosen to satisfy the plate boundary conditions on the edges parallel to the y-axis. The beam functions necessary for various types of beam boundary conditions have been tabulated by Blevins (1979) and are listed in Appendix A.

This completes the formulation of the mathematical model. Now we shall look at the various system identification techniques that can be used to extract system parameters from this model.

\subsection{System Identification}

In this section we shall first establish a more manageable form of the equations developed above and then talk about the modal information needed, and finally set up the necessary formulation for the different System Identification techniques to be implemented

\subsubsection{Some Preliminaries}

The mathematical model as formulated above is quite ungainly, and the book-keeping needed for its implementation becomes quite formidable. Hence we shall strive to recast the equations in a more manageable form by redefining some of the terms.

We first non-dimensionalize Eq. 2.18 by multiplying the whole expression with the plate area $a \times b$. Now we can define a parameter vector $\{D\}$ as follows: 


$$
\begin{gathered}
D_{1}=D_{11}, \quad D_{2}=D_{22}, \quad D_{3}=D_{12}, \quad D_{4}=D_{66} \\
D_{5}=b^{2} N_{x}, \quad D_{6}=a^{2} N_{y}, \quad D_{7}=a b N_{x y}
\end{gathered}
$$

As mentioned above, beam eigenfunctions corresponding to necessary boundary conditions have been used as trial function in the Ritz approximation. Once the assumed functions have been substituted and the integrals evaluated, Eq. 2.18 reduce to the standard eigenvalue problem:

$$
\sum_{m=1}^{p} \sum_{n=1}^{q}\left[C_{i j, m n}-\lambda \delta_{i j} \delta_{m n}\right] A_{m n}=0
$$

where,

$$
\lambda=\omega_{s}^{2} \rho h a^{2} b^{2}, \quad C_{i j, m n}=\sum_{l=1}^{7} D_{l} Q_{l, i j, m n}
$$

Here, the stiffnesses have been factored out of the equations to give us a very tidy form of the eigenvalue problem. The terms $Q_{l, i j, m n}$ are independent of material constants and loading. They are purely functions of the characteristic beam shapes and depend only on the boundary condition and geometry. Their definition is apparent from Eq. 2.18 once we substitute the beam functions and recognize the fact that the characteristic shapes of beams and their second derivatives are orthogonal. The explicit form of these 'integral' matrices is as follows: 


$$
\begin{aligned}
& Q_{1, i j, m n}=\left(\epsilon_{i}^{x}\right)^{4}\left(b^{2} / a^{2}\right) \delta_{i j} \delta_{m n} \\
& Q_{2, i j, m n}=\left(\epsilon_{j}^{y}\right)^{4}\left(a^{2} / b^{2}\right) \delta_{i j} \delta_{m n} \\
& Q_{3, i j, m n}=F_{m i}^{x} F_{j n}^{y}+F_{i m}^{x} F_{n j}^{y} \\
& Q_{4, i j, m n}=4 H_{m i}^{x} H_{n j}^{y} \\
& Q_{5, i j, m n}=H_{m i}^{x} \delta_{n j} \\
& Q_{6, i j, m n}=H_{n j}^{y} \delta_{m i} \\
& Q_{7, i j, m n}=G_{m i}^{x} G_{j n}^{y}+G_{i m}^{x} G_{n j}^{y}
\end{aligned}
$$

where $\epsilon_{i}$ is the $i$ th beam eigenvalue (non-dimensionalized), and,

$$
\begin{aligned}
F_{m i}^{x}=a \int_{0}^{a} \Phi_{m} \Phi_{i}^{\prime \prime} d x & F_{n j}^{y}=b \int_{0}^{b} \Theta_{n} \Theta_{j}^{\prime \prime} d y \\
G_{m i}^{x}=a \int_{0}^{a} \Phi_{m} \Phi_{i}^{\prime} d x & G_{n j}^{y}=b \int_{0}^{b} \Theta_{n} \Theta_{j}^{\prime} d y \\
H_{m i}^{x}=a \int_{0}^{a} \Phi_{m}^{\prime} \Phi_{i}^{\prime} d x & H_{n j}^{y}=b \int_{0}^{b} \Theta_{n}^{\prime} \Theta_{j}^{\prime} d y
\end{aligned}
$$

As a final simplification, we reduce the two sets of indices, $i j$, and $m n$, into just one set, st as follows

$$
\begin{aligned}
s & =(m-1) p+n \\
t & =(i-1) p+j
\end{aligned}
$$


Hence the system equations reduce to:

$$
([C]-\lambda[I])\{A\}=\{0\}
$$

Some of the steps to be used for identification are common to all the three methods. Hence we shall discuss them here. The first step in all the techniques is to use an informed estimate of the vector $\{D\}$. Using these initial values, the eigenvalue problem is solved, which results in a number of frequencies and their corresponding modal vectors. The next step is to use these analytically calculated value, in conjunction with experimentally determined data, and search for an optimum value of $\{D\}$ which would minimize the difference between experimental and analytical values. This is where most of the methods differ, and they will be discussed in detail in the following sections.

\subsubsection{Modal Analysis}

Extensive and accurate modal analysis is necessary for the success of the System Identification techniques to be outlined below. At least seven natural frequencies and the corresponding mode shapes are needed to determine the parameter vector $\{D\}$. However, as will be shown later, it is advantageous if more number of frequencies are available, since this will permit one to determine more number of sets of parameters which could then be averaged to give more accurate, or rather, a more representative estimation of the stiffnesses and stresses. We shall not go into details of modal analysis, which has been dealt with quite exhaustively in literature. Suffice to say that, with current state of the technology, it would not be difficult to extract even up to 
the first fifteen natural frequencies if modal tests are carefully done. Now we look at the various techniques that could be employed to back out with the parameter vector $\{D\}$ once the necessary number of frequencies has been determined.

\subsubsection{Mode Identification Technique}

This technique was first utilized by Wolf and Carne (1979) for isotropic plates. It was later extended to unstressed orthotropic plates by Deobald (1985). Here we shall set up the necessary formalism to extract the parameters of an initially stressed specially orthotropic plate. As a result, we shall be able to extract the in-plane loads in addition to the elastic properties of the material.

The modal indices of experimentally determined eigenvalues are compared to the modal indices of the associated analytical values, and the corresponding eigenvalues and modal vectors are isolated. The result of the eigenfunction solution is seven approximate eigenpairs, $\lambda_{1},\{A\}^{(1)}, \lambda_{2},\{A\}^{(2)}, \lambda_{3},\{A\}^{(3)}, \lambda_{4},\{A\}^{(1)}, \lambda_{5},\{A\}^{(5)}, \lambda_{6},\{A\}^{(6)}$, $\lambda_{7},\{A\}^{(7)}$, corresponding to the eigenvalues $\lambda_{1}^{e}, \lambda_{2}^{e}, \lambda_{3}^{e}, \lambda_{4}^{e}, \lambda_{5}^{e}, \lambda_{6}^{e}, \lambda_{7}^{e}$, respectively.

The next step is to use the approximate eigenvectors to formulate the seven by seven solution matrix, relating the seven eigenvalues to the seven bending stiffnesses. For each eigenpair, $\lambda_{i}$ and $A^{(i)}$, the th row in the Eq. 2.24 is isolated:

$$
\begin{aligned}
& \lambda_{i} A_{l}^{(i)}=A_{1}^{(i)}\left(D_{1} Q_{1 / 1}+D_{2} Q_{2 l 1}+D_{3} Q_{3 / 1}+D_{4} Q_{4 l 1}+D_{5} Q_{5 / 1}+D_{6} Q_{6 / 1}+D_{7} Q_{7 / 1}\right) \\
& +A_{2}^{(i)}\left(D_{1} Q_{1 / 2}+D_{2} Q_{2 l 2}+D_{3} Q_{3 l 2}+D_{4} Q_{4 l 2}+D_{5} Q_{5 / 2}+D_{6} Q_{6 / 2}+D_{7} Q_{7 / 2}\right) \\
& +\ldots+A_{n}^{(i)}\left(D_{1} Q_{1 / n}+D_{2} Q_{2 l n}+D_{3} Q_{3 / n}+D_{4} Q_{4 l n}+D_{5} Q_{5 l n}+D_{6} Q_{6 / n}+D_{i} Q_{7 / n}\right)
\end{aligned}
$$




$$
i=1, \ldots, 7, \quad 1 \leq l \leq n, \quad n=p \times q
$$

Tle selection of the seven equations from the set of $n$ equations may be purely arbitrary. The seven approximate eigenvalues in Eq. 2.25 may be replaced by the eigenvalues calculated from the experimental natural frequencies. The Eq. 2.25 can be reduced to the following equations by factoring out the parameter vector $\{D\}$ :

$$
\left\{\lambda^{e}\right\}=[H]\{D\}
$$

where,

$$
H_{i j}=\sum_{r=1}^{n} \frac{A_{r}^{(i)}}{A_{l}^{(i)}} Q_{j l r}, \quad i, j=1, \ldots, \tau, \quad 1 \leq l \leq n, \quad n=p \times q
$$

The entries in the solution matrix, $H_{i j}$, are functions of the approximate eigenvectors, $\{A\}^{(i)}$, and the integral matrices $Q_{i m n}$. Eq. 2.26 relate the eigenvalues from the experimental natural frequencies to new estimates of the four bending stiffnesses and the three in-plane loads. Eq. 2.26 are solved with the use of eigenvalues from experimental natural frequencies to obtain new estimates of the parameter vector $\{D\}$. The cycle is then repeated, continually upgrading the accuracy of the $D$ 's.

\subsubsection{Eigenvalue Sensitivity Analysis}

The second approach used for System Identification is the standard sensitivity analysis. It basically deals with the sensitivity of the system output on small changes in system parameters. Once a relationship is determined for the sensitivity of fre- 
quencies to the parameters, it is a straightforward technique to use the difference between analytical and experimental frequencies to determine the changes needed in the parameters.

For the current project, the sensitivity calculations were done using the approach presented by Haug and Arora (1979). They first calculate the derivative of the eigenvalue problem (Eq. 2.24):

$$
\frac{d}{d D_{j}}\left(\lambda_{i}[M]\{A\}_{i}-\left[K^{\prime}\right]\{A\}_{i}\right)=0, \quad i, j=1, \ldots, 7
$$

where $[M]$ is the mass matrix. Expanding the derivative, and pre-multiplying all the terms with $\{A\}_{i}^{T}$, we get

$$
\{A\}_{i}^{T}[M]\{A\}_{i} \frac{d \lambda_{i}}{d D_{j}}=\{A\}_{i}^{T}\left(\frac{d\left[K^{\prime}\right]}{d D_{j}}-\lambda_{i} \frac{d[M]}{d D_{j}}\right)\{A\}_{i}
$$

If the eigenvectors are mass normalized, the above equation may be written as

$$
\frac{d \lambda_{i}}{d D_{j}}=\{A\}_{i}^{T}\left(\frac{d\left[K^{i}\right]}{d D_{j}}-\lambda_{i} \frac{d[M]}{d D_{j}}\right)\{A\}_{i}
$$

In the present case, owing to the nature of formulation, the mass matrix is a unit matrix, multiplied by a constant scalar, hence 


$$
\frac{d[M]}{d D_{j}}=[0]
$$

Hence the values of eigenvalue sensitivities are given by

$$
\frac{d \lambda_{i}}{d D_{j}}=\{A\}_{i}^{T}\left(\frac{d\left[K^{\prime}\right]}{d D_{j}}\right)\{A\}_{i}
$$

which, in terms of the integral matrices defined earlier, reduces to:

$$
\frac{d \lambda_{i}}{d D_{j}}=\{A\}_{i}^{T}[Q]_{j}\{A\}_{i}
$$

It is now necessary to relate the discrepancy between the analytical and experimental frequencies with the design variables, namely, $\{D\}$. We define the following quantities:

$$
\begin{aligned}
\Delta \lambda_{i} & =\lambda_{i}^{e}-\lambda_{i} \\
\{\Delta D\} & =\{D\}^{(k+1)}-\{D\}^{(k)}
\end{aligned}
$$

where $k$ refers to the iteration number.

Now expanding $\Delta \lambda_{i}$ in a Taylor Series about $\lambda_{i}$, we get 


$$
\Delta \lambda_{i}=\sum_{j=1}^{7}\left(\frac{\partial \lambda_{i}}{\partial D_{j}} \times \Delta D_{j}+\frac{1}{2} \frac{\partial^{2} \lambda_{i}}{\partial D_{j}^{2}} \times\left(\Delta D_{j}\right)^{2}+\ldots\right)
$$

Neglecting the higher order terms, we get the simplified equation

$$
\Delta \lambda_{i} \simeq \sum_{j=1}^{7}\left(\frac{\partial \lambda_{i}}{\partial D_{j}} \times \Delta D_{j}\right)
$$

For a nonlinear equation, this is not usually exact. However, it should yield a better solution if the initial guess is close to the correct answer. The equation can be written for each measured frequency, and the solution matrices are given by

$$
\left\{\Delta \lambda_{i}\right\}^{T}=\left[\frac{\partial \lambda_{i}}{\partial D_{j}}\right]\left\{\Delta D_{i}\right\}^{T}
$$

In the above equation, the sensitivity matrix is known, as also the vector $\left\{\Delta \lambda_{i}\right\}$, and hence the equations can be solved for $\left\{\Delta D_{i}\right\}$, giving the updated parameter vector

$$
\{D\}^{(k+1)}=\{D\}^{(k)}+\{\Delta D\}^{(k)}
$$

The process is repeated with new design variables, until the results fall within a pre-specified tolerance, $\epsilon$ 


$$
\{\Delta \lambda\}^{T}\{\Delta \lambda\} \leq \epsilon
$$

\subsubsection{Unconstrained Eigenvalue Optimization}

Optimization is a powerful technique of finding the local or global minima of a given function - referred to as the cost function in optimization literature. Our objective, as outlined in a previous section, is to find the parameter vector $\{D\}$ which would minimize the difference between the measured frequency and the equivalent analytically computed frequencies. Hence, optimization seems to be a natural choice. The various techniques developed for the purpose of optimization are very general in nature and can be applied to practically any kind of minimization problem. The only requirement is to have a necessary set of relationships between the parameters with respect to which the cost function is to be minimized.

For the purposes of this project, we shall use numerical methods of solution as opposed to closed form techniques. The basic reason is that we do not have any explicit expressions for calculating the design parameters once the frequencies are available. The use of numerical techniques circumvents this problem, as it only processes the output of the mathematical model, treating the model virtually as a 'black box'. For our purposes, we used a commercial optimizing subroutine, DUMINF, by IMSL (1987). However, we shall outline some of the theoretical underpinnings of the technique to be used here to facilitate the understanding of the solution procedure. A more detailed exposition of these topics is given by Arora (1989).

The general algorithm for numerical optimization is as follows (Arora, 1989) : 
1. Start with a reasonable estimate of design variables, $\{D\}$. Set the iteration counter $k=0$.

2. Compute a search direction $\{d\}^{(k)}$ in the design space. This step generally requires gradient $\{g\}^{(k)}$ of the cost function, $\{\Delta \lambda\}^{(k)}$, for an unconstrained problem.

3. Check for convergence of the algorithm. If it has converged, terminate the iterative process. Otherwise, continue.

4. Calculate a positive step size $\alpha_{k}$

5. Calculate a new design as

$$
\{D\}^{(k+1)}=\{D\}^{(k)}+\alpha_{k}\{d\}^{(k)}
$$

Set $k=k+1$, and go to step 2 .

The cost function to be minimized was, as in sensitivity analysis,

$$
\{\Delta \lambda\}^{T}\{\Delta \lambda\}
$$

For the step 3 above, DUMINF calculates the the search direction according to the formula

$$
\{d\}^{(k)}=-[H]^{-1}\{g\}^{(k)}
$$


where $[H]$ is a positive definite approximation of the Hessian, $\partial^{2} f\left(\{D\}^{(k)}\right) / \partial D_{i} \partial D_{j}$, and $\{g\}^{(k)}$ is the gradient evaluated at $\{D\}^{(k)}$. The gradient is evaluated using a finite difference technique. The value of $\alpha_{k}$ in step 4 above is determined using a line-search technique. The new value of the stiffness vector is then estimated using Eq. 2.39. Finally, the optimality condition $\left\|g^{(k)}(D)\right\|=\epsilon$ is checked, where $\epsilon$ is the gradient tolerance.

If optimality is not achieved, $[H]$ is updated according to the BFGS (BroydenFletcher-Goldfarb-Shanno) formula

$$
[H] \longleftarrow[H]-\frac{\lambda^{2}[H]\{d\}^{(k)}\{d\}^{(k) T}[H]}{\{d\}^{(k) T}[H]\{d\}^{(k)}}+\frac{\{y\}\{y\}^{T}}{\{y\}^{T}\{d\}^{(k)}}
$$

where $\{y\}=\left\{g^{(k-1)}-g^{(k)}\right\}$. Another search direction is then computed to begin the next iteration.

After applying any one of the above three techniques, finally, the four elastic constants and the three in-plane loads are then determined by:

$$
\begin{aligned}
\nu_{x y}=D_{3} / D_{2}, & G_{x y}=\left(12 / h^{3}\right) D^{4} \\
E_{x}=\left(12 / h^{3}\right)\left(1-\nu_{x y} \nu_{y x}\right) / D_{1}, & E_{y}=\left(12 / h^{3}\right)\left(1-\nu_{x y} \nu_{y x}\right) / D_{2} \\
N_{x}=D_{5} / b^{2}, \quad N_{y}= & D_{6} / a^{2}, \quad N_{x y}=D_{\tau} / a b
\end{aligned}
$$


"Contrariwise," continued Tweedledee, "if it was so, it might be; if it were so, it would be; but as it isn't, it ain't. That's logic." 


\section{Chapter 3}

\section{FORTRAN Implementation}

In the previous chapter we discussed the theoretical formulation of various System Identification techniques. These techniques were implemented in FORTRAN on an IBM 3090 Vector facility. In this chapter we shall discuss the FORTRAN codes in some detail. The main body of the program that solves the eigenvalue problem for the frequencies and eigenvectors shall be discussed. Then solution subroutines which implement the three techniques discussed in the previous chapter, for extraction of parameters, shall be explained.

\subsection{Computer Program SYSID}

One of the major tasks to be accomplished before carrying out the identification is the calculation of eigenvalues and mode shapes of a given plate having specified boundary conditions. The program, at present, has the capability of carrying out analysis for five different combinations of clamped and free boundaries, for a rectangular plate. These are:

1. Free-Free-Free-Free (F-F-F-F)

2. Clamped-Free-Free-Free (C-F-F-F)

3. Clamped-Clamped-Clamped-Free (C-C-C-F) 


\section{Clamped-Clamped-Clamped-Clamped (C-C-C-C)}

\section{Clamped-Free-Clamped-Free (C-F-C-F)}

The choice of any one of the above conditions is controlled by the variable NBC. Even though it is easier to handle simply supported boundary conditions from an analytical point of view, these are very difficult to realize in practice. It is much easier to simulate the free and clamped type of boundaries. This was the major consideration in selecting the boundary conditions that could be handled by the program.

Another feature of the program, controlled by the variable IP, is that it can be used to solve two different kinds of problems, namely, plates that are initially stressed, and the ones that are not. Even though the major thrust of the current project was to determine in-plane loads on a plate, it was felt that it would be enlightening to study the numerical behavior of the solution process in both the cases. And, as shall be seen later, this proved to be one of the most fruitful basis for comparing some of the features of the three techniques.

Theoretically, it would be possible to generalize the program so that any number of desired parameters (from 1 to 7 ) can be computed, depending on the availability of frequencies and some of the parameters. It would be simply a matter of providing a series of control statements. However, an indiscriminate use of logical IF statements tends to downgrade the optimization process, available on the IBMI 3090 vector hardware. Hence it was decided to implement only the two possibilities mentioned above.

The variable NSRS controls the number of terms in the Rayleigh-Ritz series that the user wants to account for. A maximum of eight terms can be used at present because 
some of the data needed to generate the integral matrices $Q$ 's, has been hardwired in the subroutine INTEG. It is not advisable to use anything less than seven terms as that would not give a fair estimate of the theoretically infinite series (Whitney, 1987).

The program reads in the input data, and does some preprocessing, such as the calculation of the parameter vector $\{D\}$ using the initial estimates of the elastic constants and in-plane loads. Since the integral matrices $Q$ 's are independent of the material parameters as well as the in-plane loads, they can be calculated once and stored for future use. This is carried out using the subroutines INTEG and MATRIX, which is also a part of preprocessing. Subroutine INTEG simply assigns appropriate values to the arrays FX, FY, HX, HY, GX, and GY depending on the flag NBC. Subroutine MATRIX then forms the integral matrices, using the logic of Eq. 2.23. MATRIX also calculates the preliminary stiffness matrix, base upon the initial estimates supplied to the program. For a plate free on all the sides, rigid body modes exist, which are removed by the subroutine RIGID. RIGID searches through the stiffness matrix and condenses out rows and columns corresponding any zero diagonal term.

Next, the program calls on either the subroutine CMBIN4 or CMIBIN 7 , depending on the value of IP. These subroutines are closely patterned after the ones presented by Deobald (1985). If the number of frequencies available, say $n$, is greater than the number of parameters to be determined, say $r$, then $s$ number of distinct combinations of frequencies will be available, where

$$
s=\frac{n !}{(n-r) ! r !}
$$


This means that $s$ number of sets of the unknown parameters can be computed. This redundancy can be fruitfully used to statistically average the $s$ sets and obtain a better approximation of the unknown parameters. The subroutines CMBIN* assign the value $s$ to NOCMB and the values of NOCMB sets of identifiers to the matrix NMB.

Once the program has exited the subroutine CMBIN*, the loop on NOCMB sets of computations begins. First of all, the parameters to be updated, frequencies for the current set, and the corresponding mode numbers are transferred to the active arrays D, EGNVAL, and INDICE. Simultaneously, the frequencies read in are converted to the non-dimensional form dictated by the Eq. 2.22. Next, the loop on the number of iterations begins. This loop is solely to ensure that in case the parameter values fail to converge in a finite number of iterations, the process is stopped anyway, and the next combination of frequencies made active.

The program then calls on the subroutine HASTEN, which accelerates the convergence of parameters if oscillations are detected. Subroutine HASTEN will be described in more detail later. Only in the first cycle is the stiffness matrix $\mathrm{C}$ formulated by the subroutine MATRIX. For all subsequent calculations, the stiffness matrix has to be reformulated depending on the updated value of the parameters. Next, the program calls on the subroutine SELECT. This subroutine first solves the eigenvalue problem by calling on a standard IMSL (1987) subroutine DEVCSF. If the initial estimates of the stiffnesses are very way off the mark, this may result in very ill-formed stiffness matrix, which in turn might give some negative eigenvalues. This subroutine detects such cases, and sets the flag NOSTIF to zero, returning back to the main program. In such an event, the whole solution process is by-passed and the program stops execution. If no anomaly is detected, SELECT then compares 
the mode numbers corresponding to computed frequencies with the mode numbers of experimentally determined frequencies and isolates the analytical eigenvalues and eigenvectors corresponding to those modes, storing them in the arrays EGN and VEC respectively.

Once the analytical eigenvalues and modal vectors corresponding to the experimentally measured values have been identified and isolated, any of the three methods outlined in the previous chapter may be used to carry out identification. In case of Mode Identification and Sensitivity calculations, the appropriate subroutine, either MODEID or SENSE may be called depending upon value of the flag METHOD. The procedure is slightly different for implementation of the optimization technique and will be covered in a subsequent section.

Once the solution has been carried out, the main program will check for convergence. If the values have converged, the program will exit the loop on iterations and start computation for the next frequency combination. After each combination of frequency has been used for computation, the results are stored in the matrix $\mathrm{E}$, for post computation. After all the combinations have been tried, the program exits the combination loop and goes on to calculate the mean of all the successful combinations and the standard deviation within those sets.

Some comments on the subroutine HASTEN are in order. In most of the numerical techniques, since the consumption of CPU time may become fairly high depending on the convergence characteristics, it is a general practice to provide some method for artificially accelerating the convergence process if oscillations are detected from iteration to iteration. Subroutine HASTEN is useful only after two iterations, since 
at least two sets of values are needed to determine whether the values are in fact oscillating or not. The subroutine is designed on the premise that if the value calculated in the current iteration is bracketed by the values produced in the previous two iterations, then its obvious that the values are not converging monotonically. The values from the previous two iterations may then be roughly taken as an indication of the upper and lower bounds on the current value. The new value for the current iteration is then computed as the mean of the previous two values. If, for any particular parameter, no oscillations are detected, that parameter is passed on to the main program without any alterations.

\subsection{Subroutine MODEID}

In this section, the structure and functioning of the subroutine MODEID which is the heart of the solution process for the Mode Identification method will be discussed. The theoretical formulation of Mode Identification method has already been presented in Chapter 2.

It will be recalled from the discussion in previous chapter that the seven by seven solution matrix can be formed by selecting any one equation from $p \times q$ equations available. Subroutine MODEID has been designed to be very flexible in this respect. The variable VECMIN controls the choice of equation(s) to be used. The eigenvalue problem solved in the subroutine SELECT produces eigenvalues scaled so as to give the maximum entry in the eigenvector to be unity (or $0.99999 \ldots$, due to the idiosynchracies of computer representation!). Hence if the value of VECMIN is sufficiently close to unity, then only one equation, corresponding to the maximum generalized displacement will be selected for the solution process. Any other value of VECMIN 
(between $0.9999 \ldots$ and 0 ) will result in a number of sets of the solution matrix, and the subroutine has been designed so as to average the results of all the 'successful' solutions.

The decision as to whether the solution is successful or not is based on the condition number of the solution matrix. The condition number is computed by the IMSL subroutine DLFCRG. If the condition number RCOND is sufficiently small, then the solution matrix is taken to be ill-conditioned. It will either be difficult to invert the solution matrix, or, even if inverted, the accuracy of inversion will be suspect. Such a solution matrix is thus bypassed. Once the solution matrix is successfully inverted, the parameter vector is computed, and after calculating he values of the elastic constants and in-plane loads, the subroutine is exited.

\subsection{Subroutine SENSE}

The second solution technique, presented in Chapter 2, deals with sensitivity calculations and is implemented in the subroutine SENSE. The first task to be accomplished in this technique is normalization of the isolated modal vectors. The first loop computes the sum of the square of each element of a given eigenvector and the second loop normalizes the eigenvector, with respect to unity. Actually, for the sensitivity analysis, it is necessary to normalize the eigenvectors with respect to the mass matrix, however, since the mass matrix is a unit matrix for the formulation presented here, it is sufficient to unit normalize the eigenvectors.

Next, the subroutine computes the sensitivity matrix, and then calls on the IMSL subroutine DLFCRG to compute the condition number. If the condition number is 
sufficiently small, the flag NOSTIF is set to zero and the subroutine is exited without further calculations. If the sensitivity matrix is not ill-conditioned, then the subroutine computes the inverse of the sensitivity matrix. Finally, the incremental values of the parameters are computed and the parameter vector is updated.

\subsection{FORTRAN Program OPT}

Most of the structure in this program is same as the program SYSID. However, the whole process describe in SYSID acts as a subroutine in this program instead of being the main program. This is because the IMSL subroutine DUMINF takes the function to be minimized in form of a subroutine as an input. Once again, the program is set to solve for just the elastic constants or the elastic constants as well as the in-plane loads. The mechanics of subroutine DUMINF have already been explained in the previous chapter. Here, more attention will be focussed on the calling program itself, as well as the subroutine VIBES.

Since the function to be minimized - the sum of the squares of differences between analytical and experimental frequencies - is a scalar, the choice as to number of frequencies to be considered for minimization is up to the user. This is taken care of by the variables IFREQ and KFREQ. The use of two variables allows the user to study the effect of the number of frequencies on the solution characteristics. IFREQ refers to the starting number of frequencies and KFREQ is the limiting number of frequencies the user wants the code to use. That is, the program will go through (KFREQ - IFREQ) cycles of calculations, the number of frequencies used in each successive cycle being incremented by one. The values of 'experimental' frequencies for a C-F-C-F plate have been hardwired in the subroutine VIBES. Of course for 
general purpose, these values could be read in by the main program itself and passed on to the subroutine VIBES via a COMMON block. Subroutines MATRIX and INTEG are very much like the ones used in the program SYSID. 
'The time has come,' the Walrus said, 'To talk of many things:

Of shoes-and ships-and sealing wax-

Of cabbages-and-kings-

And why the sea is boiling hot-

And whether pigs have wings.' 


\section{Chapter 4}

\section{Discussion and Results}

The previous chapters discussed the conceptual framework of System Identification theory, and its application to orthotropic composite plates. Implementation of these ideas in FORTRAN was also presented. But, as they say, "the proof of the pudding is in the eating". This chapter will dwell on numerical simulations which were used to prove the program as well as the effect of various parameters on both the computational behavior as well as the physics of the problem.

\subsection{Numerical Simulation}

One of the chief objectives of this project was to address the fact that no closed form techniques are available to compute the elastic constants and in-plane loads of a plate, given its natural frequencies of vibration. All the system identification techniques discussed here, as well as in the literature, are iterative in nature, where the user needs to supply an initial 'guesstimate', and the technique then simply updates the values of these parameters. In a very broad sense, most of the algorithms used for updating are like curve-fitting. One tries to find the values of the parameters such that the differences between the analytical frequencies, computed using a given mathematical model, and the corresponding experimental frequencies is minimized. 
Under normal circumstances, if all the calculations are made accurately, there should be just one set of parameters satisfying the constraint imposed by the frequencies. That is to say that, in the curve-fitting parlance, there would be just one global minima of the function relating the frequencies to the parameters. However, of necessity, most of the system identification techniques are numerical in nature. This is where the problems arise. Depending on the robustness of the techniques used, the minimizing algorithm might converge to a spurious local minimum.

One of the factors that affects this behavior is the initial estimates supplied to the program. To study the effect of initial estimates on the solution characteristics, a randomized statistical analysis was carried out. Any system identification technique is only as good as the mathematical model used to characterize the phenomena of interest. Since the objective here was not to test the mathematical model per se, but the robustness of the system identification technique used, it was not decmed necessary to carry out experimental tests to determine plate natural frequencies. Instead, the 'experimental' frequencies needed to implement the techniques were generated using the same Rayleigh-Ritz model as used for identification. Hence the true values of parameters would be known in advance, which would provide a benchmark against which the results of numerical simulations could be compared.

\subsection{Statistical Analysis}

Extensive statistical analyses were carried out to test the robustness of the algorithms developed, as mentioned above. For this purpose, randomized data sets were generated, representing the initial estimates to be supplied to the programs. A lower and 
upper bound was used to generate these data sets. Sets were generated up to \pm 100 $\%$, at intervals of $\pm 10 \%$. To obtain meaningful results - that is to say, in statistical lexicon, to represent a sufficient size of the universe - one hundred sets of properties were created at each interval. Generally, a size of twenty is considered to be a fair sampling of the universe, but given the fact that some of the initial estimates would fail to produce any meaningful results, it was thought prudent to be conservative.

What counts as a 'meaningful' result is somewhat arbitrary, but certain flags were hardwired in the programs to bypass results if any of the following was encountered

- If the program converged to a negative value of any of the stiffnesses.

- If the program converged to a set where the value of shear rigidity $G_{x y}$ came out higher than the Young's modulus along the fiber direction $E_{y}$.

- If any of the in-plane loads turned out to be compressive (all the in-plane loads used for this simulation were positive, to bypass the possibility of buckling).

Some comments on randomizing are in order. Random numbers were generated using a MATLAB routine, rand (Mathworks, Inc., 1989). In the interest of generality, two types of distributions of random numbers were considered: the Normal or Gaussian distribution, and the Uniform or Rectangular distribution. The rationale for using Normal distribution is evident when the method is used for the purposes of quality control. If the manufacturing system is set to manufacture the products with certain desired properties, obviously the manufacturer is aware of the parameters to a good degree of approximation. Any initial estimate used will thus have a strong central tendency, which is best approximated by the single hump Normal curve. If, on the other hand, one needs to test a specimen of unknown pedigree, the person in charge 
will have to take an informed guess, which, even though it may be based on experience, will not exhibit a strong central tendency as in the previous case. This justifies the use of a Uniform distribution as a better approximation.

The second part of the statistical analysis was to consolidate the results of simulation in some way which would characterize the algorithm being tested. To achieve this, the results produced by each data set were averaged, and the standard deviation within each set of results was computed. In summary, the analytical process was as follows:

1. Determine the 'experimental' frequencies of the plate under consideration. For the purpose of numerical simulation, a Clamped-Free-Clamped-Free plate was considered. The parameters used to calculate the frequencies are as shown in Table (4.1). These are thus the actual or true parameters against which the performance of the techniques has to be evaluated. The first $s$ frequencies for both the stressed and unstressed plates are shown in Table (4.2).

2. Create random data sets at $\pm 10 \%$ intervals upto $\pm 100 \%$ intervals. The data sets were generated both for Normal and Uniform distributions. In addition, separate sets were generated for the case where the plates were initially unstressed and the case where in-plane loads were considered as a part of analysis.

3. Use these sets as input to the three techniques. The results thus obtained were averaged, and the standard deviations computed for each interval.

4. Plot the results for all the intervals upto $\pm 100 \%$. This was found to be a convenient format for presenting results as the behavior of the techniques becomes more evident at different ranges and provides a more fruitful tool for comparison. 
Table 4.1: Physical Properties of the Orthotropic Plate Used for Simulation

\begin{tabular}{|l|rl|}
\hline Properties & \multicolumn{2}{|c|}{ Values } \\
\hline \hline$a$ & 0.254 & $\mathrm{~m}$ \\
$b$ & 0.254 & $\mathrm{~m}$ \\
$h$ & 1.379 & $\mathrm{~mm}$ \\
$\rho$ & 1584 & $\mathrm{Kg} / \mathrm{m}^{3}$ \\
$E_{x}$ & 10 & $\mathrm{GPa}$ \\
$E_{y}$ & 100 & $\mathrm{GPa}$ \\
$G_{x y}$ & 7 & $\mathrm{GPa}$ \\
$\nu_{x y}$ & 0.025 & \\
$N_{x}$ & 10 & $\mathrm{KN} / \mathrm{m}$ \\
$N_{y}$ & 10 & $\mathrm{KN} / \mathrm{m}$ \\
$N_{x y}$ & 10 & $\mathrm{KN} / \mathrm{m}$ \\
\hline
\end{tabular}

Table 4.2: First Eight Frequencies of a C-F-C-F Plate

\begin{tabular}{|c||c|c|}
\hline \multicolumn{3}{|c|}{ Frequency $\mathrm{Hz}}$. \\
\hline \hline & Unstressed Plate & Stressed Plate \\
\hline 1 & 55.335 & 139.598 \\
2 & 74.279 & 188.830 \\
3 & 152.536 & 309.902 \\
4 & 180.124 & 317.072 \\
5 & 209.702 & 395.877 \\
6 & 299.082 & 445.703 \\
7 & 304.950 & 505.051 \\
8 & 330.183 & 556.237 \\
\hline
\end{tabular}


It was mentioned earlier that the number of frequencies needed to identify the parameters is equal to the number of parameters to be determined. However, for Optimization, the accuracy of results obtained depend upon the number of frequencies used. As shown in Figures (4.1) and (4.2), for a stressed plate where seven parameters have to be determined, the optimum number of frequencies seem to be at least 10 . For the unstressed plate, 5 frequencies gave adequately accurate results.

\subsection{Statistical Trends}

The plots resulting from the above mentioned statistical analysis are presented here (Figures (4.3) to (4.14)). The plots show the variation of mean and standard deviation of a given parameter with change in the percent bound on the initial estimates. To facilitate comparison, all the values have been normalized with respect to the corresponding actual values. For instance, all the values pertaining to $E_{x}$ have been divided by $10 \mathrm{GPa}$, the 'exact' value, and so on.

One significant fact to be noticed is that the mean values in most of the output sets are within ten percent of the actual value (Figures (4.3) to (4.14)). Some of the important features are not so obvious due to the scale used. However it was necessary to have some fixed datum for comparison. No figures have been presented for optimization because whenever a data set resulted in convergence, the converged values were accurate to atleast five decimal places. Since there was no scatter in the computed values, all the plots would be simply straight lines, centered at 1 , showing no deviation from the theoretical values.

It will be noticed from the results presented here that only six of the seven quantities, namely, $E_{x}, E_{y}, G_{x y}, N_{x}, N_{y}$, and $N_{x y}$, have been presented. The results pertaining 

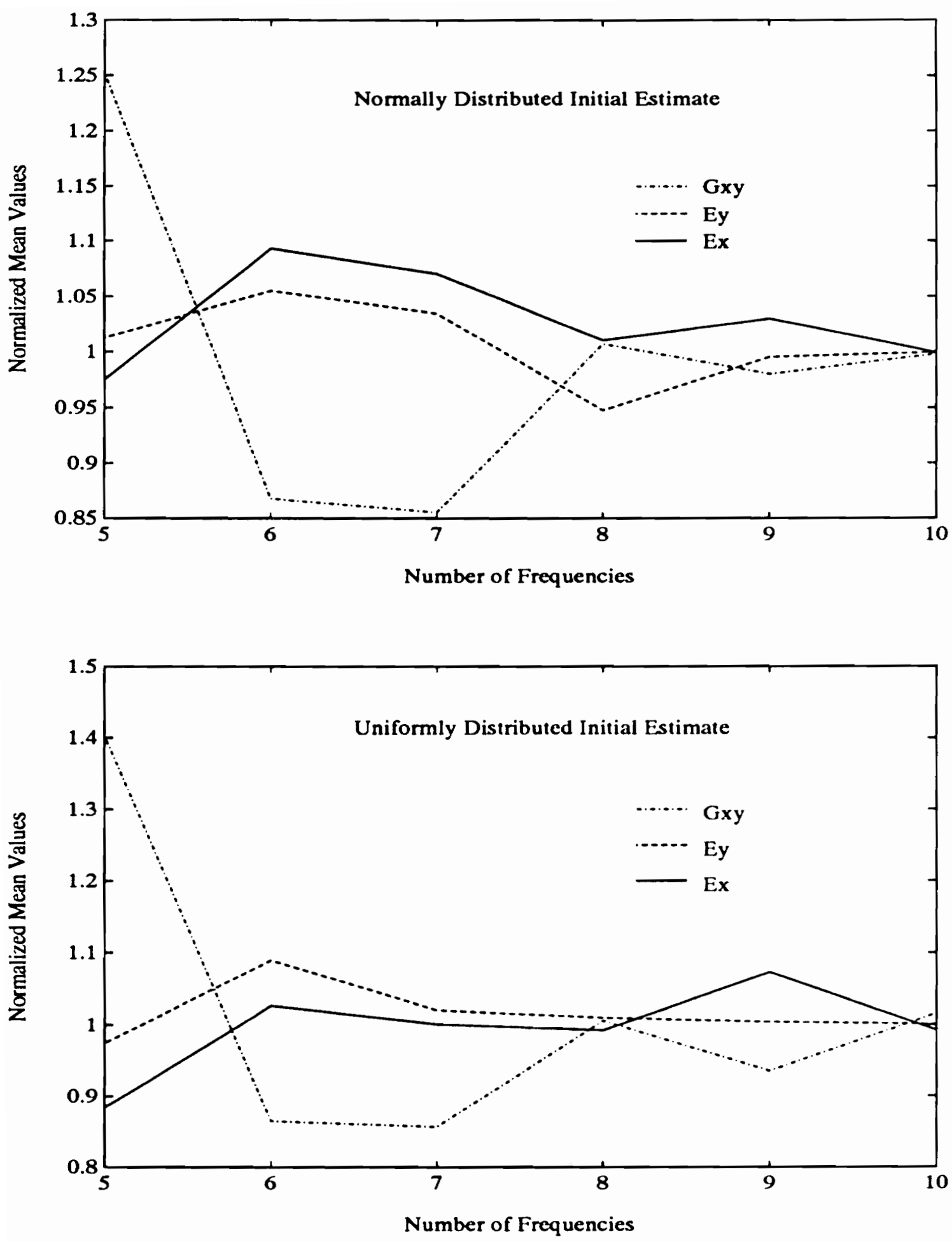

Figure 4.1: Effect of Number of Frequencies on the Mean Values of Stiffnesses for 20 $\%$ Bound on Initial Data Using Optimization 

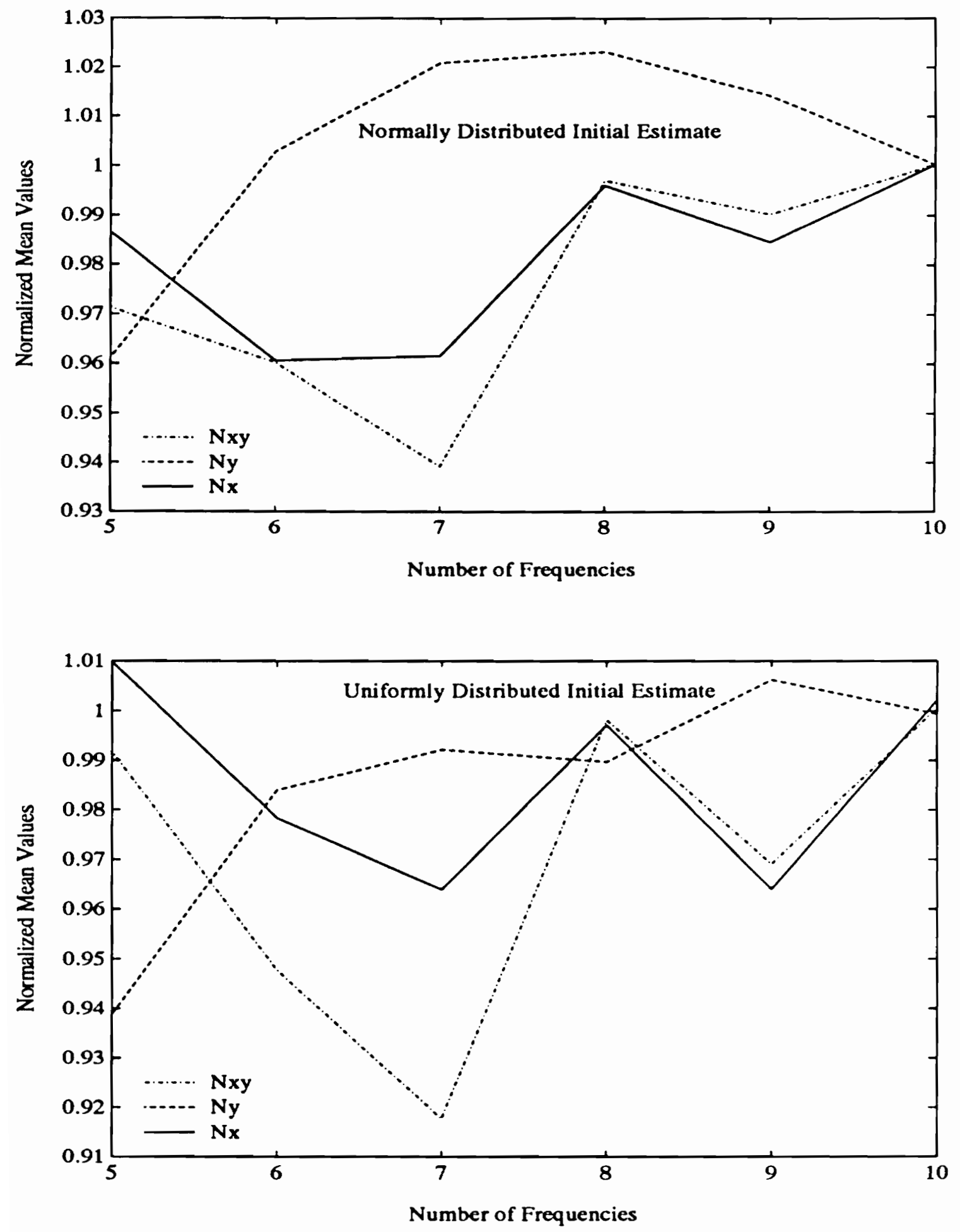

Figure 4.2: Effect of Number of Frequencies on the Mean Values of In-plane Loads for $20 \%$ Bound on Initial Data Using Optimization 
to $\nu_{x y}$ (except for optimization) have been omitted. The reason for this is that the contribution of $\nu_{x y}$ to the various stiffnesses is not very significant and hence the results obtained are most of the times absurd, such as negative values or values greater than 0.5. This fact has also been pointed out by Deobald (1985).

Also absent from the results are the values given by Sensitivity Analysis for the case where in-plane loads are applied. The exact reasons for this are not yet clear. But computationally, the program did not produce any results because the seven by seven sensitivity matrix produced was highly ill-conditioned, and therefore non-invertible. One possible reason maybe because of the difference in the way the in-plane loads affect the dynamic behavior of the plate as opposed to the plate elastic properties. It should be borne in mind that the effect of in-plane loads on the out-of-plane behavior is obtained by using the higher order von Kármán strain tensor. However, in the derivation of the sensitivities, we linearized the Taylor Series expansion by dropping the higher order terms. Apparently, the natural frequencies of the plate are much more sensitive to the elastic properties than the in-plane loads, when seen in the linear sense.

Figures (4.3) to (4.5) show the behavior of computed values of $E_{x}$ with a variation in the percentage bound on the initial estimate. The figures on top show the results for normally distributed input sets, and the ones at bottom show the results for uniformly distributed initial estimates. Comparisons of Figures (4.3) and (4.5) show that the deviation is slightly greater for Sensitivity Analysis. This implies that, statistically, Mode Identification has slightly better convergence characteristics than Sensitivity Analysis. 

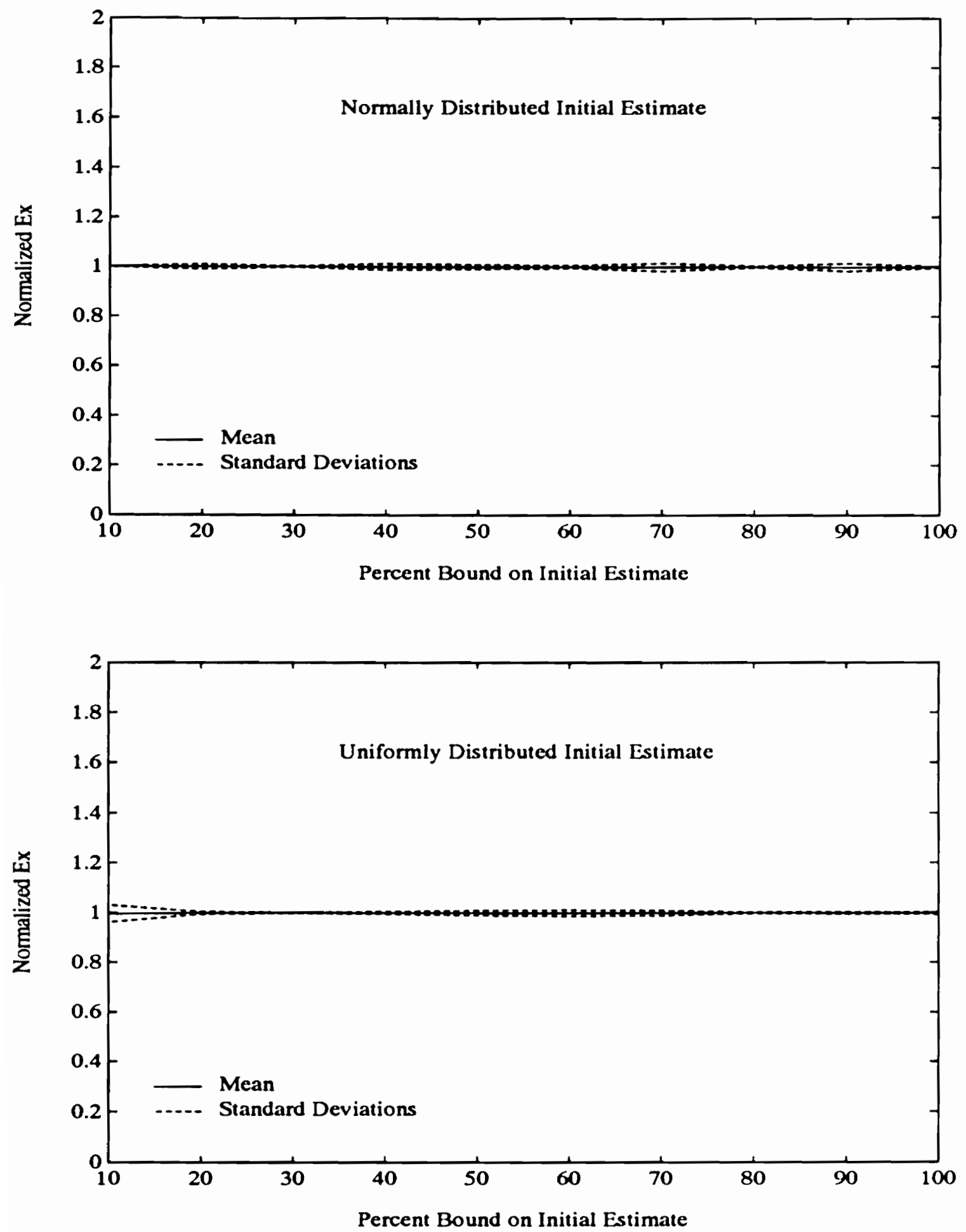

Figure 4.3: Variation of Mean and Standard Deviation of $E_{x}$ Computed by Mode Identification with Change in Percentage Bound on Initial Estimate (Unstressed Plate). 

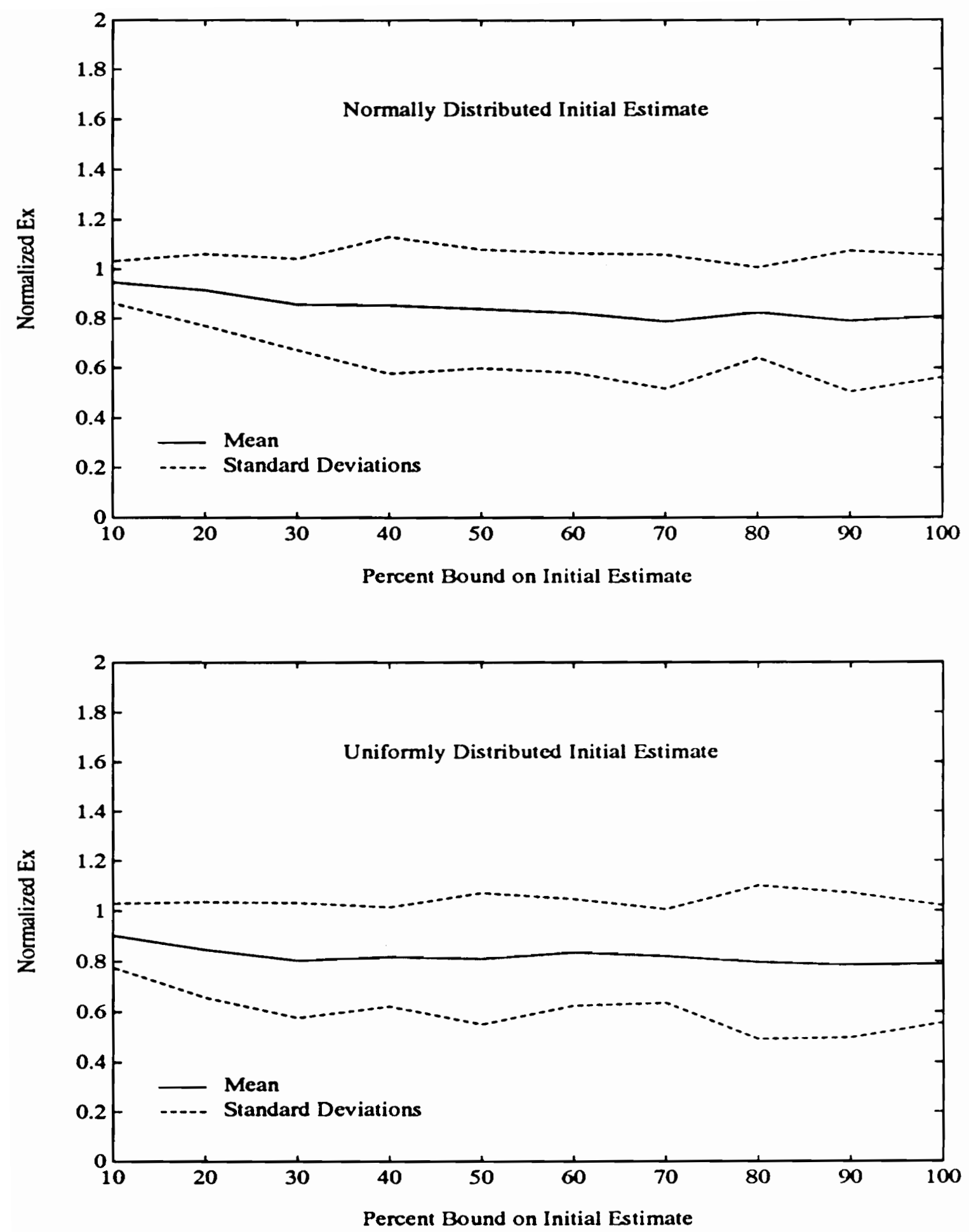

Figure 4.4: Variation of Mean and Standard Deviation of $E_{x}$ Computed by Mode Identification with Change in Percentage Bound on Initial Estimate (Stressed Plate). 

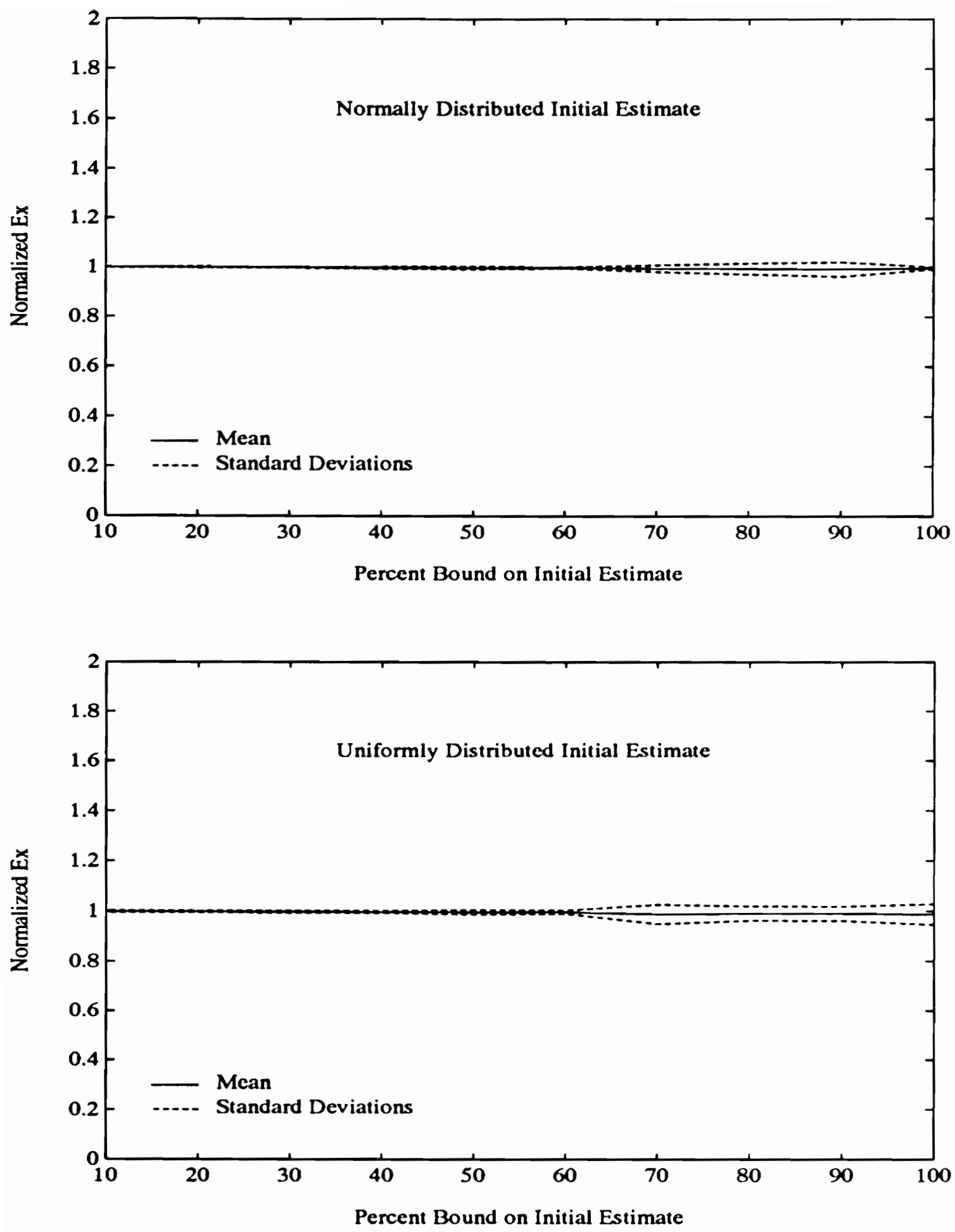

Figure 4.5: Variation of Mean and Standard Deviation of $E_{x}$ Computed by Sensitivity Analysis with Change in Percentage Bound on Initial Estimate (Unstressed Plate). 
The difference between the results for uniformly and normally distributed input sets is not very pronounced, which was somewhat surprising, as discussed later. However, there is a striking difference between Figures (4.3) and (4.4). Figure (4.3) shows the results for an unstressed plate while Figure (4.4) shows similar results for a stressed plate. The mean of the computed values of $E_{x}$ are off the theoretical value by as much as ten percent, and there is a significant scatter too, for the stressed plate. Some of the reasons for this are discussed later on.

Figures (4.6) to (4.8) and Figure (4.9) to (4.11) show the results for $E_{y}$ and $G_{x y}$ respectively. As far as general trends go, most of the comments for $E_{x}$ apply to $E_{y}$ and $G_{x y}$ too. There are some differences, however, specially in case of $E_{y}$. Both the deviation of the mean values from the exact values as well as the spread in the results are more pronounced than either for $E_{x}$ or $G_{x y}$. Specially, the results given by Sensitivity Analysis show a significant amount of scatter. The reason for this could be that $E_{y}$ has a dominant effect on the natural frequencies, and so the convergence process is more sensitive to the initial estimates of $E_{y}$.

Figures (4.12) to (4.14) show the results for the three in-plane loads $N_{x}, N_{y}$, and $N_{x y}$ obtained by Mode Identification. As compared to the computed values of the stiffnesses for a stressed plate, the values of in-plane loads show a remarkably small spread in the computed values even for very large scatter in the input data. This is very significant because most of the times, it would be easy to decide on a rough estimate of the elastic properties, but it is not so simple to reasonably estimate the in-plane loads on a plate. The results presented here show that even if the initial estimate of the in-plane loads is unreasonable, chances are that the program will converge to a good enough value. 

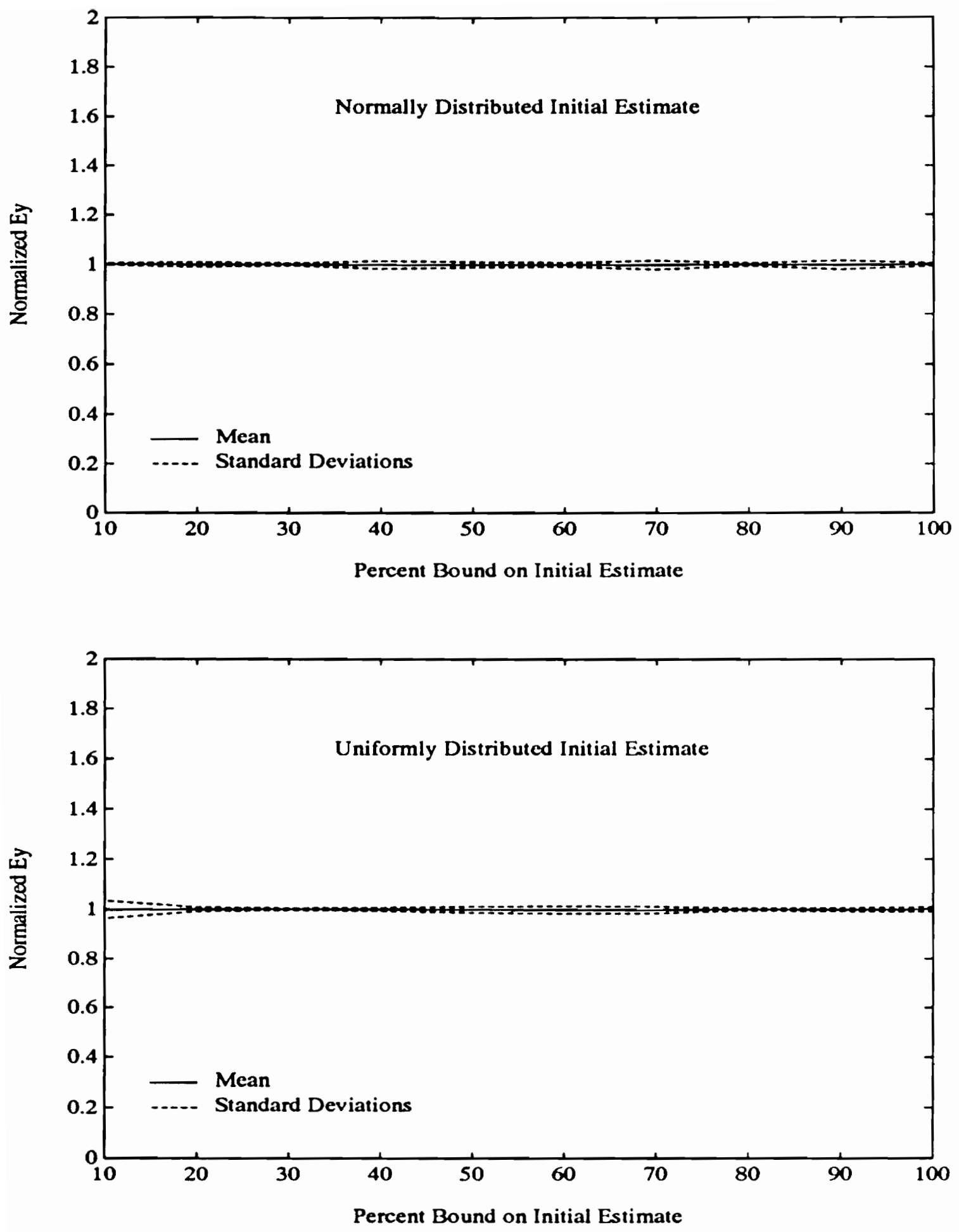

Figure 4.6: Variation of Mean and Standard Deviation of $E_{y}$ Computed by Mode Identification with Change in Percentage Bound on Initial Estimate (Unstressed Plate). 

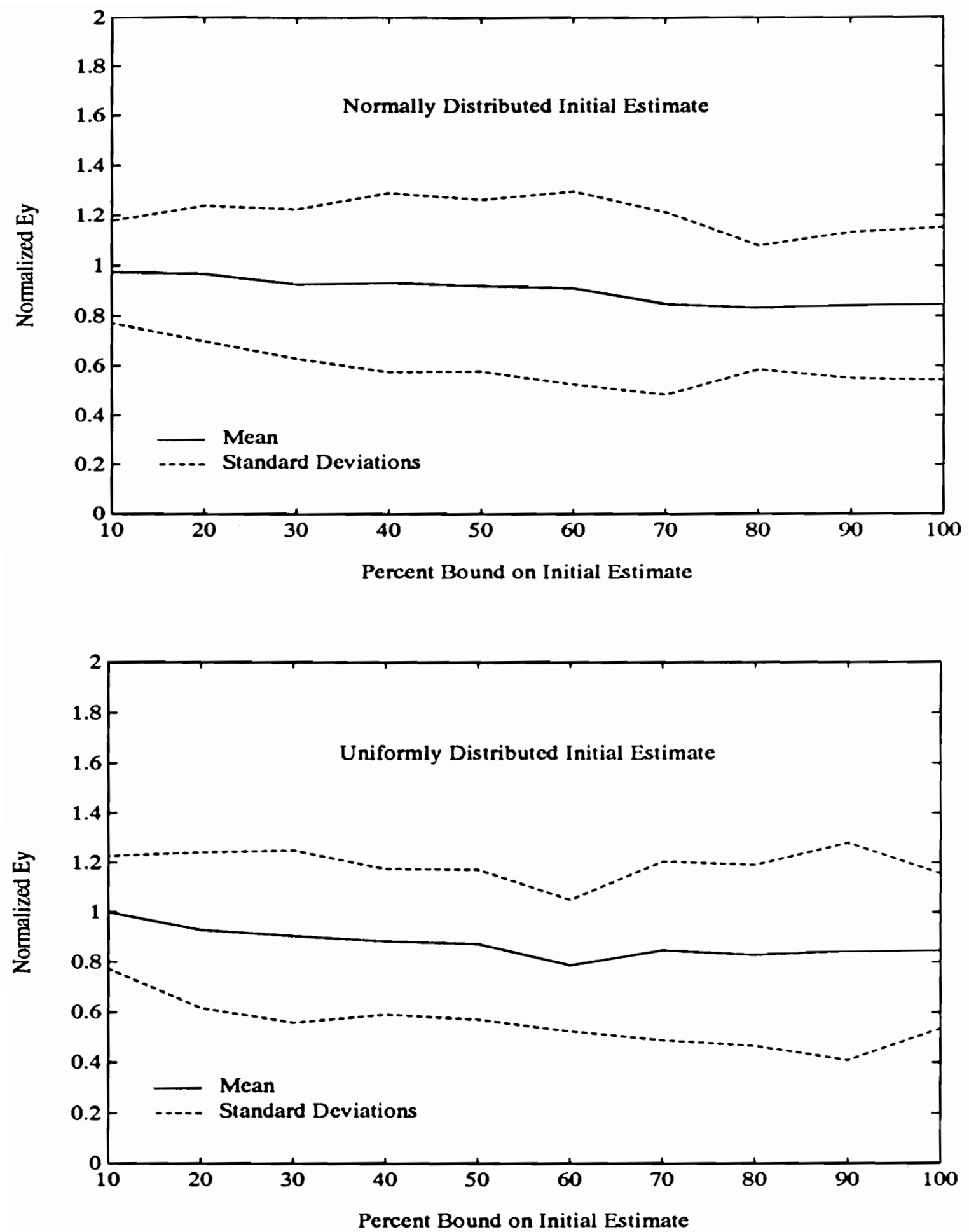

Figure 4.7: Variation of Mean and Standard Deviation of $E_{y}$ Computed by Mode Identification with Change in Percentage Bound on Initial Estimate (Stressed Plate). 

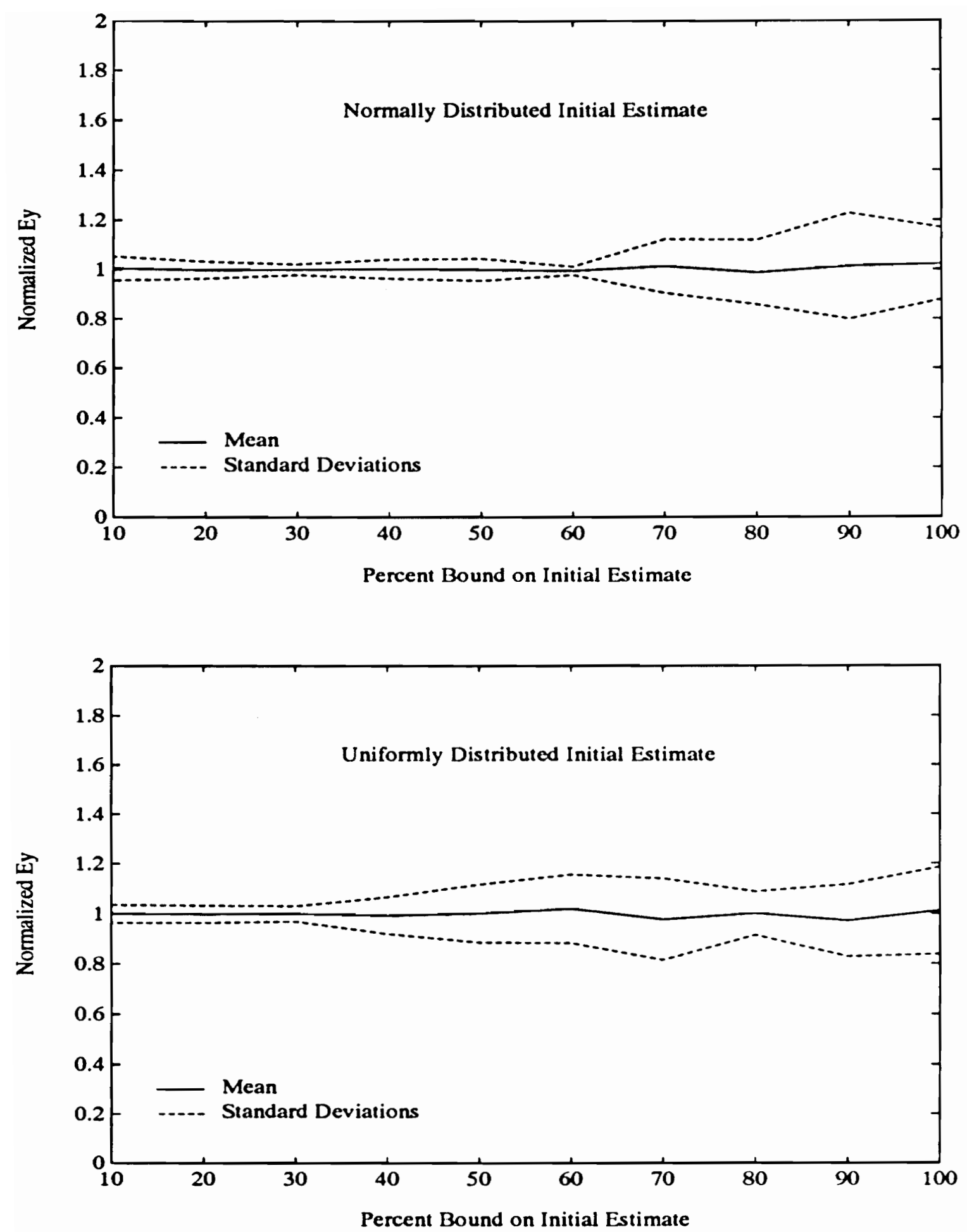

Figure 4.8: Variation of Mean and Standard Deviation of $E_{y}$ Computed by Sensitivity Analysis with Change in Percentage Bound on Initial Estimate (Unstressed Plate). 

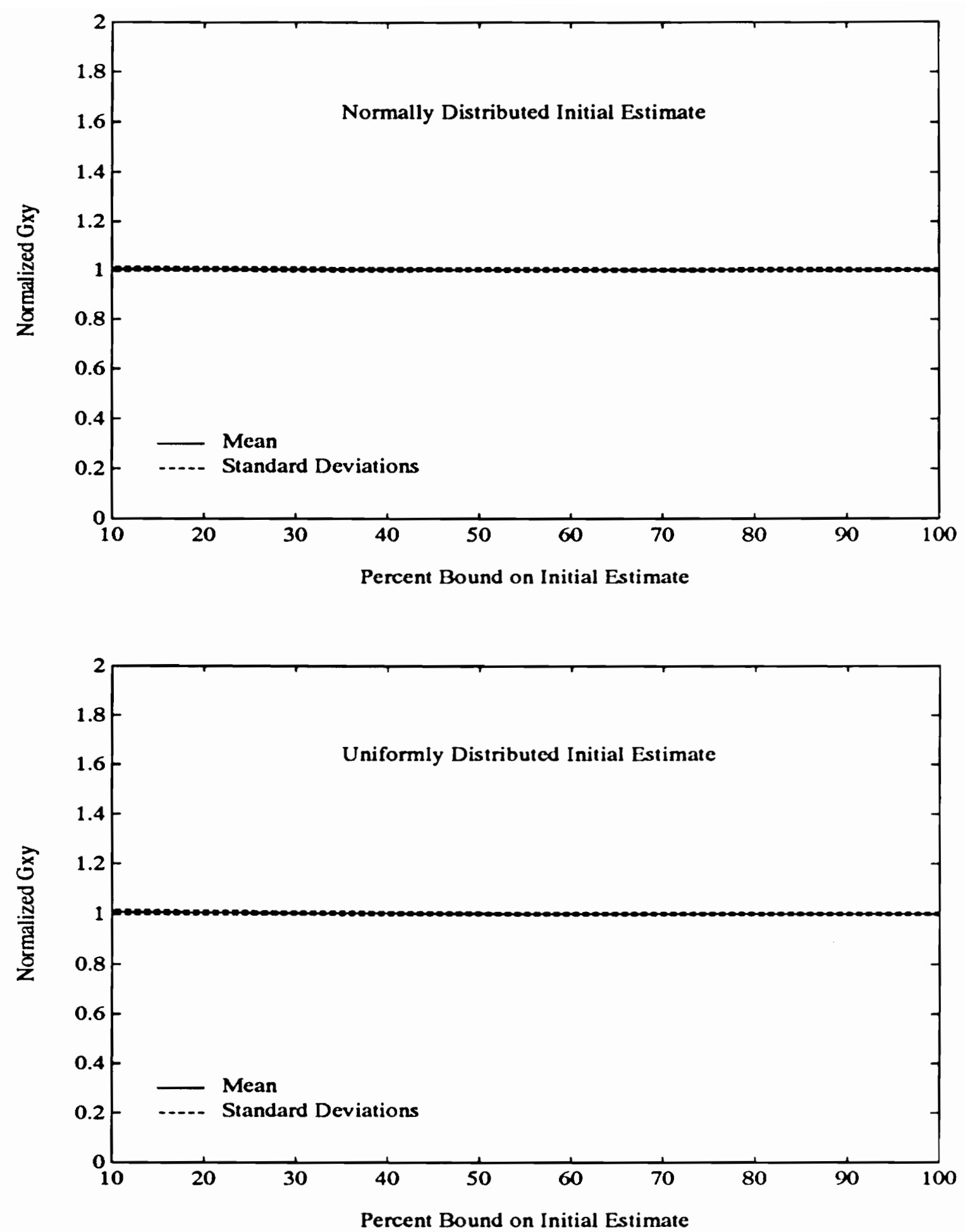

Figure 4.9: Variation of Mean and Standard Deviation of $G_{x y}$ Computed by Mode Identification with Change in Percentage Bound on Initial Estimate (Unstressed Plate). 

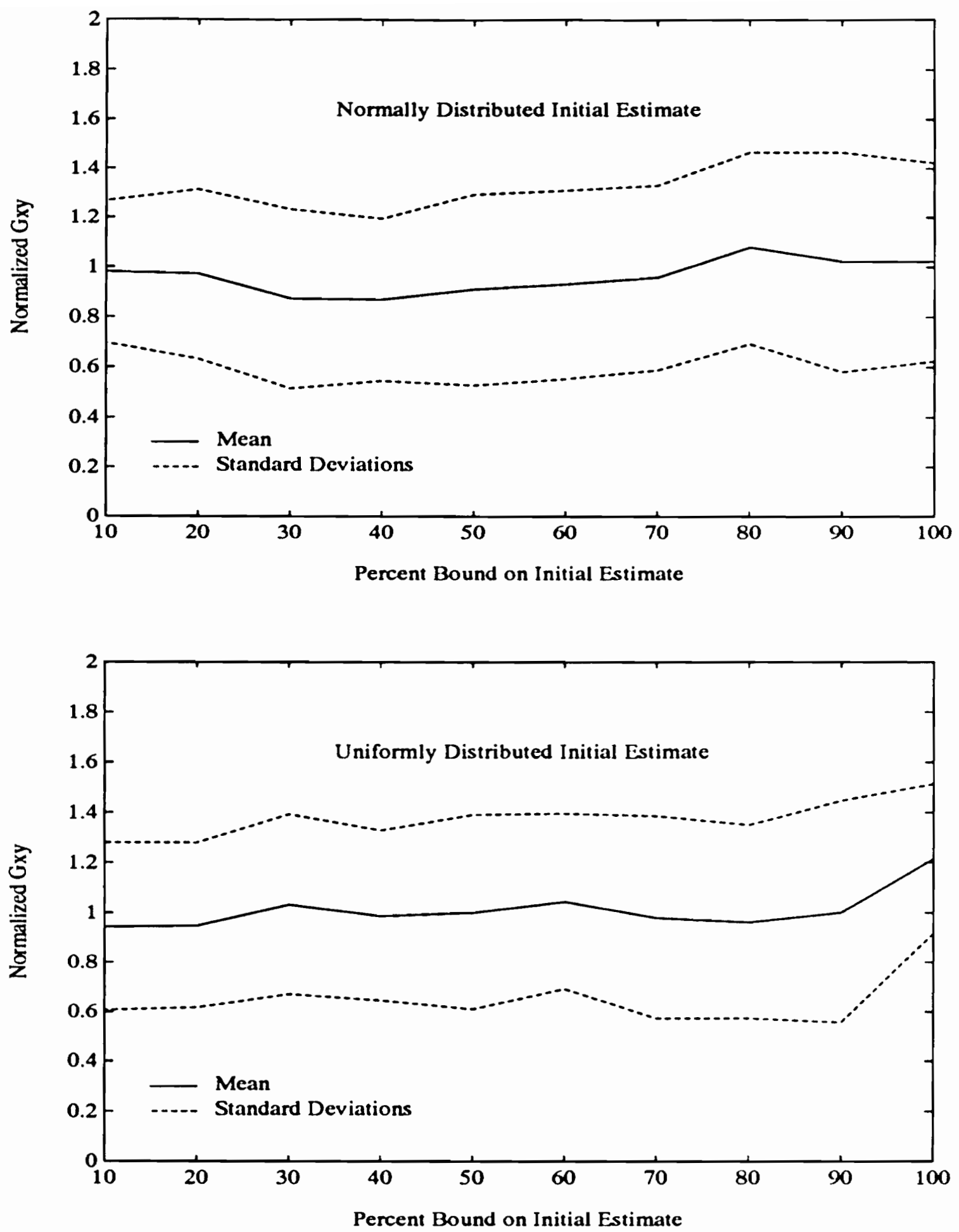

Figure 4.10: Variation of Mean and Standard Deviation of $G_{x y}$ Computed by Mode Identification with Change in Percentage Bound on Initial Estimate (Stressed Plate). 

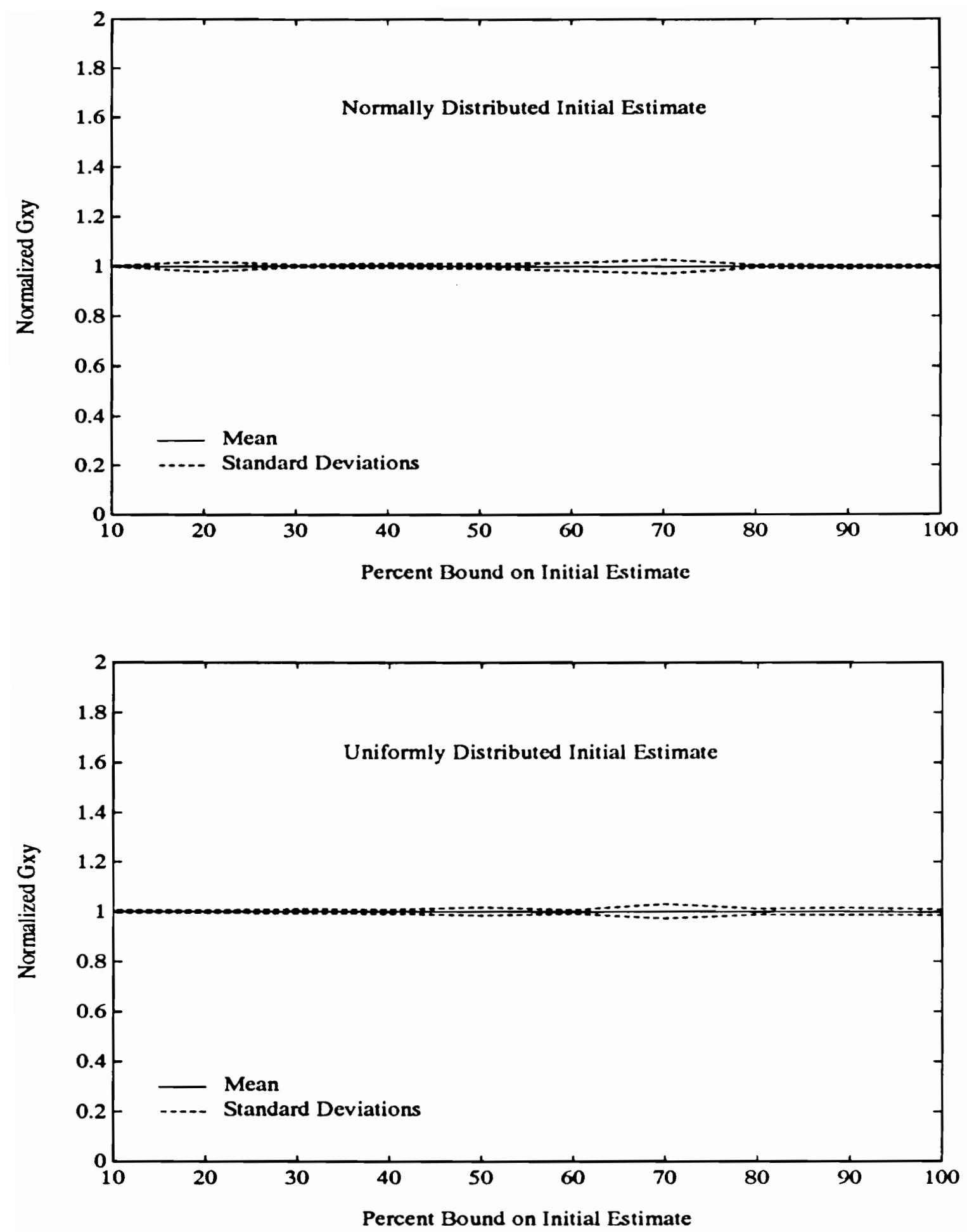

Figure 4.11: Variation of Mean and Standard Deviation of $G_{x y}$ Computed by Sensitivity Analysis with Change in Percentage Bound on Initial Estimate (Unstressed Plate). 
As stated earlier, one interesting fact that was noticed during the study was that the size of the initial data set has a definite effect on the statistical behavior of the algorithms. This may not sound very astonishing in itself, since sample size is one of the important factors in any statistical analysis, however the effect that was noticed was curious. When a data set of just 30 was used, there were definite differences between the effect of a uniformly distributed data set, and a normally distributed data set, the convergence being better for the normally distributed data set. But as the size of the data sets was increased to 100 , the effect of uniformly distributed data set approached that of the normally distributed one.

The most significant result, however, is the difference between the results obtained for the unstressed plate as against the stressed plate. In case of unstressed plate, the convergence of computed values to the actual values is, for practical purposes, exact. Not so for the stressed plate. There is a significant spread, specially in the computation of the elastic modulii.

The most obvious reason for this spread is a numerical one. In case of the unstressed plate, only a four by four solution matrix needs to be inverted, whereas for the stressed plate, it is necessary to invert a seven by seven matrix each time. This would introduce some errors, which would then propagate iteration after iteration. Second reason for this maybe that the stiffening produced by in-plane forces is significantly different than the stiffening produced the the rigidity inherent in the material. As pointed out above, in-plane loads have essentially a higher order effect on the out-of-plane behavior. 

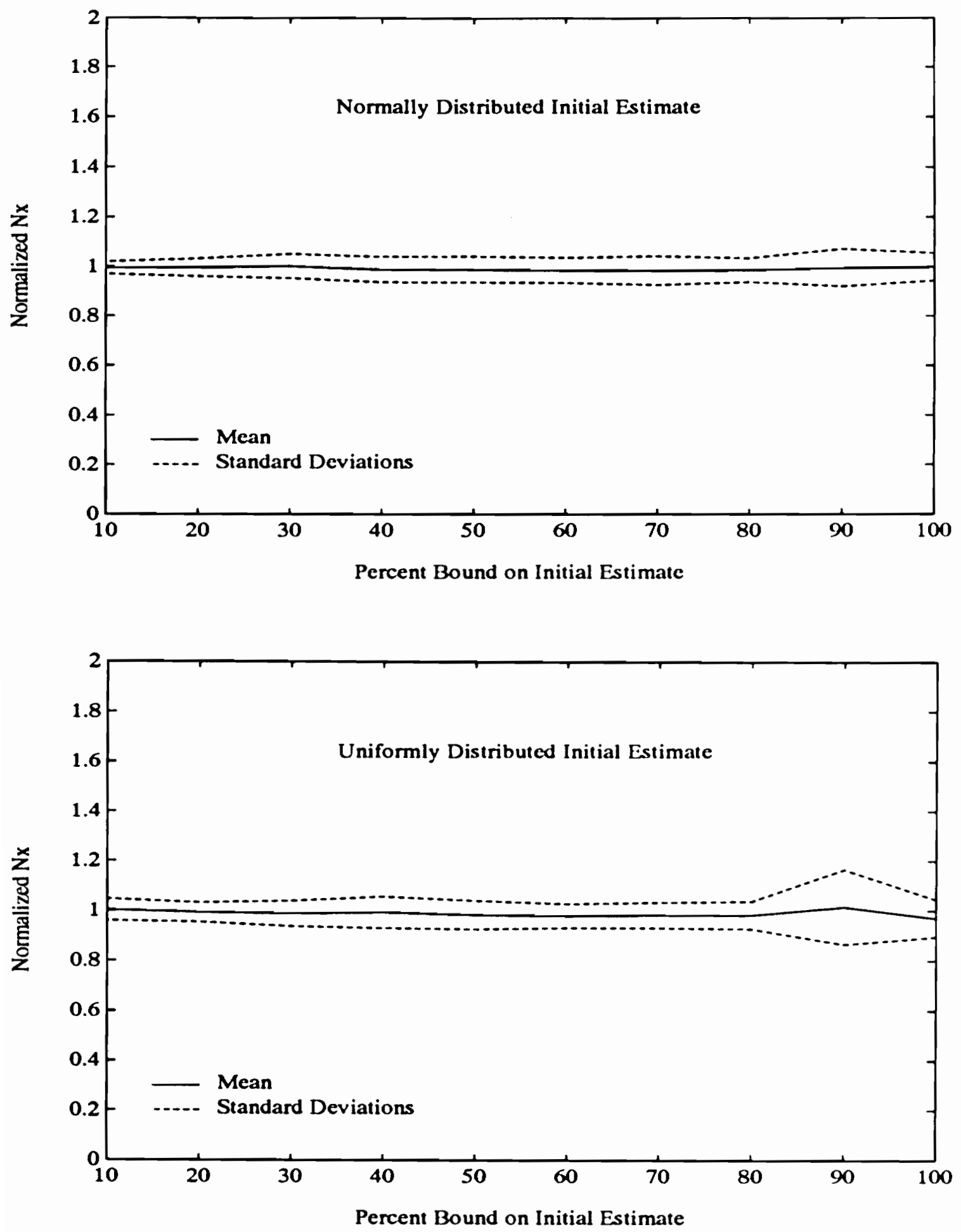

Figure 4.12: Variation of Mean and Standard Deviation of $N_{x}$ Computed by Mode Identification with Change in Percentage Bound on Initial Estimate. 

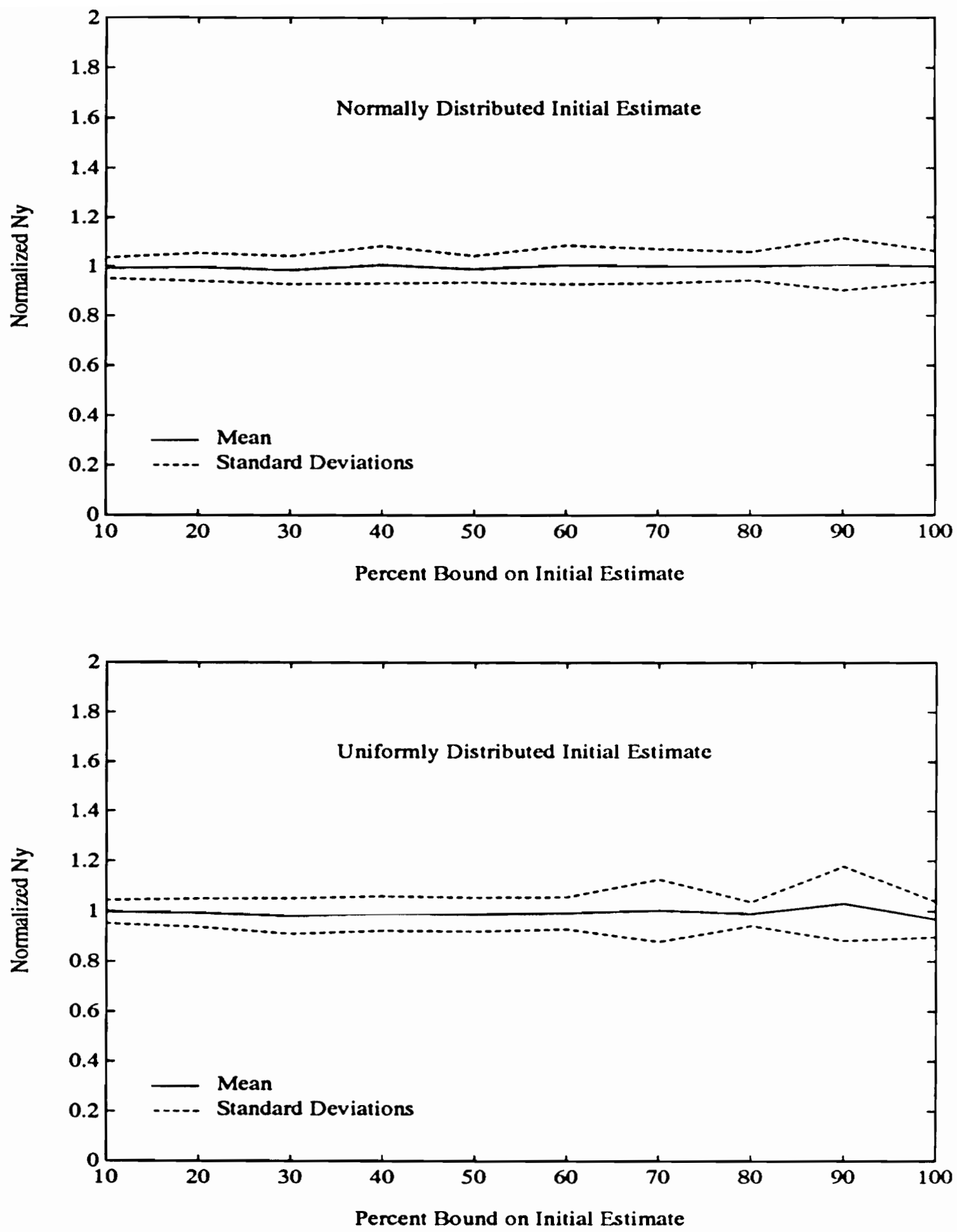

Figure 4.13: Variation of Mean and Standard Deviation of $N_{y}$ Computed by Mode Identification with Change in Percentage Bound on Initial Estimate. 

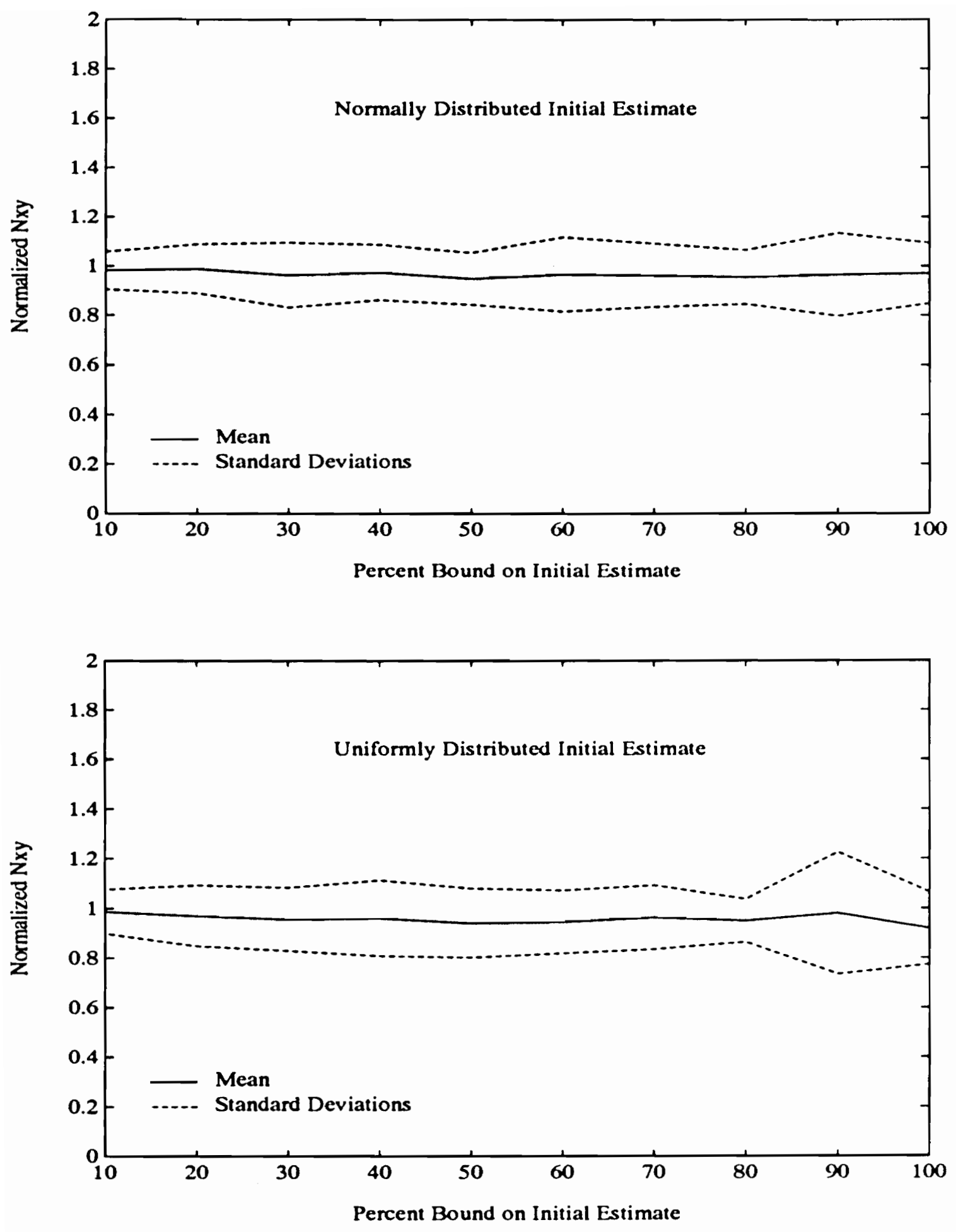

Figure 4.14: Variation of Mean and Standard Deviation of $N_{x y}$ Computed by Mode Identification with Change in Percentage Bound on Initial Estimate. 
Lastly, the figures show that less the spread in the input data, that is to say the closer the initial estimate is to the actual value, the better is the convergence. Hence, the techniques used for identification are definitely sensitive to the values of the initial estimate supplied to the program.

\subsection{Evaluation of the Three Techniques}

In most respects, the three techniques presented in this thesis behave quite differently. There are certain similarities, but the differences are more striking. In this section, some of these aspects will be discussed in detail.

The computation time taken by an algorithm is of great interest to an analyst. One can solve virtually any problem, given sufficient computational power. However, there is a price tag attached to this. From that point of view, the Mode Identification technique seems to be most suitable. In almost all the cases, the Mode Identification method consumed less CPU time than the other two techniques. At an average, it took about 10 minutes to run a full data set, with 100 sets of random input, on the IBM 3090 Vector facility at the author's institution. As opposed to that, Sensitivity Analysis consumed roughly twice that much Central Processor time, and the optimization method consumed a relatively astronomical 400 minutes, at an average. These times are for an unstressed plate. The times were somewhat higher for the stressed plate calculations.

The number of iterations that the three techniques needed to converge to the 'true' value varied by a wide margin. Table (4.3) shows the average number of iterations for the input data set with a twenty percent bound. The number of iterations needed 
for the stressed plate are roughly twice that needed for the unstressed plate. Hence, roughly, it would take twice as much computation time for a stressed plate as opposed to the unstressed plate. Compared to the Mode Identification and Sensitivity Analysis, optimization goes through prohibitively large number of iterations, which is reflected in the CPU times consumed by them. Even though Sensitivity Analysis needs less number of iterations than Mode Identification, it takes a larger chunk of computation time because, as seen from Eq. 2.26 and Eq. 2.32, there is more computation involved in calculating the elements of sensitivity matrix as opposed to the elements of the solution matrix in Mode Identification.

In most of the cases, there is generally a trade-off between computational accuracy and computational cost. From the point of view of accuracy, the optimization technique is undoubtedly superior to the other two techniques. In addition to calculating the six parameters, i.e. $E_{x}, E_{y}, G_{x y}, N_{x}, N_{y}$, and $N_{x y}$, quite accurate values were also obtained for the Poisson's ratio, using optimization. Hence if the cost is of no concern, or where the accuracy is of utmost importance, using the optimization technique would be the best solution.

Two other factors need to be emphasized here. Wherever in-plane loads are to be determined, the Sensitivity Analysis as presented here would be of no use. The other factor is the number of experimental frequencies necessary for determination of parameters. In case of both the Mode Identification and Sensitivity Analysis, the minimum number of frequencies needed is equal to the number of parameters that need to be identified. It would be beneficial if more number of frequencies were available in which case various combinations of frequencies could be used and the results averaged to obtain more reliable results. However, as shown in Figure (4.1), it is es- 
sential to have more number of frequencies than the number of unknown parameters while using optimization.

This may be because in case of optimization, the objective function, which is the sum of the square of differences between the analytical and experimental frequencies, is a scalar, whereas the frequencies are treated as a vector in the other two techniques. Which means that in the optimization technique there is no one-to-one correspondence between the number of frequencies and the number of parameters. Potentially, a continuous structure has infinite number of natural frequencies, and if the phenomena of interest is to be accurately modelled, a large number of frequencies would have to be included in the objective function. However this is not feasible, as the computation time increases as the number of frequencies is increased, and any modal analysis will produce just so many frequencies.

The various similarities and differences of the three techniques are summarized in Table (4.3). Overall, the Mode Identification technique seems to be most promising. It is cheap, efficient, and reasonably accurate. Optimization, though very accurate, is computationally very expensive, and would most likely need a powerful processor to keep the computation time within reasonable limits. There are no specific advantages associated with Sensitiviy Analysis, unless the computed values of sensitivities are already available from previous calculations or need to be calculated for some other purpose. 
Table 4.3: Comparison of the Three Techniques

\begin{tabular}{|l||l|l|l|}
\hline \multicolumn{1}{|c||}{ Attribute } & \multicolumn{1}{c|}{ Mode ID } & \multicolumn{1}{c|}{ Sensitivity } & \multicolumn{1}{c|}{ Optimization } \\
\hline \hline CPU Time & 1 Unit & 2 Units & 40 Units \\
\hline $\begin{array}{l}\text { Computation of In- } \\
\text { plane Loads }\end{array}$ & Possible & Not Possible & Possible \\
\hline $\begin{array}{l}\text { Computation of } \\
\text { Poisson's Ratio }\end{array}$ & $\begin{array}{l}\text { Possible, but inac- } \\
\text { curate }\end{array}$ & $\begin{array}{l}\text { Possible, but inac- } \\
\text { curate }\end{array}$ & $\begin{array}{l}\text { Possible and rea- } \\
\text { sonably accurate }\end{array}$ \\
\hline $\begin{array}{l}\text { Number of frequen- } \\
\text { cies needed }\end{array}$ & $\begin{array}{l}\text { Equal to number of } \\
\text { parameters to be } \\
\text { determined }\end{array}$ & $\begin{array}{l}\text { Equal to number of } \\
\text { parameters to be } \\
\text { determined }\end{array}$ & $\begin{array}{l}\text { Greater than num- } \\
\text { ber of parameters } \\
\text { to be determined }\end{array}$ \\
\hline $\begin{array}{l}\text { Overall robustness } \\
\text { (without in-plane } \\
\text { loads) }\end{array}$ & Reasonably good & Reasonably good & Best of the three \\
\hline $\begin{array}{l}\text { Overall robustness } \\
\text { (with in-plane loads) }\end{array}$ & Good & N/A & $\begin{array}{l}\text { Superior to Mode } \\
\text { ID }\end{array}$ \\
\hline \hline \multicolumn{2}{|c|}{ Average Number of Iterations for 20\% Bound } \\
\hline \hline $\begin{array}{l}\text { Uniform Distribution } \\
\text { Unstressed Plate }\end{array}$ & 6 & 3 & 285 \\
\hline $\begin{array}{l}\text { Uniform Distribution } \\
\text { Stressed Plate }\end{array}$ & 13 & N/A & 695 \\
\hline $\begin{array}{l}\text { Normal Distribution } \\
\text { Unstressed Plate }\end{array}$ & 6 & 2 & 270 \\
\hline $\begin{array}{l}\text { Normal Distribution } \\
\text { Stressed Plate }\end{array}$ & 12 & N/A \\
\hline
\end{tabular}


"When I use a word," Humpty Dumpty said, in rather a scornful tone, "it means just what I choose it to mean - neither more nor less."

"Speak in French when you ca'n't think of the English for a thing-" 


\section{Chapter 5}

\section{Conclusions and Recommendations}

\subsection{Conclusions}

This thesis considered various System Identification techniques to compute unknown system parameters. Specifically, detailed formulation was presented for three techniques, as applied to an orthotropic plate. The algorithms were subsequently implemented in FORTRAN on the mainframe at the author's institution. The two major goals of this project were to develop suitable methods for extracting the values of in-plane loads of a composite structure, in addition to the material elastic properties, given a set of experimental natural frequencies, and to investigate the robustness of the algorithms with respect to the scatter in values of initial estimates.

A concise summary of the results discussed in previous chapter is presented below:

- Sufficiently accurate values of the elastic properties and in-plane loads can be obtained, even with a large scatter in data, with all three techniques. Optimization gives somewhat less scatter in the output than the other two techniques. 
- The scatter in the computed value of parameters depends on number of parameters to be computed. If in-plane loads are to be computed, in addition to stiffnesses, the scatter is larger than while computing stiffnesses alone.

- Its not possible to compute in-plane loads using Sensitivity Analysis, owing to highly ill-conditioned matrices generated during the solution process.

- Only optimization gives the values of Poisson's ratio to any degree of accuracy.

- The CPU time required by the three techniques vary widely from each other. While Mode Identification takes about ten minutes on an average for 100 data sets, and Sensitivity Analysis consumes about twenty minutes of CPU time, the corresponding value for optimization is in the region of four hundred minutes, almost forty times that for Mode Identifications.

- The number of frequencies required by both the Mode Identification and Sensitivity Analysis are same as the number of parameters to be identified. Optimization, however, typically needs higher number of experimental frequencies than the number of parameters to be determined.

In short, Mode Identification is a good, robust technique, requiring minimal CPU time, with reasonably good accuracy, but unable to extract Poisson's ratio. Optimization is superior from the point of view of accuracy, but is computationally rather expensive. Sensitivity Analysis does not have anything to recommend it over the other two techniques. 


\subsection{Recommendations}

As mentioned in the previous chapter, any Identification technique is only as good as the mathematical model used. The current thesis used a relatively simplified thin plate model, with the simplest laminate lay-up. The approaches discussed here for extraction of parameters could be made more universal by:

- using a more generalized plate theory which would take account of anisotropy.

- including the effects of rotary inertia which become significant as the structure gets thicker and shorter.

- using the so-called first or higher order shear deformation theories which would more accurately portray the mechanics of the structure.

- using a generalized shell theory.

- incorporating the effects of damping in the system equations.

- incorporating other material parameters like density in the list of unknown parameters.

In addition to investigating a different mathematical model, it might be fruitful to make the current algorithms more efficient either by reprogramming them in FORTRAN itself or in some other languages such as $\mathrm{C}$.

As discussed in the literature review, there are innumerable ways of updating the stiffness matrix based on the difference between analytical and experimental frequencies, and other modal data. Some of these techniques might prove to be either more accurate or cheaper than the ones presented here. Other techniques, such as the ones based on finite element type of formulation, might also be able to handle more 
complex issues such as material inhomogeniety and non-linearity. After all, one thing that history teaches us is that there are always better alternatives, provided one has time and money. 


\section{References}

Abartsumyan, S. A., 1970, Theory of Anisotropic Plates, (English translation), Technomic, Stamford, Connecticut.

Arora, J. S., 1989, Introduction to Optimum Design, New York: McGraw-Hill.

Barker, D. K., 1989, Active Dynamic Response Tuning of Adaptive Composites Utilizing Embedded Nitinol Actuators, Master's Thesis, Virginia Polytechnic Institute and State University.

Baruch, M., and Itzhack, S., 1978, "Optimal Weighted Orthogonalization of Measured Modes," AIAA Journal, Vol. 16, No. 4, April, (346 - 351).

Berman, A., 1975, "Determining Structural Parameters from Dynamic Testing," Shock and Vibration Digest, Vol. 7, January, (10 - 17).

Berman, A., 1979, "Parameter Identification Techniques for Vibrating Structures," Shock and Vibration Digest, Vol. 11, January, (13 - 16).

Berman, A., and E. G. Nagy, 1983, "Improvement of a Large Analytical Model Using Test Data," AIAA Journal, Vol. 21, No. 8, August, (1168 - 1173).

Blakely, K. D., and W. B. Walton, 1983, “Selection of Measurement and Parameter Uncertainties for Finite Element Model Revision," and IMAC, Orlando, Florida, $(82-86)$. 
Blevins, R. D., 1979, Formulas for Natural Frequencies and Mode Shapes, New York: Van Nostrand Reinhold.

Buehler, W. J., and R. C. Wiley, 1965, “Nickel-Base Alloys,” U.S. Patent 3,174,851, March 23.

Caldersmith, G., and T. D. Rossing, 1984 "Determination of Modal Coupling in Vibrating Rectangular Plates,” Applied Acoustics, Vol. 17, No. 1, (33 - 44).

Chen, J. C., and J. A. Garba, 1980, "Analytical Model Improvement Using Modal Test Results," AIAA Journal, Vol. 18, No. 6, June, (684-690).

Chen, T. Y., and B. P. Wang, 1988, "Finite Element Model Refinement Using Modal Analysis Data," Proceedings of AIAA/ASME 29th Strucutres, Structural Dynamics, and Materials Conference, April, (1219-1229).

Chia, C. Y., 1980, Nonlinear Analysis of Plates, New York: McGraw-Hill.

Clarke, Arthur C., 1984, Profiles of The Future : An Inquiry Into The Limits of The Possible, New York: Holt, Reinhart, and Winston.

Collins, J. D., G. C. Hart, T. K. Hasselman, and B. Kennedy, 1974, "Statistical Identification of Structures," AIAA Journal, Vol. 12, No.2, February, (187 190).

Cross, W. B., A. H. Kariotis, and F. J. Stimler, 1969, "Nitinol Characterization Study," NASA CR-1433, September.

Delaey, R. V., H. Tas Krishnan, and H. Warlimont, 1974, "Thermoelasticity, Pseudoelasticity and the Shape Memory Effects Associated with Martensitic Transformations," Journal of Material Science, Vol. 9, (1521 - 1545). 
Deobald, L. R., 1985 "Determination of Elastic Constants of Orthotropic Plates by a Modal Analysis Rayleigh-Ritz Technique.,"Master's Thesis, University of Idaho.

Deobald, L. R., and R. F. Gibson, 1988, "Determination of elastic constants of orthotropic plates by a modal analysis/Rayleigh-Ritz technique.," Journal of Sound and Vibration, Vol. 124, (269 - 283).

DeWilde, W. P., B. Narmon, H. Sol, and M. Roovers, 1984, "Determination of the material constants of an anisotropic lamina by free vibration analysis," Proceedings of the 2nd International Modal Analysis Conference, Orlando, FL, Vol. I, (44-49).

DeWilde, W. P., H. Sol, and M. Van Overmeire, 1986, "Coupling of Lagrange Interpolation, Modal Analysis and Sensitivity Analysis in the Determination of Anisotropic Plate Rigidities.," Proceedings of the 4th International Modal Analysis Conference, Los Angeles, California, (1058 - 1063).

Dobson, B. J., 1983, "Modification of Finite Element Models Using Experimental Modal Analysis," 2nd IMAC, Orlando, Florida, (593 - 597).

Eykhoff, Pieter, 1979, System Identification: Parameter and State Estimation, Chichester: John Wiley \& Sons, 2nd. Reprint.

Goldstein, D., 1978, A Source Manual for Information on Nitinol and NiTi, Naval Surface Weapons Center, Silver Spring, Maryland, Report NSWW/WOL TR 78-26.

Hall, B. M., E. D. Calkin, and M. S. Sholar, 1970, "Linear Estimation of Structural Parameters from Dynamic Test Data," Proceedings of AIAA/ASME 11th 
Structures, Structural Dynamics, and Materials Conference, April, (193 - 197).

Haug, E. J., and J. S. Arora, 1979, Applied Optimal Design: Mechanical and Structural Systems, New York: Wiley.

Heylan, W., and P. Sas, 1986, "Review of Modal Optimization Techniques," 5th IMAC, Orlando, Florida, (1177 - 1182).

Ibrahim, S. R., and A. A. Saafan, 1986, "Correlation of Analysis and Test in Modelling of Structures - Assessment and Review," 5th IMAC, Orlando, Florida, $(1651-1660)$.

Intcrnational Mathematical and Statistical Library, 1987, STAT/LIBRARY, Version 1.0, Vol. 3, April, (965 - 966).

Jackson, C. M., j. H. Wagner, and R. J. Wasilewski, 1972, “55-Nitinol - The Alloy with a Memory: Its Physical Metallurgy, Properties, and Applications," NASA$S P-5110$, p. 91

Jain, V. K., and G. J. Dobcek, 1979, "System Identification Techniques: A Tutorial Review," in 79-WA/DSC-20, ASME, New York.

Kabe, A. K., 1985, "Stiffness Matrix Adjustment Using Mode Data," ALA Journal, Vol. 23, No. 9, September, (1431 - 1436).

Kagiwada, H. H., 1974, System Identification: Methods and Applications, Addison-Wesley Publishing Company, Inc., Reading, Massachusetts.

Kapania, R. K., and S. Raciti, 1989a, "Recent Advances in Analysis of Laminated Beams and Plates, Part I: Shear Effects and Buckling," AIAA Journal, Vol. 27, No. $7,(923-934)$. 
Kapania, R. K., and S. Raciti, 1989b, "Recent Advances in Analysis of Laminated Beams and Plates, Part II: Vibrations and Wave Propagation," AIAA Journal, Vol. 27, No. 7, (935 - 946).

Leissa, A. W., 1973, "The Free Vibration of Rectangular Plates," Journal of Sound and Vibration, 31 (3), (257 - 293).

Lekhnitskii, S. G., 1968, Anisotropic Plates, translated from the Second Russian Edition by S. W. Tsai and T. Cheron, Gordon and Breach.

Liang, C., J. Jia, and C. A. Rogers, 1989a, "Behavior of Shape Memory Alloy Reinforced Composites - Part I: Model Formulation and Concepts," Proceedings of the 30th Structures, Structural Dynamics and Materials Conference, Mobile, Al, April 3-5.

Liang, C., J. Jia, and C. A. Rogers, 1989b, "Behavior of Shape Memory Alloy Reinforced Composites - Part II: Results," Proceedings of the 30th Structures, Structural Dynamics and Materials Conference, Mobile, Al, April 3-5.

The Mathworks, Inc., 1989, PC-MATLAB User's Guide, (3-158), February.

Noor, A. K., and W. S. Burton, 1989, "Assessment of Shear Deformation Theories for Multilayered Composite Plates," Applied Mechanics Reriew, Vol. 42, No. $1,(1-12)$.

Pakstys, M. P., 1982, "Correlation of Experimental and Analytical Structural Dynamics Parameters - A 1982 Overview," 1st IMAC, Orlando, Florida, (59 $63)$.

Perkins, J., ed., 1975, Shape Memory Effects in Alloys, New York: Plenum Press. 
Pilkey, W. D., and R. Cohen, (Eds.), 1972, System Identification of Vibrating Structures, ASME, New York.

Reddy, J. N., 1984, Energy and Variational Methods in Applied Mechanics, New York: John Wiley \& Sons, Inc.

Rogers, C. A., 1988, "Novel Design Concepts Utilizing Shape Memory Alloy Reinforced Composites," Proceedings of the American Society for Composites 3rd Technical Conference on Composite Materials, Technomic Publishing Company, Seattle, September.

Rogers, C. A., D. K. Barker, K. D. Bennett, and R. II. Wynn, Jr., 198Sa, "Demonstration of a Smart Material with Embedded Actuators and Sensors for Active Control," Proceedings of SPIE's International Symposium on Fiber Optics, Optoelectronics, and Laser Applications in Science and Engineering, Boston, MA, September 6-9.

Rogers, C. A., C. Liang, and D. K. Barker, 1988b, "Dynamic Control Concepts Using Shape Memory Alloy Reinforced Plates," ARO Smart Materials, Structures, and Mathematical Issues Workshop Proceedings, Virginia Polytechnic Institute and State University, Blacksburg, VA, September 15-16.

Rogers, C. A., and H. H. Robertshaw, 1988, "Development of a Novel Smart Material," ASME Winter Annual Meeting, Chicago, Illinois, Nov. 27-Dec. 2.

Saburi, T., and C. M. Wayman, 1979, "Crystallographic Similarities in Shape Memory Martensites," Acta Metallurgica, Vol. 27, p. 979

Sage, A. P., and J. L. Melsa, 1971, System Identification, New York: Academic Press. 
Schetky, L., 1979, "Shape Memory Alloys," Scientific American, Vol. 241, p. 74.

Shye, K., and M. Richardson, 1986, "Mass, Stiffness, and Damping Estimates from Structural Measurements, " 5th IMAC, Orlando, Florida, (756 - 761).

Stiles, Peter A., 1988, Improvement of Structural Dynamic Models via System Identification, Masters Thesis, Virginia Polytechnic Institute and State University.

Timoshenko, S., and S. Woinowsky-Krieger, 1959, Theory of Plates and Shells, 2nd ed., McGraw-Hill, New York.

Wayman, C. M., and K. Shimizu, 1972, “The Shape Memory ('Marmem') Effect in Alloys," Metal Science J., Vol. 6, p. 175.

Whitney, J. M., 1987, Structural Analysis of Laminated Anisotropic Plates, Technomic Publishing Co., Inc.

Wolf, J. A., Jr., and T. G. Carne, 1979, "Identification of the elastic constants for composites using modal analysis," Meeting of the Society for Experimental Stress Analysis, San Francisco, California, Paper No. A-48.

Young, D., 1950, "Vibrations of Rectangular Plates by the Ritz Method," Journal of Applied Mechanics., Vol. 17, (448 - 453).

Zelenev, Yu. V., and L. M. Electrova, 1973, "Determination of the Dynamic Parameters of Polymer Plates," Soviet Physics-Acoustics, Vol. 18, No. 3, (339 $341)$. 


\section{Appendix A}

\section{Beam Eigenvalues and Frequency Parameters}

\section{A.1 Beam Vibration Equations and Boundary Con- ditions}

The non-dimensionalized form of the Euler beam equation for free vibration is given by:

$$
E I \frac{d^{4} y}{d x^{4}}-\beta^{4} y=0
$$

where,

$$
\beta^{4}=\left(\frac{\epsilon}{l}\right)^{4}, \quad \epsilon^{4}=\frac{\rho \omega^{2} l^{4}}{E I}
$$

The general solution to the fourth order differential equation is given by:

$$
y(x)=A \cosh \left(\frac{\epsilon x}{l}\right)+B \sinh \left(\frac{\epsilon x}{l}\right)+C \cos \left(\frac{\epsilon x}{l}\right)+D \sin \left(\frac{\epsilon x}{l}\right)
$$

The boundary conditions relevant to the beam functions used in this work are: 
Clamped End

$$
\text { at } x=0 \text { and/or } l\left\{\begin{array}{r}
y=0 \\
d y / d x=0
\end{array}\right.
$$

\section{Free End}

$$
\text { at } x=0 \text { and/or } l\left\{\begin{array}{lll}
M=0 & \text { or } & d^{2} y / d x^{2}=0 \\
V=0 & \text { or } & d^{3} y / d x^{3}=0
\end{array}\right.
$$

\section{A.2 Solutions for Beam Equation}

This section reiterates the transcendental equations for eigenvalues, $\epsilon_{i}$, equations for frequency parameters, $\alpha_{i}$, and characteristic functions for beams having free-free, clamped-free, and clamped-clamped boundary conditions. Rigid body modes for the free-free beam are also presented.

\section{Transcendental Equations}

Free-Free and Clamped-Clamped Beams

$$
\begin{aligned}
& \cos (\epsilon) \cosh (\epsilon)-1=0 \\
& \epsilon_{1}=\epsilon_{2}=0 \text { for free-free beam }
\end{aligned}
$$


Clamped-Free Beam

$$
\cos (\epsilon) \cosh (\epsilon)+1=0
$$

\section{Frequency Parameter}

Free-Free and Clamped-Clamped Beams

$$
\begin{aligned}
\alpha_{i} & =\frac{\cosh \left(\epsilon_{i}\right)-\cos \left(\epsilon_{i}\right)}{\sinh \left(\epsilon_{i}\right)-\sin \left(\epsilon_{i}\right)} \\
i & =3,4,5, \ldots, \infty \text { for free-free beam } \\
i & =1,2,3, \ldots, \infty \text { for clamped-clamped beam }
\end{aligned}
$$

Clamped-Free Beam

$$
\begin{aligned}
\alpha_{i} & =\frac{\sinh \left(\epsilon_{i}\right)-\sin \left(\epsilon_{i}\right)}{\cosh \left(\epsilon_{i}\right)-\cos \left(\epsilon_{i}\right)} \\
i & =1,2,3, \ldots, \infty
\end{aligned}
$$

\section{Characteristic Functions}

Free-Free Beam

$$
\begin{aligned}
\phi_{1} & =1 \\
\phi_{2} & =\sqrt{3}(1-2 x / l) \\
\phi_{i} & =\cosh \left(\frac{\epsilon_{i} x}{l}\right)+\cos \left(\frac{\epsilon_{i} x}{l}\right)-\alpha_{i}\left(\sinh \left(\frac{\epsilon_{i} x}{l}\right)+\sin \left(\frac{\epsilon_{i} x}{l}\right)\right) \\
i & =3,4,5, \ldots, \infty
\end{aligned}
$$


Clamped-Clamped and Clamped-Free Beams

$$
\begin{aligned}
\phi_{i} & =\cosh \left(\frac{\epsilon_{i} x}{l}\right)-\cos \left(\frac{\epsilon_{i} x}{l}\right)-\alpha_{i}\left(\sinh \left(\frac{\epsilon_{i} x}{l}\right)-\sin \left(\frac{\epsilon_{i} x}{l}\right)\right) \\
i & =1,2,3, \ldots, \infty
\end{aligned}
$$

\section{A.3 Eigenvalues and Frequency Parameters}

Eq. A.5 and Eq. A.6 can be solved numerically to find the roots, $\epsilon_{i}$. Subsequently, Eq. A.7 and Eq. A. 8 can be used to compute the frequency parameters, $\alpha_{i}$. These values are reproduced below from Blevins (1979). 
Table A.1: Beam Eigenvalues, $\epsilon_{i}$

\begin{tabular}{|c||l|c|c|}
\hline $\mathrm{i}$ & Free-Free & Clamped-Free & Clamped-Clamped \\
\hline 1 & 0.0 & 1.87510407 & 4.73004074 \\
2 & 0.0 & 4.69409113 & 7.85320462 \\
3 & 4.73004074 & 7.85475744 & 10.9956078 \\
4 & 7.85320462 & 10.99554073 & 14.1371655 \\
5 & 10.9956078 & 14.13716839 & 17.2787597 \\
6 & 14.1371655 &. &. \\
7 & 17.2787597 &. &. \\
& $(2 i-3) \pi / 2$ & $(2 i-1) \pi / 2$ & $(2 i+1) \pi / 2$ \\
& for $\mathrm{i}>7$ & for $\mathrm{i}>5$ & for $\mathrm{i}>5$ \\
\hline
\end{tabular}

Table A.2: Beam Frequency Parameters, $\alpha_{i}$

\begin{tabular}{|c||c|c|c|}
\hline $\mathrm{i}$ & Free-Free & Clamped-Free & Clamped-Clamped \\
\hline 1 & - & 0.734095514 & 0.982502215 \\
2 & - & 1.018467319 & 1.000777312 \\
3 & 0.982502215 & 0.999224 .497 & 0.999966450 \\
4 & 1.000777312 & 1.000033553 & 1.000001450 \\
5 & 0.999966450 & 0.999998550 & 0.999999937 \\
6 & 1.000001450 & & \\
7 & 0.999999937 & & \\
& $\doteq 1.0 \forall i>7$ & $\doteq 1.0 \forall i>5$ & $\doteq 1.0 \forall i>5$ \\
\hline
\end{tabular}




\section{Appendix B}

\section{Listing of Computer Program SYSID}

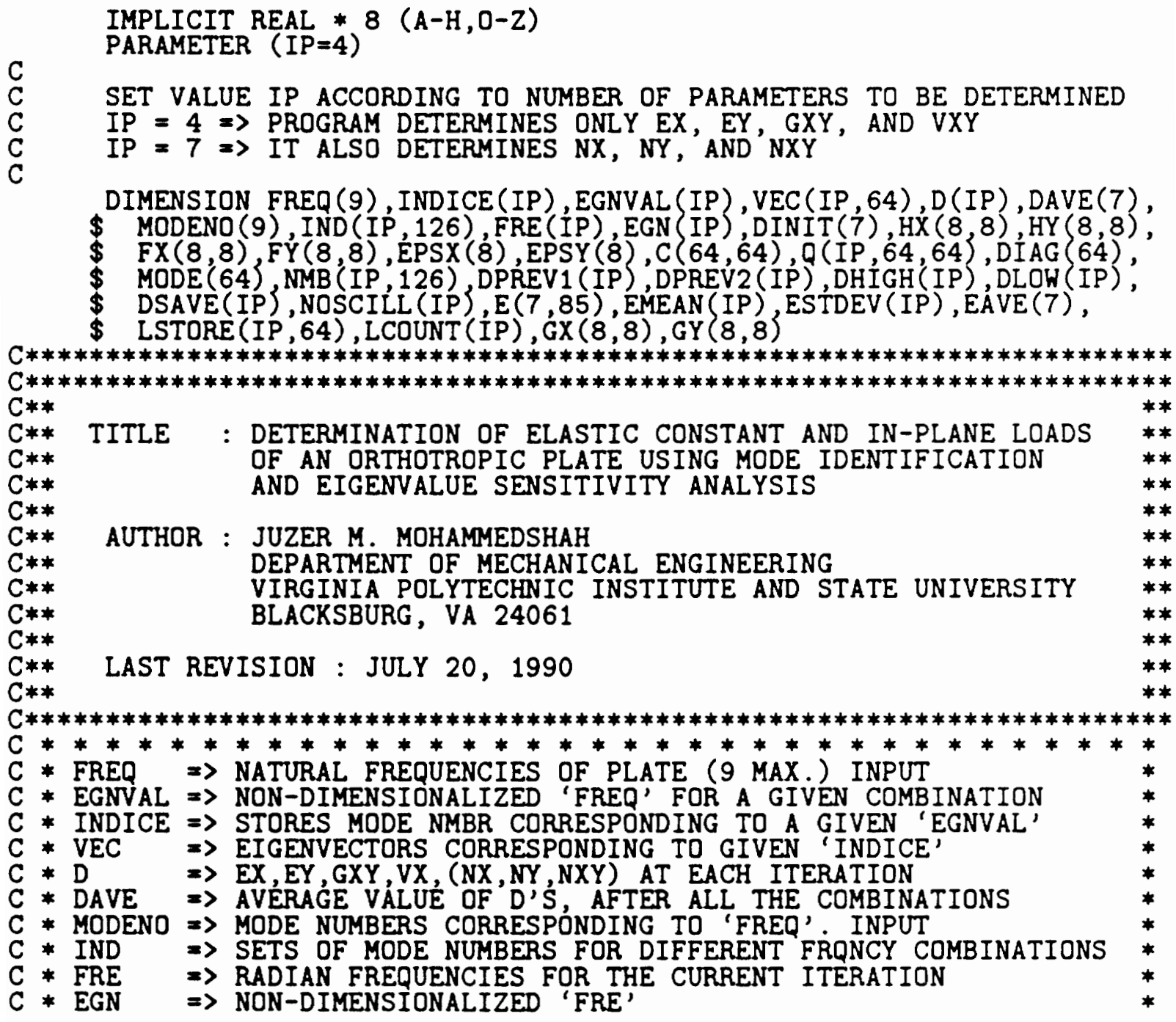




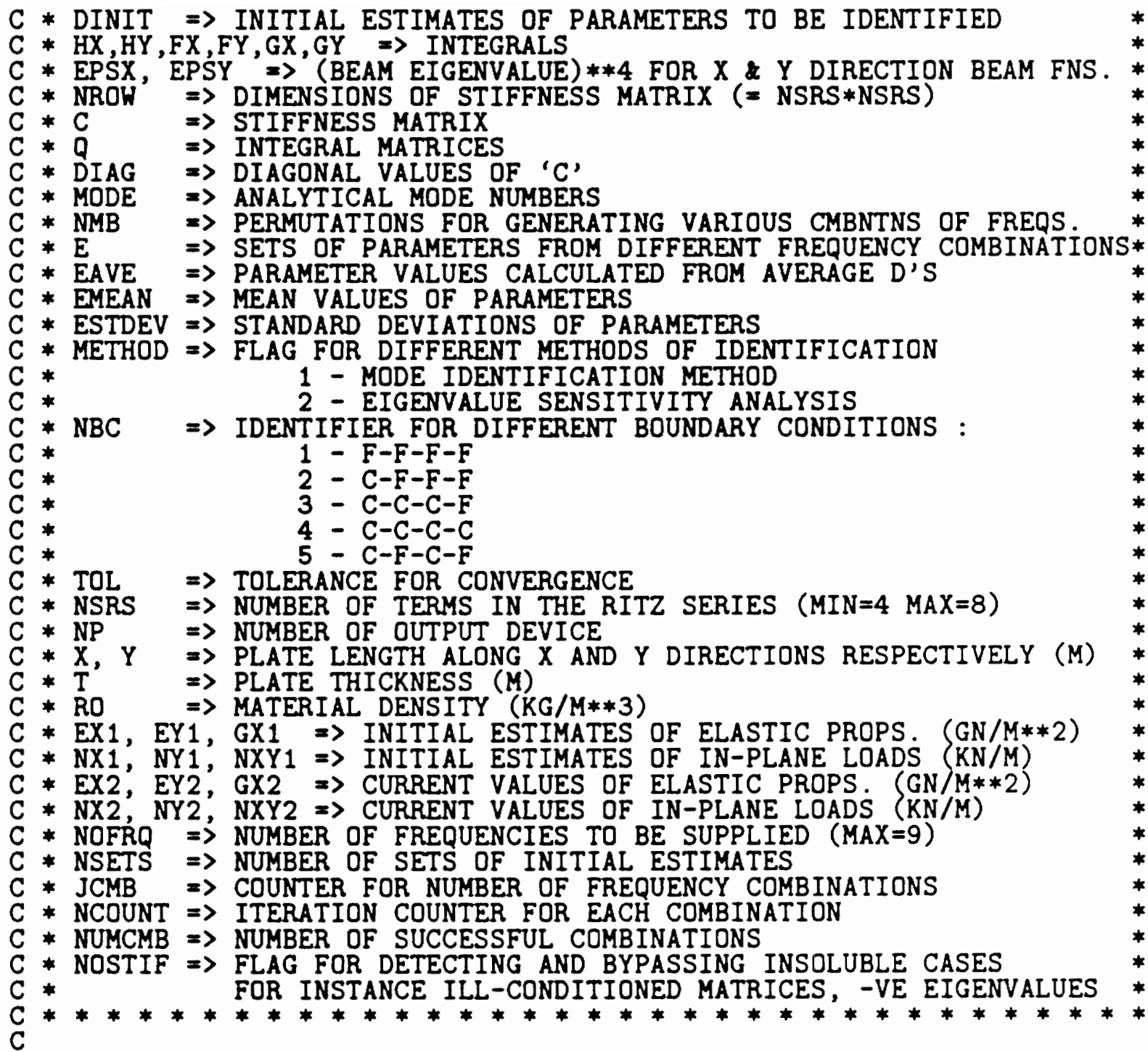

CALL ERSET $(0,0,0)$

C

$\mathrm{C}$
$\mathrm{C}$

$P I=4 . D O * \operatorname{DATAN}(1 . D 0)$

C DATA INPUT BEGINS HERE

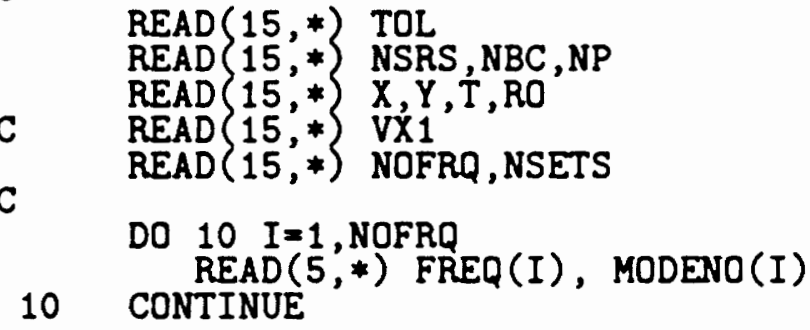

$\operatorname{READ}(15, *)$ METHOD

C $\mathrm{C}$ VALUES OF INTEGRALS APPROPRIATE TO 'NBC' ARE ASSIGNED IN INTEG 
CALI INTEG (HX , HY , FX , FY, EPSX, EPSY, NSRS , NBC , GX , GY)

$\mathrm{C}$
$\mathrm{C}$ DO-LOOP ON NUMBER OF SETS BEGINS HERE

DO 170 NSET $=1$, NSETS

$\operatorname{VX} 1=0.025$

WRITE $(4, *)$ 'SET NUMBER = ', NSET

IF (IP.EQ.4) READ $(7, *)$ EX 1, EY1, GX1

IF (IP.EQ.7) READ (7,*) EX1,EY1,GX1, DNX1,DNY1,DNXY1

C CONVERT FORCES TO GN/M FROM KN/M

DNX $1=D N X 1 * 1 \cdot D-6$

DNY $1=$ DNY $1 * 1 . D-6$

DNXY $1=D N X Y 1 * 1 . D-6$

$\stackrel{\mathrm{C}}{\mathrm{C}}$

WRITE OUT INITIAL ESTIMATES SUPPLIED -- FOR CHECK

IF (IP.EQ.4) WRITE (4,*) EX1,EY1,GX1

IF (IP .EQ. 7) WRITE $(4, *)$ EX1, EY $1, G X 1, D N X 1, D N Y 1, D N X Y 1$

C

INITIALIZE VARIOUS QUANTITIES

NUMCMB $=0$

C

DO $20 I=1$, IP

DAVE (I $)=0 . D 0$

DPREV $1(I)=0 . D 0$

20 CONTINUE

DPREV $2(I)=0$. DO

C

CALCULATE NON-DIMENSIONALIZING FACTOR FL

$F L=(X * Y * 2 . * P I * D S Q R T(R D * T))$

$V Y=(E Y 1 / E X 1) * V X 1$

C

$\mathrm{P}=(\mathrm{T} * * 3) /(12 . *(1 .-\mathrm{VX} 1 * \mathrm{VY}))$

C

$\operatorname{DINIT}(1)=E X 1 * P$

DINIT (2) $=E Y 1 * P$

$\operatorname{DINIT}(3)=V X 1 * \operatorname{DINIT}(2)$

$\operatorname{DINIT}(4)=(\mathrm{GX} 1 *(\mathrm{~T} * * 3)) / 12$.

IF (IP .EQ. 7) THEN

$\operatorname{DINIT}(5)=D N X 1 * Y * Y$

DINIT 6$\}=D N Y 1 * X * X$

ENDIF

DINIT $(7)=D N X Y 1 * X * Y$

C
C
C

C
C
C
C
C

ASSEMBLE THE INTEGRAL AND STIFFNESS MATRICES FOR FIRST ITERATION

CALL MATRIX (DINIT , X , Y,HX , HY , FX , FY, EPSX, EPSY , $, C, D I A G, N R O W$, NSRS , \$MODE, NBC , GX, GY, IP)

C GENERATE MODE-NUMBERS --THE SOLVERS USED IN THIS PROGRAM GIVE AN ASCENDING ORDER OF EIGENVALUES SO IT IS NOT NECESSARY TO CALCULATE MODE NUMBERS FROM EQUATIONS

$\operatorname{MODE}(1)=1$

DO $30 I=1,63$

$\operatorname{MODE}(I+1)=\operatorname{MODE}(I)+1$ CONTINUE 


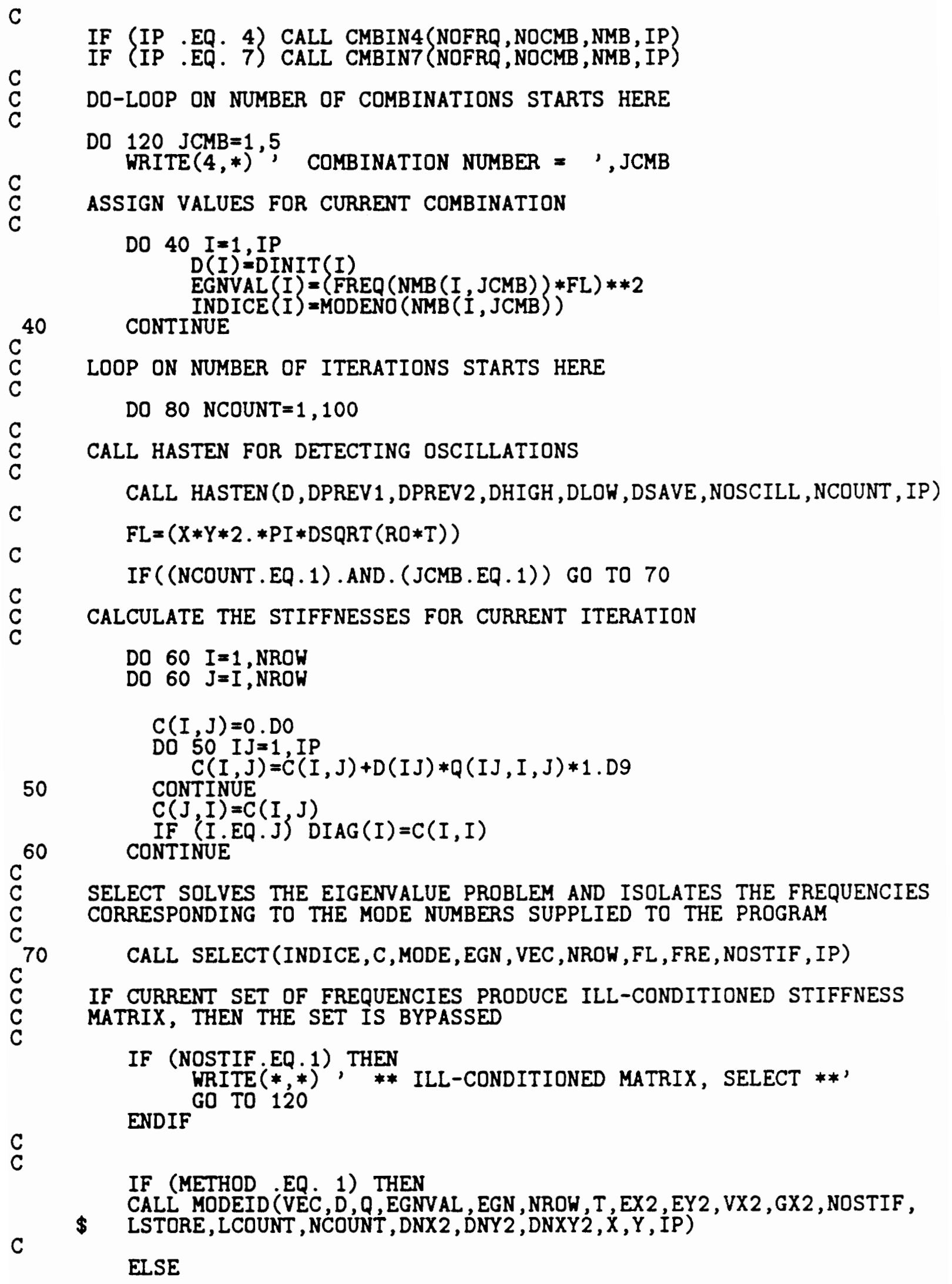


CALL SENSE (VEC, D , Q, EGNVAL, EGN, NROH, T, EX2 , EY 2, VX2 , GX2, NOSTIF, DNX2, DNY2, DNXY2, IP, TOLER, $X, Y$ )

C

C

$\stackrel{\mathrm{C}}{\mathrm{C}}$

C

C
C
C

IF CURRENT SET OF FREQUENCIES PRODUCE ILL-CONDITIONED SOLUTION MATRIX, THEN THE SET IS BYPASSED

IF (NOSTIF.EQ.1) THEN ENDIF WRITE $(*, *)$, ** ILL-CONDITIONED SOLUTION MATRIX **' GO TO 120

CALCULATE ABSOLUTE ERROR BETWEEN PREVIOUS AND CURRENT ITERATIONS

$E X C M P=D A B S(E X 2-E X 1)$

$E Y C M P=D A B S(E Y 2-E Y 1)$

GXCMP $=$ DABS $(G \times 2-G \times 1\}$

VXCMP $=$ DABS $(V X 2-V X 1) * 10$.

$E X 1=E X 2$

$E Y 1=E Y 2$

GX1 $=G \times 2$

$V X 1=V X 2$

IF (IP .EQ. 7) THEN

$D X C M P=D A B S(D N X 2-D N X 1) * 10 . D 4$

$D Y C M P=D A B S(D N Y 2-D N Y 1) * 10 . D 4$

$D X Y C M P=D A B S(D N X Y 2-D N X Y 1) * 10 . D 4$

DNX1 $=$ DNX2

DNY1 $=$ DNY 2

ENDIF

DNXY1 $=D N X Y 2$

WRITE $(*, *)$ ' ITERATION $=$ ', NCOUNT

WRITE $(*, *)$ EX2,EY2, GX2, VX2, DNXं2, DNY2, DNXY2, TOLER

CHECK FOR TOLERANCE, CONTINUE IF ERROR IS GREATER THAN 'TOL'

IF (IP . EQ - 4) THEN

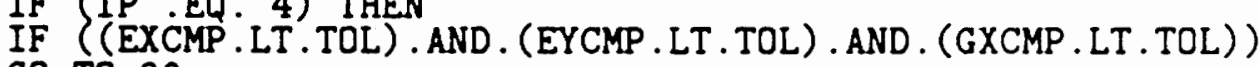

$\$$

GO TO 90

ENDIF

IF (IP .EQ. 7) THEN

IF ( (EXCMP . LT TOL) . AND . (EYCMP . LT . TOL) . AND . (GXCMP . LT . TOL) . AND .

\$ (DXCMP.LT.TOL).AND. (DYCMP.LT.TOL) . AND. (DXYCMP.LT.TOL))

$\$$ GO TO 90

ENDIF

CONTINUE

BYPASS THE COMBINATION IF IT GIVES NEGATIVE STIFFNESSES

IF $((E X 2 . L T .0 .0)$.OR $(E Y 2 . L T .0 .0)$. OR. (GX2.LT.0.0)) THEN

WRITE $(*, *)$, SKIPPED'

GO TO 120

ENDIF

CONSOLIDATE RESULTS OF DIFFERENT COMBINATIONS AND CALCULATE MEANS AND STANDARD DEVIATIONS FOR CURRENT SET

NUMCMB $=$ NUMCMB +1

$E(1, N U M C M B)=E X 2$

$E(2, N U M C M B)=E Y 2$

$\mathrm{E}(3, \mathrm{NUMCMB}\}=\mathrm{GX} 2$ 


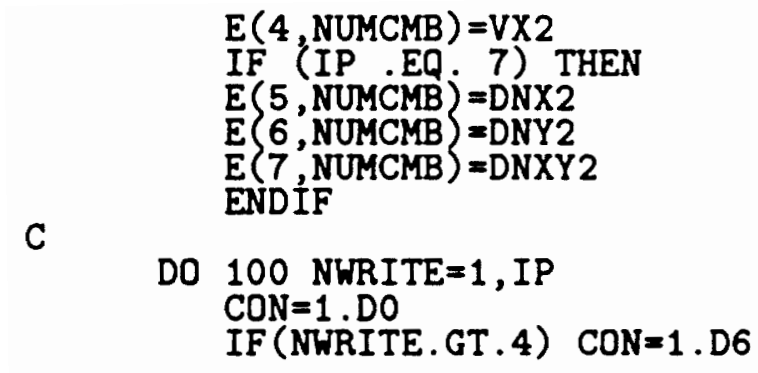

100 CONTINUE

WRITE (NWRITE+7,*) NSET, E(NWRITE, NUMCMB) *CON

$\mathrm{C}$
$\mathrm{C}$

DO $110 \quad I=1$, IP

$\operatorname{DAVE}(I)=\operatorname{DAVE}(I)+D(I)$

$\operatorname{IND}(I, N U M C M B)=\operatorname{INDICE}(I)$

NOSTIF $=0$

$\mathrm{C}^{120}$ CONTINUE

IF (NUMCMB.EQ.O) GO TO 170

DO $140 \quad I=1$, IP

EMEAN $(I)=0$.

DO $130 \mathrm{~J}=1$, NUMCMB

130 CONTINUE

$\operatorname{EMEAN}(I)=\operatorname{EMEAN}(I)+E(I, J)$

140 CONTINUE

$\operatorname{EMEAN}(I)=\operatorname{EMEAN}(I) / N U M C M B$

$$
\text { C }
$$

DO $160 \quad I=1$, IP

ESTDEV $(I)=0$.

IF (NUMCMB.EQ.1) GO TO 160

DO $150 \mathrm{~J}=1$, NUMCMB

150 CONTINUE $\operatorname{ESTDEV}(I)=\operatorname{ESTDEV}(I)+(E(I, J)-\operatorname{EMEAN}(I)) * * 2$

160 CONTINUE

$\operatorname{ESTDEV}(I)=\operatorname{DSQRT}(\operatorname{ESTDEV}(I) /(N U M C M B-1))$

$\operatorname{EAVE}(4)=\mathrm{DAVE}(4) / \mathrm{DAVE}(2)$

VYX =EAVE (4)*DAVE (2)/DAVE (1)

$P=(T * * 3)\rangle(12 . *(1 .-\operatorname{EAVE}(4) * V Y X))$

$\operatorname{EAVE}(1)=\mathrm{DAVE}(1) / \mathrm{P}$

EAVE 2$\}=D A V E(2) / P$

$\operatorname{EAVE}(3)=12 . * D A V E(4) /(T * * 3)$

IF (IP .EQ. 7) THEN

EAVE $(5)=D A V E(5) /(Y * Y)$

EAVE $\{6)=D A V E(6) /(X * X)$

EAVE $(7)=D A V E(7) /(X * Y)$

C

ENDIF

170 CONTINUE

STOP

END 
SUBROUTINE CMBIN7 (NOFRQ, NOCMB , NMB , IP)

IMPLICIT REAL * $8(\mathrm{~A}-\mathrm{H}, \mathrm{O}-\mathrm{Z})$

DIMENSION NMB (IP, 126), COMB (85)

C

SUBROUTINE CMBIN7 READS FROM DATA STATEMENTS ALL POSSIBLE COMBINATIONS OF NOFRQ NUMBER OF FREQUENCIES, TAKEN 7 AT A TIME

DATA COMB/1234567,1234568,1234578,1234678,1235678, 1245678,1345678, $\$ 2345678,1234569,1234579,1234589,1234679,1234689,1234789,1235679$, $\$ 1235689,1235789,1236789,1245679,1245689,1245789,1246789,1256789$, $\$ 1345679,1345689,1345789,1346789,1356789,1456789,2345679,2345689$, $\$ 2345789,2346789,2356789,2456789,3456789,1234560,1234570,1234580$, $\$ 1234590,1234670,1234680,1234690,1234790,1234890,1235670,1235680$, $\$ 1235690,1235790,1235890,1236890,1237890,1245670,1245680,1245690$, $\$ 1245790,1245890,1246890,1247890,1257890,1267890,1345670,1345680$, $\$ 1345690,1345790,1345890,1346890,1347890,1357890,1367890,1467890$, $\$ 1567890,2345670,2345680,2345690,2345790,2345890,2346890,2347890$, $\$ 2357890,2367890,2467890,2567890,3567890,4567890$ /

C

IF (NOFRQ.EQ.7) NOCMB $=1$

IF NOFRQ.EQ.8 NOCMB $=8$

IF NOFRQ. EQ.9) NOCMB $=36$

C

IF (NOFRQ.EQ.10) NOCMB $=85$

DO $10 I=1$, NOCMB

$\operatorname{NMB}(1, I)=\operatorname{INT}(\operatorname{COMB}(I) / 1 . D 6)$

$N M B\{2, I\}=I N T$ COMB I $/ 1 \cdot D 5-10 . * N M B(1, I)$

NMB $\{3, I\}=I N T$ COMB $\{/ 1 . D 4-100 . * \operatorname{NMB}(1, I)-10 . * N M B(2, I))$

$\operatorname{NMB}\{4, I)=I N T(C O M B(I) / 1000,-1000 * * \operatorname{NMB}(1, I)-100 * * N M B(2, I)-$

$\$$

10. *NMB $(3, I))$

$\operatorname{NMB}(5, I)=I N T(\operatorname{COMB}(I) / 100,-1$
$100 . * \operatorname{NMB}(3, I)-10 * * \operatorname{NMB}(4, I))$

$100 * \mathrm{MB}(3, \mathrm{I})-10 \mathrm{M}$

$\operatorname{NMB}(6, I)=I N T(C O M B(I) / 10 .-1 . D 5 * \operatorname{NMB}(1, I)-1 . D 4 * \operatorname{NMB}(2, I)-$

$\$$

1000. *NMB $(3, I)-100$ *NMB $(4, I)-10 . * \operatorname{NMB}(5, I))$

$\operatorname{NMB}(7, I)=I N T(C O M B(I)-1 . D 6 * \operatorname{NMB}(1, I)-1 . D 5 * \operatorname{NMB}(2, I)-$

10

$\$$

1.D4*NMB $(3, I)-1000 . \operatorname{NMB}(4, I)-100 * \operatorname{NMB}(5, I)-10 . * \operatorname{NMB}(6, I))$

CONTINUE

RETURN

END

SUBROUTINE CMBIN4 (NOFRQ, NOCMB, NMB , IP)

IMPLICIT REAL * $8(\mathrm{~A}-\mathrm{H}, \mathrm{O}-\mathrm{Z})$

DIMENSION NMB (IP , 126), COMB (126)

C

SUBROUTINE CMBIN7 READS FROM DATA STATEMENTS ALL POSSIBLE

C COMBINATIONS OF NOFRQ NUMBER OF FREQUENCIES, TAKEN 7 AT A TIME

C

DATA COMB/1234,1235,1245, 1345,2345,1236, 1246,1256,1346, 1356, 1456 , $\$ 2346,2356,2456,3456,1237,1247,1257,1267,1347,1357,1367,1457,1467$, $\$ 1567,2347,2357,2367,2457,2467,2567,3457,3467,3567,4567,1238,1248$, $\$ 1258,1268,1278,1348,1358,1368,1378,1458,1468,1478,1568,1578,1678$, $\$ 2348,2358,2368,2378,2458,2468,2478,2568,2578,2678,3458,3468,3478$, $\$ 3568,3578,3678,4568,4578,4678,5678,1239,1249,1259,1269,1279,1289$, $\$ 1349,1359,1369,1379,1389,1459,1469,1479,1489,1569,1579,1589,1679$, $\$ 1689,1789,2349,2359,2369,2379,2389,2459,2469,2479,2489,2569,2579$, $\$ 2589,2679,2689,2789,3459,3469,3479,3489,3569,3579,3589,3679,3689$, $\$ 3789,4569,4579,4589,4679,4689,4789,5679,5689,5789,6789$ / 
C

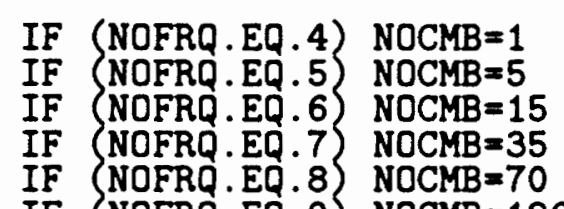

C IF (NOFRQ.EQ.9) NOCMB $=126$

DO $10 I=1$, NOCMB

$$
\begin{aligned}
& \operatorname{NMB}(1, I)=\operatorname{INT}(\operatorname{COMB}(I) / 1000 .)
\end{aligned}
$$

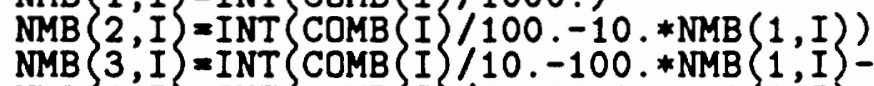

MMB $3, I$ = INT

SUBROUTINE HASTEN (D , DPREV1, DPREV2, DHIGH , DLOW, DSAVE, NOSCILL , NCOUNT, $\$$ IP)

IMPLICIT REAL * $8(A-H, 0-Z)$ $\$$

DIMENSION D (IP), DPREV1 (IP), DPREV2(IP), DHIGH (IP), DLOW (IP), DSAVE(IP), NOSCILL (IP)

C
C
C
C
C
C
C
C
C
C
C
C
C
C
C
C
C
C
C
C
C

SOMETIMES A SET OF FREQUENCIES HILL CAUSE TWO PREVIOUS STIFFNESS ESIMATES $D(I)$ TO BRACKET THE CURRENT ONE, WHICH MEANS THE STOFFNESSES ARE OSCILATING RATHER THAN CONVERGING MONOTONICALLY. THIS SUBROUTINE WILL DETECT AND OSCILLATING SYSTEM, AND TAKE THE AVERAGE OF UPPER AND LOWER BOUNDS FROM PREVIOUS ITERATIONS TO COMPUTE CURRENT ESTIMATE OF STIFFNESSES.

DIF1 = DIFFERENCE BETWEEN PREVIOUS TWO STIFFNESS ESTIMATES

DIF2 = DIFFERENCE BETWEEN CURRENT AND PREVIOUS ESTIMATES

SIGN1 = SIGN OF SLOPE BETWEEN PREVIOUS TWO ESTIMATES

SIGN2 = SIGN OF SLOPE BETWEEN CURRENT AND PREVIOUS ESTIMATES

DPREV1 = ESTIMATE OF STIFFNESSES TWO ITERATIONS AGO

DPREV2 = ESTIMATE OF STIFFNESS FROM PREVIOUS ITERATION

DHIGH $=$ UPPER BOUND ON STIFFNESS D(I)

DLOW = LOWER BOUND ON STIFFNESS D(I)

DSAVE = AVERAGE OF DHIGH AND DLOW FROM PREVIOUS ITERATION

NOSCIL = FLAG IDENTIFYING AN OSCILLATING SYSTEM

DO $10 I=1$, IP

C FIRST TWO ESTIMATES ARE RECORDED AND THE SUBROUTINE EXITED

IF (NCOUNT.EQ.1) THEN

DPREV $1(I)=D(I)$

$\operatorname{NOSCILL}(I)=0$

ENDIF

GO TO 10

IF (NCOUNT . EQ . 2) THEN

ENDIF

DPREV $2(I)=D(I)$

C SYSTEM IS CHECKED FOR SUBSEQUENT OSCILLATIONS 
C

IF (NOSCILL(I).EQ.0) THEN

DIF $1=$ DPREV 2 (I) -DPREV 1 (I)

$D I F 2=D(I)-D P R E V 2(I)$

SIGN1=DABS (DIF 1) DIF1

SIGN2=DABS (DIF2) /DIF2

IF (SIGN1.NE.SIGN2) THEN

C
C

NOSCILL $(I)=1$

IF OSCILLATION DETECTED INITIAL UPPER AND LOWER BOUNDS ARE RECORDED

IF (SIGN 1.EQ. $(-1$.$) ) THEN$

DLOW (I) =DPREV2 (I)

DHIGH $(I)=$ DPREV 1 (I)

ELSE

IF (D(I).LT.DHIGH(I)) $\operatorname{DHIGH}(I)=D(I)$
$\operatorname{DLOW}(I)=\operatorname{DPREV} 1$ (I)
IF (D (I). GT.DLOW(I)) DLOW(I) $=D(I)$
DHIGH $(I)=D P R E V 2(I)$

ENDIF

ELSE

GO TO 5

DPREV 1 (I) $=$ DPREV2 (I)

DPREV $2(I)=D(I)$

GO TO 10

ENDIF

ENDIF

$\mathrm{C}$
$\mathrm{C}$

ELSE

$\begin{array}{ll}\text { C } & \text { ENDIF } \\ \text { C } & \text { A NEW ESTIMATE IS MADE BY AVERA } \\ \text { C } & \begin{array}{l}\text { D(I })=(\operatorname{DHIGH}(I)+\operatorname{DLOW}(I)) / 2 . \\ \text { DSAVE }(I)=D(I)\end{array}\end{array}$

UPPER AND LOWER BOUNDS OF THE TRUE STIFFNESSES ARE RECORDED

IF (D(I).GT.DSAVE(I)) THEN

$\operatorname{DLOW}(I)=\operatorname{DSAVE}(I)$

IF (D (I).LT.DHIGH(I)) $\operatorname{DHIGH}(I)=D(I)$

IF (DSI).GT.DLOH(I)) $\operatorname{DLOW}(I)=D(I)$

$\mathrm{C}_{10 \text { CONTINUE }}$

RETURN

END

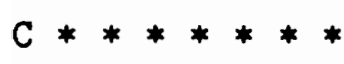

SUBROUTINE SELECT (INDICE, C, MODE, EGN, VEC , NROW , FL , FRE, NOSTIF , IP) IMPLICIT REAL * 8 (A-H,O-Z)

$\$$ DIMENSION INDICE(IP), $\mathrm{C}(64,64)$

C SUBROUTINE SELECT SOLVES THE EIGENVALUE PROBLEMS AND ISOLATES

C THE EIGENVALUES AND EIGENVECTORS CORRESPONDING TO THE SUPPLIED

C MODE NUMBERS FOR CURRENT FREQUENCY COMBINATION

C NOSTIF $=0$

C 
C DEVCSF IS AN IMSL SUBROUTINE FOR SOLVING THE EIGENVALUE PROBLEM CALL DEVCSF (NROH, C, 64, EGN1, V1,64)

C
C
C
C
C
C

IF THE STIFFNESS MATRIX IS ILL-CONDITIONED, THE EIGENVALUE SOLWUION WILL SOMETIMES PRODUCE NEGATIVE EIGENVALUES.

IF THESE ARE DETECTED, THE SUBROUTINE IS EXITED AND THE CURRENT FREQUENCY COMBINATION BYPASSED

\section{NSIGN $=0$}

DO $10 \quad I=1, N R O W$

10
IF $(E G N 1$ (I). LT .0.) $N S I G N=N S I G N+1$

CONTINUE

IF (NSIGN.NE.0) THEN

ENDIF

NOSTIF $=1$ GO TO 50

DO IFRQ $=1$, NROW

DO 40 JFRQ $=1$, IP

IF (INDICE (JFRQ) .EQ.MODE (IFRQ)) THEN DO $30 \mathrm{~J}=1$, NROW

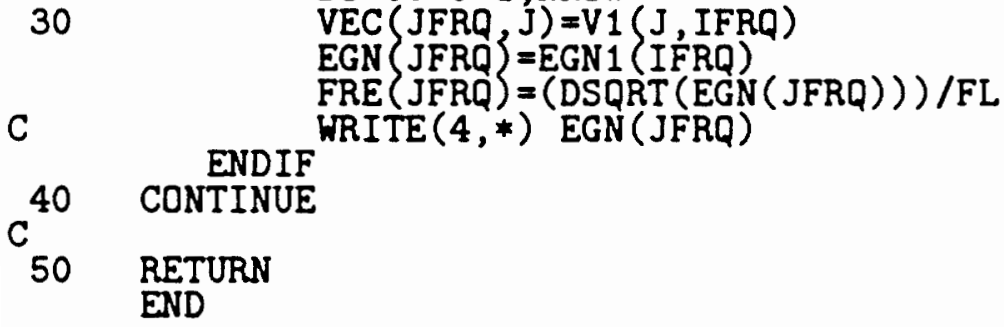

30

SUBROUTINE INTEG (HX , HY , FX , FY , EPSX , EPSY , NSRS , NBC , GX , GY)

IMPLICIT REAL * $8(\stackrel{A}{-H}, \mathrm{O}-\mathrm{Z})$

DIMENSION HCC $(8,8), \operatorname{ECC}(8), \operatorname{HCF}(8,8), \operatorname{FCF}(8,8), \operatorname{ECF}(8), \operatorname{HFF}(8,8)$, $\$ F F F(8,8), E F F(8), H X(8,8), H Y(8,8), F X(8,8), F Y(8,8), \operatorname{EPSX}(8), \operatorname{EPSY}(8)$, $\$ \operatorname{GX}(8,8), \operatorname{GY}(8,8), \operatorname{GCC}(8,8), \operatorname{GCF}(8,8), \operatorname{GFF}(8,8)$

$\mathrm{C}$
$\mathrm{C}$
$\mathrm{C}$
$\mathrm{C}$
$\mathrm{C}$
$\mathrm{C}$
$\mathrm{C}$
$\mathrm{C}$
$\mathrm{C}$
$\mathrm{C}$
$\mathrm{C}$
$\mathrm{C}$
$\mathrm{C}$

THIS SUBROUTINE READS AND ASSIGNS VALUES OF INTEGRALS [ $\left.0^{\prime} * 0^{\prime}\right]$ $[0 * 0,1]$, AND [0*0'], WHERE 0 REPRESENTS CHARACTERISTIC EQUAT IÓNS OF BEAMS HAVING BOUNDARY CONDITIONS $C-C, C-F$, AND $F-F$.

NOTE THAT INTEGRAL $\left[0^{\prime} * 0^{\prime}\right]=-$ INTEGRAL $\left[0 * 0^{\prime} ;\right]$ FOR $C-\dot{C}$ BEAM.

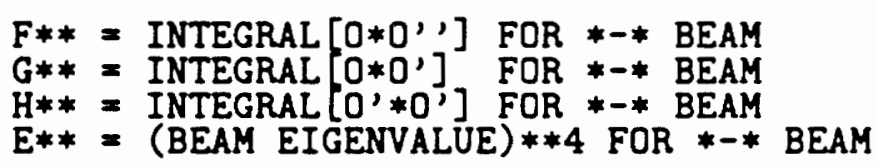

C

B. C. $=$ CLAMP-CLAMP

DATA HCC/

$\begin{array}{rrrrr}1 & 12.302621800, & -0.000235305, & -9.731340410, & 0.678856552, \\ 1 & -7.522723200, & -1.697464940, & -4.581011770, & -1.385425570, \\ 2 & -0.000235305, & 46.050796500, & 0.000607593, & -18.479766800, \\ 2 & -0.198340356, & -11.395145400, & -3.533231740, & -9.851717950, \\ 3 & -9.731340410, & 0.000607593, & 98.902328500, & 1.892457960, \\ 3 & -24.054809600, & -5.964126590, & -17.241073600, & -5.481415750, \\ 4 & 0.678856552, & -18.479766800, & 1.892457960, & 167.829102000, \\ 4 & 2.152745250, & -28.560119600, & -2.548910140, & -28.262176500, \\ 5 & -7.522723200, & -0.198340356, & -24.054809600, & 2.152745250,\end{array}$


$-10.134684600,406.780518000$, $-4.581011770$ -3.533231740 , $-27.574127200$ $-1.385425570$ $-32.597671500$ $-9.851717950$ $-10.546148300,-10.762842200$,
$-32.597671500,-10.762842200$, $-17.241073600,-2.548910140$, $543.384521000,-37.355880700$, $-5.481415750,-28.262176500$, $-37.355880700,699.727295000 /$

C

8

DATA GCC/0.000000000,

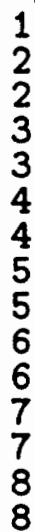

C

C $\$$ $-0.005364357$ 3.341986489, -1.714818668 , -0.000049938 , -0.017283897 , 0.954946048 , -9.503928702 , 0.005364378 , 0.001185575 , 0.347346065 , 11.304002963, 0.064807822 , 0.397319996 , 0.199370754 , 3.710916737,

DATA ECC/500.563819
-3.341986489 , -0.347346496 , 0.000000004 -0.185918599 , 5.516237518, -2.239951754 , -0.095625189 , -0.743846363 , 1.714814451 -11.352697274 , 0.186005197 , 0.499996874 , 0.749916533 13.393541925, 0.122969756 , 0.304656474 ,
0.000049938 , -0.064807391 , -5.516237498 , -0.750003131 , 0.000000025 , -0.244139070 , 7.766445798, -2.606757801 , 0.017272953 , -0.348625251 , 2.240176510, -14.393544580 , 0.243914313 , 0.500005782 , 1. 191130456 15.406765138,
-0.954945912 , -0.199371186 , 0.095597867 , -0.122883158 , -7.766516710 , -1.190905700 , 0.049771810 , -0.663178733 , 9.519292065, -3.759611200 , 0.428342011 , 0.695340400 , 2.922264964 , -16.406770919 , 0.347673394 $0.500000000 \%$

3803.537280 ,

14617.627675

39943.794240 89135.472862, 173881.209049, $508481.754222 j$

B . C . $=$ CLAMP

308208.754615

$50881.754222 \%$

DATA HCF/

$\begin{array}{lr}1 & 4.647777560 \\ 1 & 4.555281640 \\ 2 & -7.379818920 \\ 2 & -22.714614900 \\ 3 & 3.941558840, \\ 3 & 19.970123300 \\ 4 & -6.579140660 \\ 4 & -48.378967300 \\ 5 & 4.555281640, \\ 5 & 227.567612000, \\ 6 & -3.497818950, \\ 6 & -38.209808300 \\ 7 & 2.107947350 \\ 7 & 8.671960830 \\ 8 & -3.313279150 \\ 8 & -40.837844800, \\ & \end{array}$

DATA FCF/
-7.379818920 , -3.497818950 , 32.417083700 ,

5.714778900 , -22.352417000 , -22.998931900 , 13.534735700, 7.286973000, -22.714614900 , -38.209808300 , 5.714778900 289.916260000 , -12.788772600 , -27.819076500 , 6.515783310 , -9.046735760 ,
3.941558840 ,

2.107947350 , -22.352417000 , -12.788772600 , 77.299270600 ,

7.527808190 -35.578308100 , -32.126739500 , 19.970123300, 8.671960830, -22.998931900 , -27.819076500 , 7.527808190 , 406.780518000 , $-22.376907300$ -32.596771200 ,

1.873855590, 0.744799733 ,

0.858243644 , $-11.743103000$ 3.719502450, 27.453353900 , 11.214952500, -37.290023800 , 4.803012850 51.615371700 , $-171.772369000$ -31.059570300 ,
$-13.294366800$

3.846709250, -9.042172430 , 7.301417350 , 30.333969100 , 14.647676500 , -33.455459600 , 10.124386800, 28.842269900,
1.564507480, 0.645055234 , 3.229339600, 3.227341650, $-45.904098500$ 8.169593810, -8.291215900 , 10.192223500, 36.200973500 , 19.413223300, -11.558756800 ,
-6.579140660 , -3.313279150 , 13.534735700, 6.515783310 , -35.578308100 , -22.376907300 , 142.730255000 , 9.180227280 , -48.378967300 , -40.837844800 , 7.286973000, -9.046735760 , -32.126739500 , -32.596771200 , 9. 180227280 543.384277000

1. 087450980 , 0.560268760 , 5.538409230, 3.045678140, 4.265100480, 6.679442410, -98.975265500 , 12.754301100, -7.645484920 , 12.752507200, 27.180481000, 


\begin{tabular}{|c|c|c|c|c|}
\hline $\begin{array}{l}6 \\
7 \\
7 \\
8 \\
8\end{array}$ & $\begin{array}{r}3.883368490,-2 \\
38.732864400,- \\
31.895813000, \\
-43.810592700, \\
-5.971074100,\end{array}$ & $\begin{array}{l}72.637451000, \\
28.051605200, \\
7.398610120,-3 \\
40.607589700, \\
32.608886700\end{array}$ & $\begin{array}{ll}0, & 2 \\
0, & 2 \\
0, & 1 \\
0 ; & 3 \\
0,-5 & 3\end{array}$ & $\begin{array}{l}0, \\
0, \\
0 \\
0 \\
0\end{array}$ \\
\hline $\begin{array}{l}{ }^{\text {DATA }} \\
1 \\
2 \\
2 \\
3 \\
3 \\
4 \\
4 \\
5 \\
5 \\
6 \\
6 \\
7 \\
7 \\
8\end{array}$ & $\begin{array}{r}\text { CF/1.999999653, } \\
3.906707492, \\
0.759472436, \\
-4.477691755, \\
0.215668168, \\
3.043345717, \\
0.121106086, \\
-10.106878411, \\
0.066557526, \\
1.973354706, \\
0.206741697, \\
9.439883716, \\
-0.101239325, \\
0.096832797, \\
0.142260439, \\
3.328522227,\end{array}$ & $\begin{array}{r}-4.759429810, \\
-2.206747906, \\
1.999957721, \\
2.270503129, \\
2.222172568, \\
-3.901730611, \\
0.612297276, \\
1.971117439, \\
0.504468388, \\
-11.426522738, \\
-0.270517886, \\
0.500003191, \\
0.687104503, \\
11.376173941, \\
-0.250587423, \\
0.276346504,\end{array}$ & 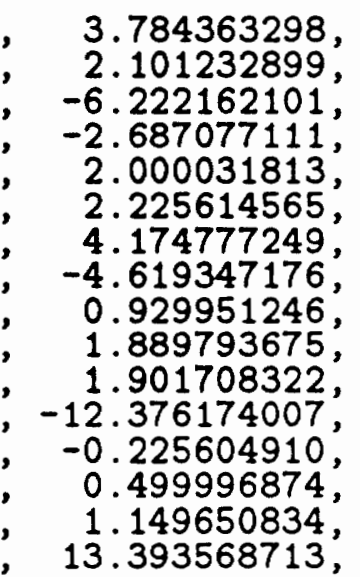 & $\begin{array}{r}-4 . \\
-2 . \\
3 . \\
2 . \\
-8 . \\
-3 . \\
-3 . \\
1 . \\
2 . \\
6 . \\
-5 . \\
0 . \\
0 . \\
2 . \\
-14 .\end{array}$ \\
\hline
\end{tabular}

DATA ECF/12.362360,485.518699,3806.546016,14617.272688,

C

$\$ 39943.826575,89135.472862,173881.209049,308208.579967 /$

C

$\begin{array}{lr}\text { DATA HFF/ } \\ 1 & 0.000000000 \\ 1 & 0.000000000 \\ 2 & 0.000000000 \\ 2 & -0.000775326 \\ 3 & 0.000000000 \\ 3 & 35.379486100 \\ 4 & 0.00000000 \\ 4 & -0.001849043 \\ 5 & 0.000000000 \\ 5 & 186.874100000 \\ 6 & 0.000000000\end{array}$

6
7
7
8
8

C
-5.798403740 , 0.000000000 , 77.154861500 , 0.000000000 , 20.257400500,

B. C . =FREE-FREE

0.000000000

0.000000000 12.000001000

14.949345600,

0.000002768 ,

-2.856481550 ,

13.856106800,

62.129821800,

-0.000775326 ,

-5.798403740 ,

14.949345600,

298.768066000,

0.168660641 ,

-6.063485150 ,

10.392305400,

78.682891800,
0.000000000 , 0.000000000 , 0.000002768 , 0.168660641 , 49.480819700, 36.161911000 , 0.000723010 , 0.725679994 , 35.379486100 , 77.154861500 , -2.856481550 ,

-6.063485150 , 36.161911000 , 399.724609000,

9.203477860, 28.854400600,
0.000000000 , 0.000000000 , 13.856106800, 10.392305400, 0.000723010 , 9.203477860, 108.922546000, 45.469558700 , -0.001849043 , 20.257400500, 62.129821800,

78.682891800 , 0.725679994 , 28.854400600, 45.469558700 , $488.462158000 \%$

$\begin{array}{lr}\text { DATA FFF/0.000000000, } \\ 1 & 0.000000000, \\ 2 & 0.000000000 \\ 2 & 0.000000000 \\ 3 & 18.589099330 \\ 3 & 1.800793100 \\ 4 & 0.000679540 \\ 4 & -0.000309820, \\ 5 & 43.983424980, \\ 5 & -98.902324070 \\ 6 & -4.460344590, \\ 6 & -3.129612640 \\ 7 & 68.273667020 \\ 7 & 59.400005830,\end{array}$

0.000000000 ,

0.000000000 ,

0.000000000 ,

0.000000000 ,

0.000000830 ,

-0.075994450 ,

40.593583140,

5.702385000,

-0.003505290 ,

-1.145433830 ,

90.721488370,

$-166.421830350$

1. 288651840

$-2.891380940$
0.000000000 , 0.000000000 , 0.000000000 , 0.000000000 , -12.302620380 , 0.563740680 , 0.000648630 , 0.040956240 , 52.587346550 , 9.741179820 , -6.064181250, -1.263411750 , 100.385383380 , -264.818928150 ,
0.00000000 , 0.00000000 , 0.00000000 , 0.00000000 , 0.00008536 , 0.09107627 , -46.05079406 , 1.68559197, -0.00119083 , 1.73061494, 59.88557406, 10.60052041, 0.95999765 , 6.54467761, 


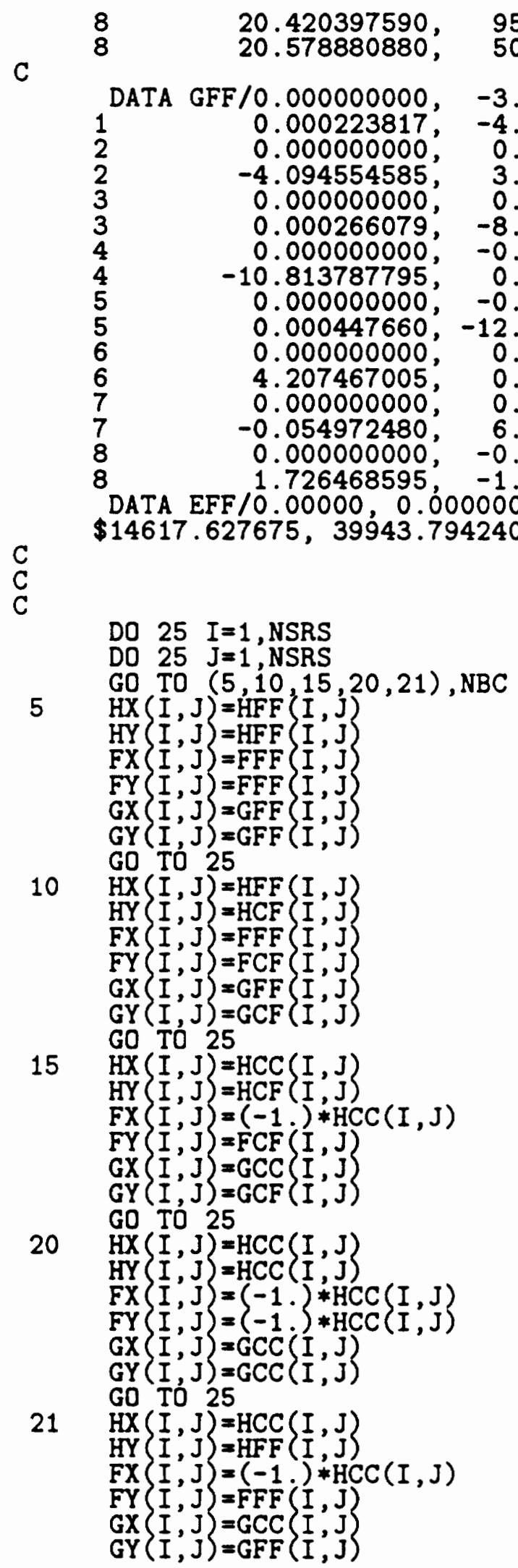

$\mathrm{C}$
$\mathrm{C}$

DO $25 I=1$, NSRS

DO $25 \mathrm{~J}=1$, NSRS

GO TO $(5,10,15,20,21), N B C$

$\mathrm{HX}(I, J)=\operatorname{HFF}(I, J)$

$\mathrm{HY}\{I, J\}=\mathrm{HCF}\} I, J\}$

FX $\{I, J\}=F F F\{I, J\}$

$F Y\{I, J\}=F C F\{I, J\}$

$G X\{I, J\}=G F F\} I, J\}$

GY $(I, J)=G C F(I, J)$$$
\text { GO TO } 25
$$

$\operatorname{HX}(I, J)=\operatorname{HCC}(I, J)$

$\mathrm{HY}\{I, J\}=\mathrm{HCF}(I, J)$

$F X\{I, J\}=(-1). * \operatorname{HCC}(I, J)$

$F Y\{I, J\}=F C F(I, J)$

$G X\{I, J\}=G C C\{I, J\}$

GY $(I, J)=G C F(I, J)$

GO TÓ 25

$20 \quad \operatorname{HX}(I, J)=\operatorname{HCC}(I, J)$

HY $\{I, J\}=H C C(I, J)$

FX $\{I, J\}=(-1). * \operatorname{HCC}(I, J)$

$F Y\} I, J\}=(-1,\{\operatorname{HCC}(I, J)$

$\operatorname{GX}\{(I, J\}=\operatorname{GCC}(I, J)$

21

$$
\text { GO TO } 25
$$

$\mathrm{HX}(I, J)=\operatorname{HCC}(I, J)$

HY $\{I, J\}=$ HFF $(I, J)$

$F X(I, J)=(-1), * \operatorname{HCC}(I, J)$

$F Y\{I, J\}=F F F(I, J)$

$G X\{I, J\}=G C C\{I, J\}$

$G Y(I, J)=G F F(I, J)$

DATA EFF $/ 0.00000,0.000000,500.563819,3803.537280$ $9.779363525,-1.500000001 \%$

$\$ 14617.627675,39943.794240$, 89135.472862, 173881.387703/ 


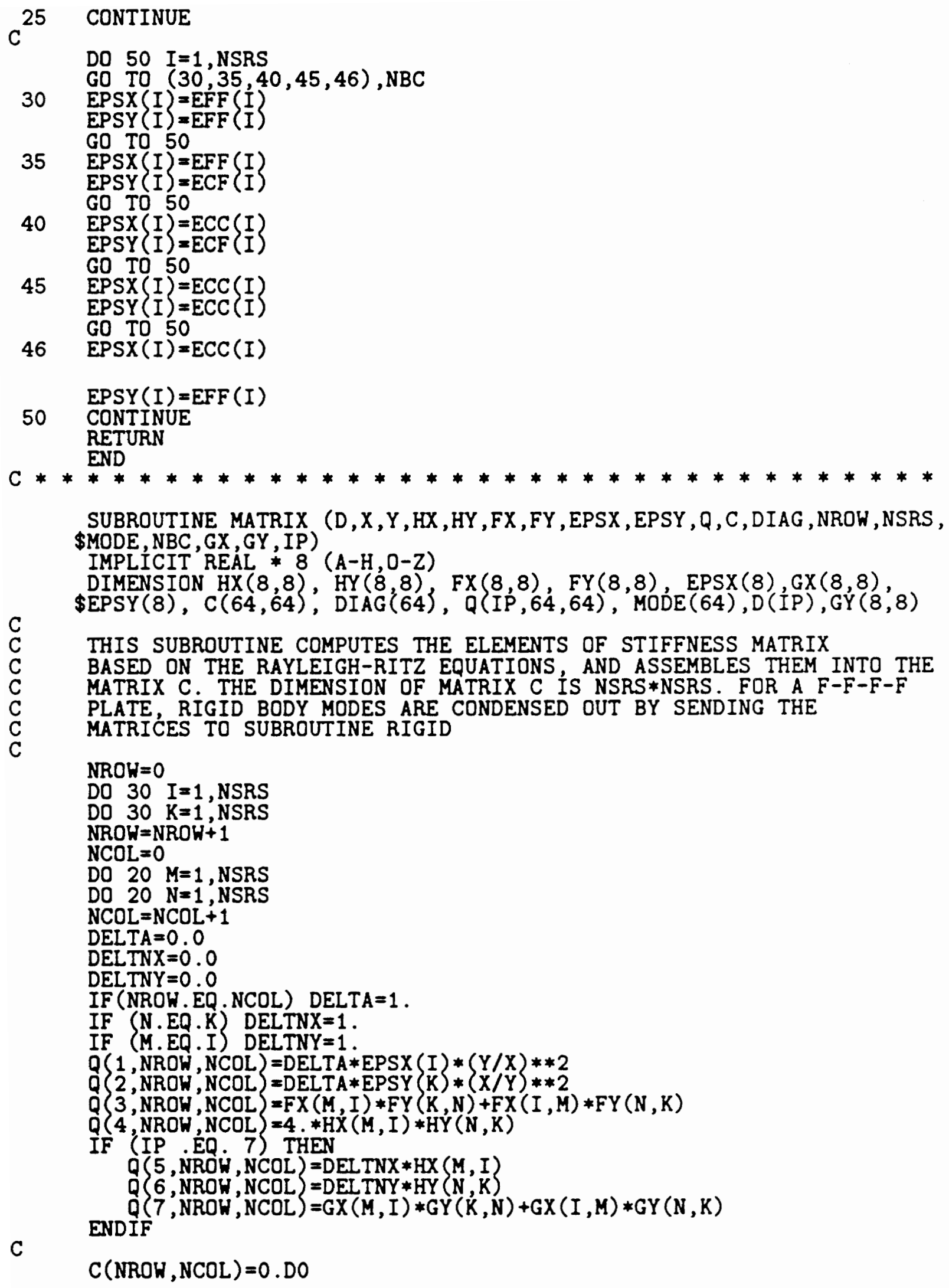

SUBROUTINE MATRIX (D , X , Y, HX , HY , FX , FY , EPSX , EPSY , Q , C , DIAG , NROW , NSRS , \$MODE, NBC , GX, GY , IP)

IMPLICIT REAL * $8(\mathrm{~A}-\mathrm{H}, \mathrm{O}-\mathrm{Z})$

DIMENSION HX $(8,8), \quad H Y(8,8), F X(8,8), F Y(8,8), \operatorname{EPSX}(8), \operatorname{GX}(8,8)$, $\$ \operatorname{EPSY}(8), C(64,64), \operatorname{DIAG}(64), \mathrm{Q}(\mathrm{IP}, 64,64), \operatorname{MODE}(64), D(\operatorname{IP}), G Y(8,8)$

$C$
$C$
$C$
$C$
$C$
$C$
$C$

THIS SUBROUTINE COMPUTES THE ELEMENTS OF STIFFNESS MATRIX

BASED ON THE RAYLEIGH-RITZ EQUATIONS, AND ASSEMBLES THEM INTO THE MATRIX C. THE DIMENSION OF MATRIX $C$ IS NSRS $*$ NSRS. FOR A $F-F-F-F$ PLATE, RIGID BODY MODES ARE CONDENSED OUT BY SENDING THE MATRICES TO SUBROUTINE RIGID

NROW $=0$

DO $30 \quad I=1$, NSRS

DO $30 \mathrm{~K}=1$, NSRS

$\mathrm{NROH}=\mathrm{NROH}+1$

$\mathrm{NCOL}=0$

DO $20 M=1$, NSRS

DO $20 \mathrm{~N}=1$, NSRS

$\mathrm{NCOL}=\mathrm{NCOL}+1$

DELTA $=0.0$

DELTNX $=0.0$

DELTNY $=0.0$

IF (NROW.EQ.NCOL) DELTA $=1$.

IF (N.EQ.X) DELTNX=1.

IF (M.EQ.I) DELTNY $=1$.

$Q(1$, NROW , NCOL $)=D E L T A * E P S X(I) *(Y / X) * * 2$

Q $\{2, \mathrm{NROH}, \mathrm{NCOL}=\mathrm{DELTA} *$ EPSY $\} \mathrm{K}\} *(\mathrm{X} / \mathrm{Y}) * * 2$

Q $\{3, N R O W, N C O L\{=F X(M, I) * F Y(K, N)+F X(I, M) * F Y(N, K)$

$\mathrm{Q}(4, \mathrm{NROW}, \mathrm{NCOL})=4 . * \mathrm{HX}(\mathrm{M}, I) * \mathrm{HY}(\mathrm{N}, \mathrm{K})$

IF (IP .EQ. 7 ) THEN

$Q(5, \mathrm{NROH}, \mathrm{NCOL})=\mathrm{DELTNX} * \mathrm{HX}(\mathrm{M}, \mathrm{I})$

Q $\{6, \mathrm{NROW}, \mathrm{NCOL}\}=\mathrm{DEL} T N Y * \mathrm{HY}(\mathrm{N}, \mathrm{K})$ ENDIF

Q $7, N$ NROH, NCOL $)=G X(M, I) * G Y(X, N)+G X(I, M) * G Y(N, K)$

C

$\mathrm{C}(\mathrm{NROH}, \mathrm{NCOL})=0 . \mathrm{DO}$ 
DO 10 IJ $=1$, IP

10 CONTINUE

$C(N R O H, N C O L)=C(N R O W, N C O L)+1 . D 9 * D(I J) * Q(I J, N R O W, N C O L)$

c

IF (NROW.EQ.NCOL) DIAG (NROH) $=\mathrm{C}($ NROH , NCOL)

20 CONTINUE

C

CONTINUE

IF (NBC.EQ.1) CALL RIGID (C,DIAG,Q,MODE,NROW,IP)

RETURN

END

C

SUBROUTINE RIGID (C,DIAG, Q,MODE, NROH, IP)

IMPLICIT REAL * $8(A-H, O-Z)$

DIMENSION $C(64,64), \operatorname{DIAG}(64), Q(I P, 64,64), \operatorname{MODE}(64)$

$\mathrm{C}$
$\mathrm{C}$
$\mathrm{C}$
$\mathrm{C}$
$\mathrm{C}$

THIS SUBROUTINE CONDENSES OUT THE RIGID BODY MODES FROM THE

STIFFNESS AND INTEGRAL MATRICES. RIGID BODY MODES ARE DETECTED BY ZEROS ON THE DIAGONAL

$I 1=0$

DO $30 I=1$, NROW

$\mathrm{J} 1=0$

DO $20 \mathrm{~J}=1$, NROW

$C(I-I 1, J-J 1)=C(I, J)$

DO $10 \mathrm{~K}=1$, IP

10

$Q(K, I-I 1, J-J 1)=Q(K, I, J)$

20

CONTINUE $(\mathrm{JIAG}(\mathrm{J}) . E Q .0.) \mathrm{J} 1=\mathrm{J} 1+1$

$c^{30}$

CONTINUE

$$
\text { IF (DIAG(I).EQ.0.) I } 1=I 1+1
$$

CONTINUE

$I 1=0$

DO $40 \quad I=1$, NROH

$\operatorname{DIAG}(I-I 1)=\operatorname{DIAG}(I)$

MODE $(I-I 1)=$ MODE $(I)$

40 CONTINUE

IF (DIAG (I) . EQ.0.) I1 $=I 1+1$

NROW=NROW $-I 1$

RETURN

END

SUBROUTINE MODEID(VEC , D , Q, EGNVAL, EGN ,NROW , T , EX2 , EY2,VX2, GX2,

$\$$ NOSTIF, LSTORE, LCDUNT, NCOUNT, DNX2 , DNY 2 , DNXY $2, X, Y, I P\}$

IMPLICIT REAL * $8(\mathrm{~A}-\mathrm{H}, \mathrm{O}-\mathrm{Z})$

DIMENSION VEC (IP, 64), D'(IP), Q(IP, 64,64), EGNVAL (IP), EGN (IP)

$\operatorname{HINV}(7 ; 7), H(7,7)$, DDELTA $(7)$, HHOLD $(7), F A C(7,7), \operatorname{IPVT}(7)$,

$\$$

LCOUNT (IP), LSTORE (IP , 64), HSAVE $(50,7,7)$, DHÓLD $(99,7)$

C THIS SUBROUTINE USES 'IP' EIGENVECTORS FROM SUBROUTINE SELECT

C TO FACTOR OUT THE 1IP' STIFFNESSES FROM 'IP' ROWS IN THE

C STIFFNESS MATRIX. FOR EACH EIGENVECTOR, THE ROWS IN THE STIFFNESS

C MATRIX ARE IDENTIFIED CORRESPONDING TO THE VECTOR LOCATION HAVING

C AN ABSOLUTE VALUE GREATER THAN 'VECMIN'. THE ROWS ARE TAKEN IN ALL 
C POSSIBLE COMBINATION TO FORM AN 'IP' BY 'IP' SOLUTION MATRIX, H.

C THE AVERAGE OF SOLUTIONS IS CALCULATED FOR LOW CONDITION NUMBERS.
C THESE ARE THEN USED TO UPDATE THE EXISTING STIFFNESSES. IF NO GOOD

C SOLUTON IS FOUND, A FLAG IS SET AND THE SUBROUTINE EXITED.

$\mathrm{H}$ = 'IP' BY 'IP' SOLUTION MATRIX USED TO CALCULATE DDELTA

HINV $=$ INVERSE OF $\mathrm{H}$

VECMIN $=$ CRITERIA USED TO IDENTIFY ROWS IN STIFFNESS MATRIX

LCOUNT $=$ COUNTS THE NUMVER OF ACCEPTABLE ROWS BASED ON VECMIN

LSTORE = ACCEPTABLE ROW LOCATIONS BASED ON VECMIN

HSAVE $=$ ARRAY STORING THE VALUES OF ' $\mathrm{H}$ '

DHOLD = VECTOR WHICH STORES DDELTA

DDELTA = ESTIMATED CHANGE IN STIFFNESSES

$\operatorname{CALL}$ ERSET $(0,0,0)$

MCOUNT $=0$

VECMIN $=0.95$

$\mathrm{C}$
$\mathrm{C}$

IDENTIFY AND STORE SUITABLE VECTOR VALUES

DO 20 I $=1$, IP

LCOUNT $(I)=0$

DO $10 \mathrm{~J}=1$, NROW

IF (DABBS(VEC $(I, J))$. GE. VECMIN) THEN

ENDIF

LCOUNT I I $=$ LCOUNT (I) +1

10 CONTINUE

20 CONTINUE

C COMPUTE AND SAVE ROWS IN POSSIBLE HSAVE MATRICES

DO $30 \quad I=1$, IP

DO $30 L=1, L$ COUNT (I)

DO $30 \mathrm{~K}=1$, IP

HSAVE $(L, I, K)=0$.

DO $30 \mathrm{~J}=1$, NROW

$\$$

$\operatorname{HSAVE}(L, I, K)=\operatorname{HSAVE}(L, I, K)+\operatorname{VEC}(I, J) *$

C

30 CONTINUE

C

MATRIX COMBINATIONS ARE INVERTED AND CONDITION CHECKED

C

DO $80 \quad L 1=1$, LCOUNT ( 1$)$

DO 80 L2 $=1, \mathrm{LCOUNT}\} 2\}$

DO 80 L $3=1$, LCDUNT 3

DO 80 L4 $=1$, LCOUNT ( 4 )

IF (IP .EQ. 4) GO TO 40

DO 80 L5 $=1$, LCOUNT (5)

DO 80 L $6=1$, LCOUNT 6 )

C

DO 80 L $7=1$, LCOUNT $(7)$

DO $50 \quad I=1, I P$

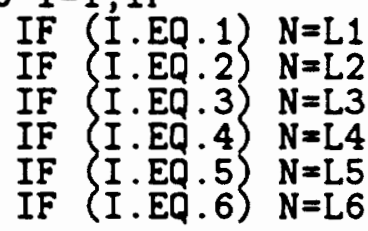


ONE SOLUTION MATRIX IS ASSIGNED

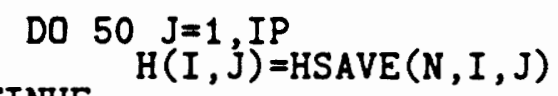

$\mathrm{C}$
$\mathrm{C}$
$\mathrm{C}$

CONTINUE

SOLUTION MATRIX IS CHECKED FOR CONDITIONING. ILL-CONDITIONED MATRICES ARE BY-PASSED

CALL DLFCRG (IP , H, 7, FAC , 7 , IPVT , RCOND) NOSTIF $=0$

C

IF (RCOND.LE.1.D-8) THEN NOSTIF $=1$ C $\operatorname{GOTTE}(* ; *)$ 'RCOND FAILS' ENDIF

C SOLUTION MATRIX IS INVERTED USING IMSL SUBROUTINE DLINRG CALL DLINRG (IP, $\mathrm{H}, 7, \mathrm{HINV}, 7$ )

C

$\stackrel{C}{\mathrm{C}}$

MCOUNT $=$ MCOUNT +1

CHANGES IN STIFFNESSES ARE CALCULATED AND STORED IN DHOLD DO $70 I=1$, IP DHOLD (MCOUNT, $I)=0$. DO $60 \mathrm{~J}=1$, IP

C

IF NO SUCCESSFUL SOLUTIONS HAVE BEEN FOUND, THE SUBROUTINE IS EXITED

IF (MCOUNT .EQ. O) THEN

ENDIF NOSTIF $=1$

$$
\text { RETURN }
$$

C ALL THE SUCCESSFUL RESULTS ARE ADDED FOR AVERAGING

DO $90 \quad I=1$, IP

$\operatorname{DDELTA}(I)=0 . D O$

DO $90 \mathrm{~J}=1$, MCOUNT

90 CONTINUE

$\operatorname{DDELTA}(I)=\operatorname{DDELTA}(I)+\operatorname{DHOLD}(J, I)$

C

RESULTS ARE AVERAGED AND USED TO UPDATE THE CURRENT VALUES

DO $100 \quad I=1, I P$

$D(I)=D(I)+(D D E L T A(I) / M C O U N T) * 1 . D-9$

C $\operatorname{WRITE}(4, *)$ D (I),DDELTA (I),DCOUNT

100 CONTINUE 


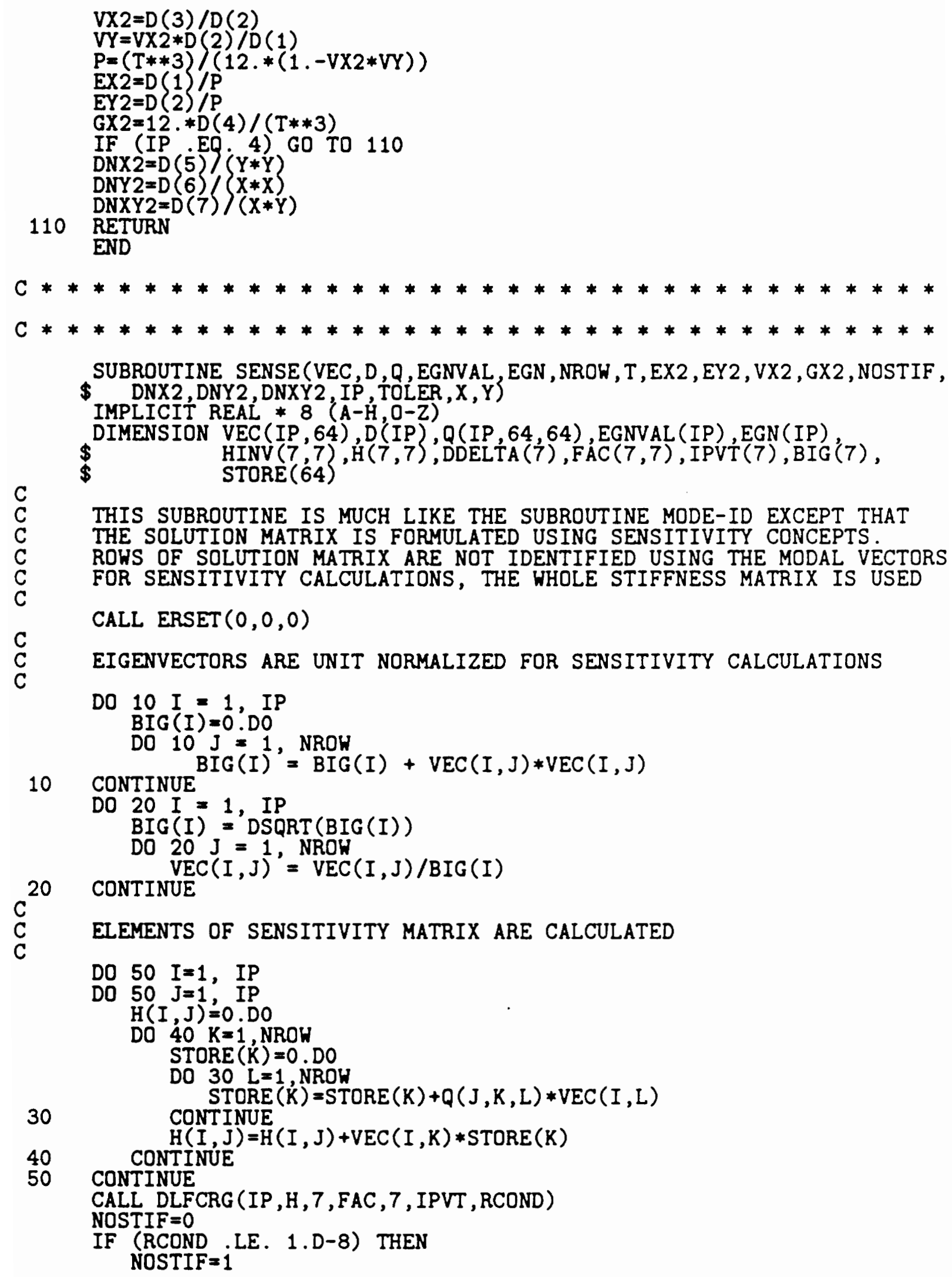

C THIS SUBROUTINE IS MUCH LIKE THE SUBROUTINE MODE-ID EXCEPT THAT

C THE SOLUTION MATRIX IS FORMULATED USING SENSITIVITY CONCEPTS.

C ROWS OF SOLUTION MATRIX ARE NOT IDENTIFIED USING THE MODAL VECTORS

C FOR SENSITIVITY CALCULATIDNS, THE WHOLE STIFFNESS MATRIX IS USED

C

CALL ERSET $(0,0,0)$

$\mathrm{C}$
$\mathrm{C}$

EIGENVECTORS ARE UNIT NORMALIZED FOR SENSITIVITY CALCULATIONS

DO $10 I=1$, IP

$B I G(I)=0 . D O$

DO $10 \mathrm{~J}=1$, NROH

CONTINUE $\operatorname{BIG}(I)^{\prime}=\operatorname{BIG}(I)+\operatorname{VEC}(I, J) * \operatorname{VEC}(I, J)$

DO $20 I=1$, IP

$\operatorname{BIG}(I)=\operatorname{DSQRT}(B I G(I))$

20 CONTINUE

DO $20 \mathrm{~J}=1$, NROW

$\mathrm{C}$
$\mathrm{C}$

ELEMENTS OF SENSITIVITY MATRIX ARE CALCULATED

DO $50 I=1$, IP

DO $50 \mathrm{~J}=1$, IP

$\mathrm{H}(\mathrm{I}, \mathrm{J})=0 . \mathrm{DO}$

DO $40 \mathrm{~K}=1$, NROW

$\operatorname{STORE}(K)=0 . D O$

DO $30 \mathrm{~L}=1$, NROW

30 CONTINUE

50 CONTINUE

CALL DLFCRG (IP , H , 7 , FAC , 7 , IPVT , RCOND)

NOSTIF $=0$

IF (RCOND .LE. 1.D-8) THEN NOSTIF $=1$ 
C WRITE $(*, *)$ 'RCOND FAILS'
GO TO $90^{\circ}$
ENDIF DLINRG (IP $, \mathrm{H}, 7, \mathrm{HINV}, 7)$
CALL DLING

$\stackrel{\mathrm{C}}{\mathrm{C}}$

$$
\text { DO } \begin{aligned}
& 60 I=1, I P \\
& \text { DDELTA } \left.\}^{\prime I}\right)=0 . D O \\
& \text { DO } 60 \quad J=1, I P
\end{aligned}
$$

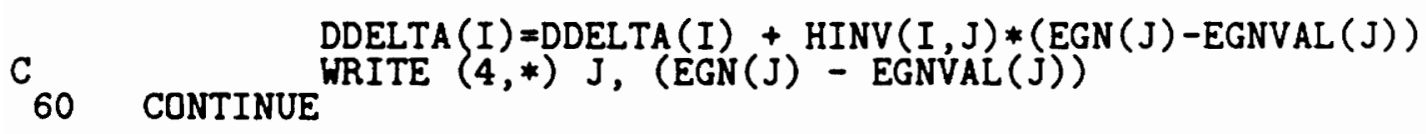

C

TOLER $=0$. DO

DO $70 I=1$, IP

70 CONTINUE

C

DO $80 I=1$, IP

80 CONTINUE $\quad$ (I) $=\mathrm{D}(\mathrm{I})-(\operatorname{DDELTA}(I)) * 1 . D-9$

$V \times 2=D(3) / D(2)$

$V Y=V X 2 * D(2) / D(1)$

$\mathrm{P}=(\mathrm{T} * * 3)>(12 . *(1 .-\mathrm{VX} 2 * V Y))$

$E X 2=D(1) / P$

$E Y 2=D(2) / P$

$G \times 2=12 . * D(4) /(T * * 3)$

IF (IP EQ 4) GO TO 90

$D N X 2=D(5))(Y * Y)$

$D N Y 2=D(6)<X * X)$

90

$D N X Y 2=D(7)>(X * Y)$

RETURN

END 


\section{Appendix C \\ Listing of Computer Program OPT}

Most of the structure of the computer program OPT is similar to SYSID. Most of the variables used are also same as those used in SYSID. The chief difference is that an IMSL subroutine DUMINF has been used for unconstarined optimization computations. The usage is described in the IMSL Math-Library manual (IMSL, 1987). Hence the usage of the subroutine and explanation of various variables and subroutines used by DUMINF willnot be repeated here. Most of the comments in the program SYSID apply to the program OPT. Additional comments are given in the program. 


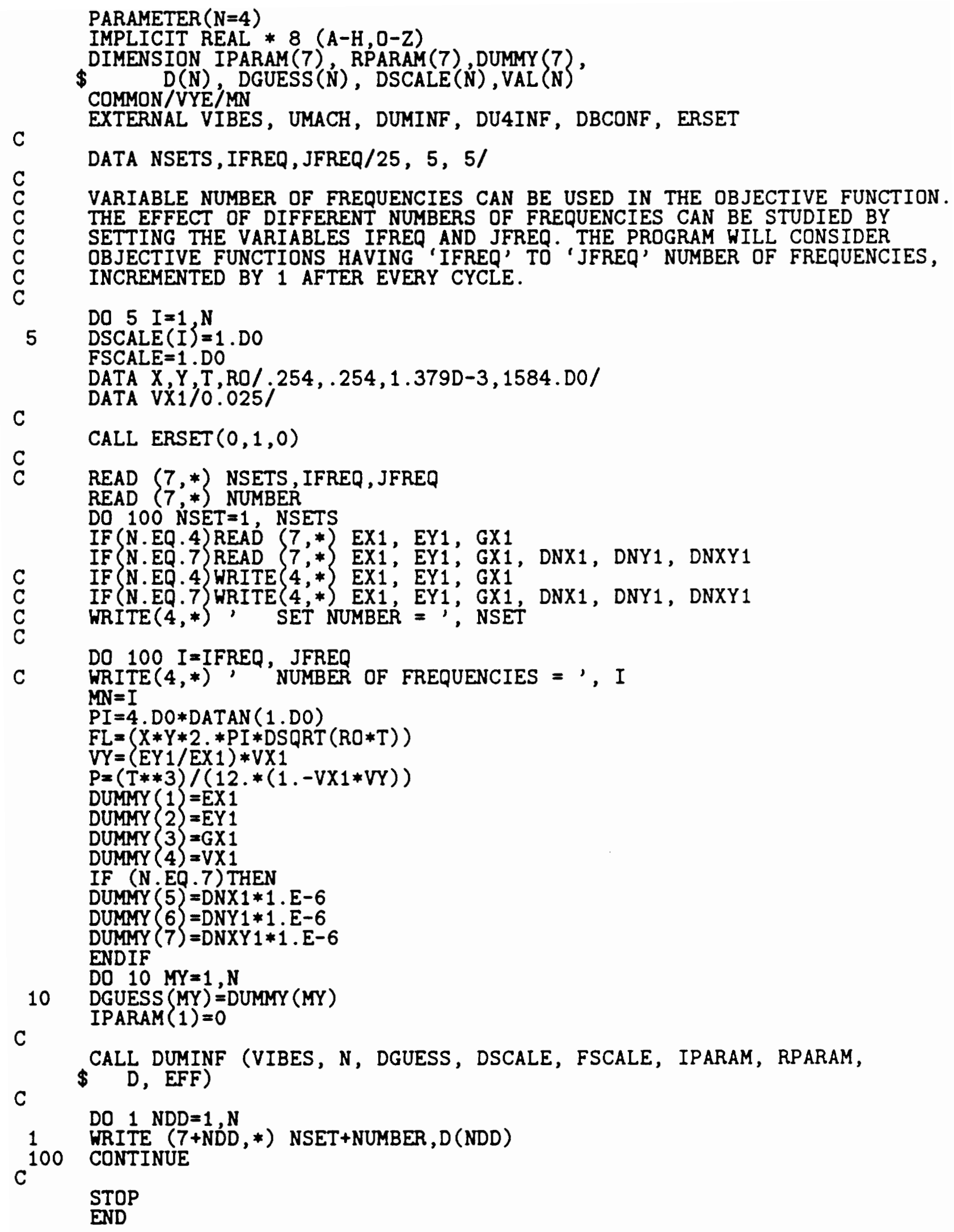

VARIABLE NUMBER OF FREQUENCIES CAN BE USED IN THE OBJECTIVE FUNCTION. THE EFFECT OF DIFFERENT NUMBERS OF FREQUENCIES CAN BE STUDIED BY SETTING THE VARIABLES IFREQ AND JFREQ. THE PROGRAM WILL CONSIDER OBJECTIVE FUNCTIONS HAVING 'IFREQ' TO 'JFREQ' NUMBER OF FREQUENCIES, INCREMENTED BY 1 AFTER EVERY CYCLE. 
SUBROUTINE VIBES (N,D,EFF)

IMPLICIT REAL *8 $(\hat{A}-\mathrm{H}, \mathrm{O}-\mathrm{Z})$

DIMENSION FREQ (64), VEC $(64,64), D(N)$

$\$ \operatorname{EGN}(64), \mathrm{HX}(8,8), H Y(8,8), G X(8,8), G Y^{\prime}(8,8), \operatorname{FREQ7}(64), \operatorname{FREQ} 4(64)$,

$\$ F X(8,8), F Y(8,8), \operatorname{EPSX}(8), \operatorname{EPSY}(8), C(64,64), E(7), Q(7,64,64)$

C

C

C

C

$c^{10}$

C

C COMMON/VYE/MN

DATA NSRS, NBC , NP $/ 8,5,4 /$

DATA $X, Y, T, R O / .254, .254,1.379 D-3,1584 . D O /$

THE FOLLOWING FREQUENCY VALUES ARE FOR A C-F-C-F PLATE ONLY

\section{DATA FREQ4/}

$1.1099079571 D+04, .1980421350 D+04, .8351414340 D+04, .1164560284 D+05$,

$2.1578417753 \mathrm{D}+05,3210675049 \mathrm{D}+05, .3337887230 \mathrm{D}+05, .3913126560 \mathrm{D}+05$,

$3.7335524761 \mathrm{D}+05, .8775980719 \mathrm{D}+05, .9287903350 \mathrm{D}+05, .9956983731 \mathrm{D}+05$,

$4.1235408951 \mathrm{D}+06, .1496256947 \mathrm{D}+06, .1848697590 \mathrm{D}+06, .1958703314 \mathrm{D}+06$,

$5.2143814370 \mathrm{D}+06, .2860916352 \mathrm{D}+06, .2886866976 \mathrm{D}+06, .3365443153 \mathrm{D}+06$,

$6.3821221005 \mathrm{D}+06, .3846045920 \mathrm{D}+06, .4103530313 \mathrm{D}+06, .4629610838 \mathrm{D}+06$,

$7.4753172493 \mathrm{D}+06, .5129995298 \mathrm{D}+06, .6180826502 \mathrm{D}+06, .6774120332 \mathrm{D}+06$,

$8.7149899453 \mathrm{D}+06, .7433260464 \mathrm{D}+06, .8456483228 \mathrm{D}+06, .8485764408 \mathrm{D}+06$,

$9.9016691302 \mathrm{D}+06, .9741497584 \mathrm{D}+06, .1105957662 \mathrm{D}+07, .1117694752 \mathrm{D}+07$,

$1.1129493617 \mathrm{D}+07, .1165971316 \mathrm{D}+07, .1205482577 \mathrm{D}+07, .1304026545 \mathrm{D}+07$,

$2.1331904911 \mathrm{D}+07, .1610791125 \mathrm{D}+07, .1668636716 \mathrm{D}+07, .1672113304 \mathrm{D}+07$,

$3.1991217186 D+07, .2081835592 D+07, .2086837309 D+07, .2258029743 D+07$,

$4.2298828844 D+07, .2508167428 D+07, .2658480057 D+07, .2888715291 D+07$,

$5 \quad .3418575145 \mathrm{D}+07, .3466903905 \mathrm{D}+07, .3862057272 \mathrm{D}+07, .3979153346 \mathrm{D}+07$,

$6.4153661813 \mathrm{D}+07, .4186470423 \mathrm{D}+07, .4484193175 \mathrm{D}+07, .4931604323 \mathrm{D}+07$,

$7.5042107144 \mathrm{D}+07, .5605221490 \mathrm{D}+07, .6389105515 \mathrm{D}+07, .7389716001 \mathrm{D}+07 \%$ DATA FREQ7/

$10.699477035 \mathrm{D}+04,0.127985233 \mathrm{D}+05,0.344719213 \mathrm{D}+05,0.360854272 \mathrm{D}+05$, $20.562517939 \mathrm{D}+05,0.713026106 \mathrm{D}+05,0.915558251 \mathrm{D}+05,0.111053959 \mathrm{D}+06$,

$30.134491740 \mathrm{D}+06,0.168483681 \mathrm{D}+06,0.190707732 \mathrm{D}+06,0.209403681 \mathrm{D}+06$,

$40.231406000 \mathrm{D}+06,0.241753677 \mathrm{D}+06,0.332897265 \mathrm{D}+06,0.355115906 \mathrm{D}+06$, $50.389868628 \mathrm{D}+06,0.407024334 \mathrm{D}+06,0.464253778 \mathrm{D}+06,0.513276828 \mathrm{D}+06$,

$60.534687546 \mathrm{D}+06,0.608117063 \mathrm{D}+06,0.655245766 \mathrm{D}+06,0.665097383 \mathrm{D}+06$,

$70.688261233 \mathrm{D}+06,0.798240982 \mathrm{D}+06,0.881059736 \mathrm{D}+06,0.946612569 \mathrm{D}+06$,

$80.103187809 \mathrm{D}+07,0.107458566 \mathrm{D}+07,0.110385227 \mathrm{D}+07,0.114685577 \mathrm{D}+07$,

$90.120274552 \mathrm{D}+07,0.127238715 \mathrm{D}+07,0.135577761 \mathrm{D}+07,0.140275652 \mathrm{D}+07$,

$10.156699858 \mathrm{D}+07,0.161696206 \mathrm{D}+07,0.162672672 \mathrm{D}+07,0.165448212 \mathrm{D}+07$,

$20.184873480 \mathrm{D}+07,0.198171223 \mathrm{D}+07,0.200367827 \mathrm{D}+07,0.225831378 \mathrm{D}+07$,

$30.228927140 \mathrm{D}+07,0.237905507 \mathrm{D}+07,0.254190578 \mathrm{D}+07,0.261962323 \mathrm{D}+07$,

$40.279105115 \mathrm{D}+07,0.288784535 \mathrm{D}+07,0.325392357 \mathrm{D}+07,0.333587375 \mathrm{D}+07$,

$50.401756216 \mathrm{D}+07,0.402493084 \mathrm{D}+07,0.418799472 \mathrm{D}+07,0.433004007 \mathrm{D}+07$,

$60.458217141 \mathrm{D}+07,0.480432319 \mathrm{D}+07,0.494997116 \mathrm{D}+07,0.543805494 \mathrm{D}+07$,

$70.576259209 \mathrm{D}+07,0.623977846 \mathrm{D}+07,0.713550729 \mathrm{D}+07,0.819418567 \mathrm{D}+07$ )

DO $10 I=1,64$

FREQ (I) =FREQ4 (I)

IF (N.EQ.7) FREQ (I) =FREQ7 (I)

CONTINUE

CALL INTGRL (HX , HY , FX , FY , EPSX , EPSY , NSRS , NBC , GX , GY)

DATA VX1/0.025\%

$P I=4 . D 0 * D A T A N(1 . D 0)$

$F L=(X * Y * 2 . * P I * D S Q R T(R D * T))$

$V X=0.025$

$V Y=D(2) / D(1) * D(4)$ 
C

$\mathrm{P}=(\mathrm{T} * * 3) /(12 . *(1-\mathrm{D}(4) * \mathrm{VY}))$
$\mathrm{E}(1)=\mathrm{D}(1) * \mathrm{P}$

$E(2)=D(2) * P$

$E\} 3\}=D\} 4\} * E(2)$

$E(4)=D(3) * T * * 3 / 12$.

IF (N.EQ.7) THEN

$E(5)=D(5) * Y * Y$

$E(6)=D(6) * X * X$

$E(7)=D(7) * X * Y$

ENDIF

C

CALL MATRIX (X, Y, HX , HY , FX , FY ,EPSX , EPSY , Q, NROH, NSRS , NBC , GX , GY , N )

DO $30 \quad I=1$, NROH

DO $30 \mathrm{~J}=\mathrm{I}$, NROW

$C(I, J)=0 . D O$

DO $20 \mathrm{~K}=1, \mathrm{~N}$

CONTINÚE

$C(J, I)=C(I, J)$

30

CONTINUE

CALL DEVCSF (NROH, C, 64, EGN, VEC , 64)

C

$E F F=0$.

DO $40 \quad I=1, M N$

40 CONTINUE

$E F F=E F F+(\operatorname{EGN}(I)-F R E Q(I)) * * 2$

C WRITE $(*, *) \mathrm{MN}, \mathrm{D}$

RETURN

$C * *$ END

SUBROUTINE INTGRL (HX , HY , FX FY , EPSX , EPSY , NSRS , NBC , GX , GY)

IMPLICIT REAL * $8(\mathrm{~A}-\mathrm{H}, \mathrm{O}-\mathrm{Z})$

DIMENSION HCC $(8,8), \operatorname{ECC}(8), \operatorname{HCF}(8,8), \operatorname{FCF}(8,8), \operatorname{ECF}(8), \operatorname{HFF}(8,8)$ $\$ F F F(8,8), \operatorname{EFF}(8), H_{X}^{\prime}(8,8), H Y^{\prime}(8,8), F X(8,8), F Y(8,8), \operatorname{EPSX}(8), \operatorname{EPSY}(8)$,

C
C
C $\$ \operatorname{GX}(8,8), \operatorname{GY}(8,8), \operatorname{GCC}(8,8), \operatorname{GCF}(8,8), \operatorname{GFF}(8,8)$

C THE VALUES IN THE FOLLOWING DATA STATEMENTS HAVE BEEN EXCISED

C AS THEY ARE THE SAME AS GIVEN IN THE PREVIOUS PROGRAM

C DATA ECC/

DATA HCF/

DATA FCF/

C DATA ECF/

C

DATA HFF/

C

C

DATA FFF/

C

DATA EFF/

DATA GCC/ 


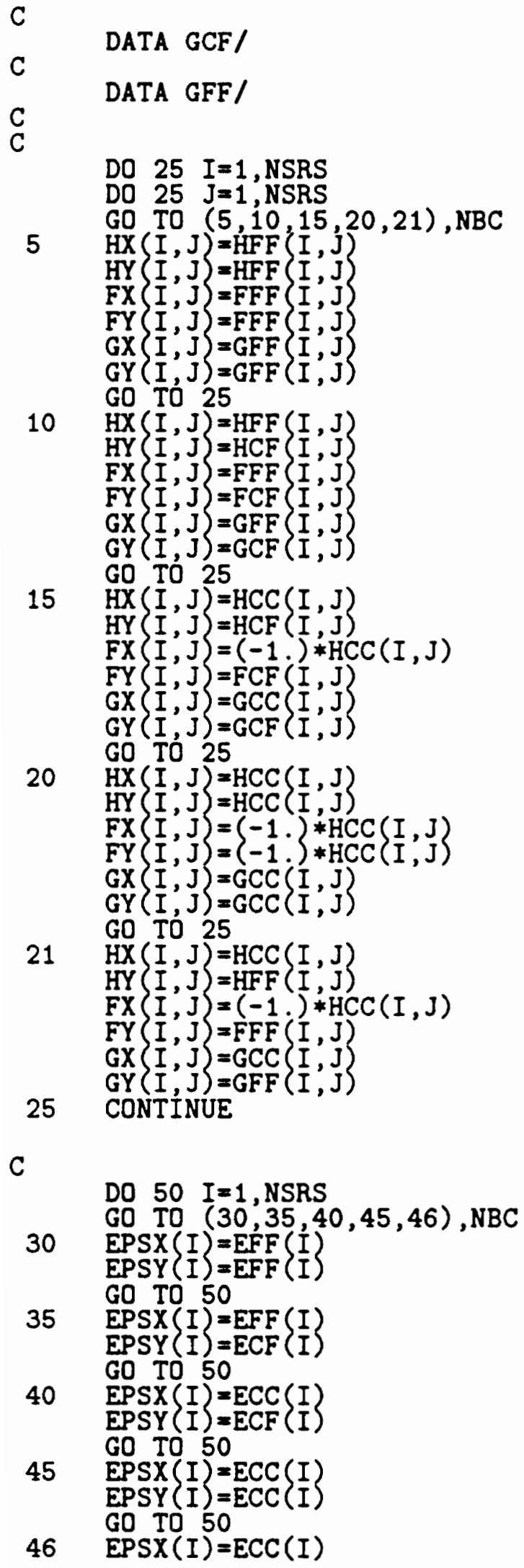

C

DO $50 \quad I=1$, NSRS GO TO $(30,35,40,45,46), \mathrm{NBC}$ EPSY $\{$ I $=$ EFF $(I)$ GO TO 50 GO TO 50

$40 \quad$ EPSX $(I)=E C C(I)$ $\operatorname{EPSY}(I)=\operatorname{ECF}(I)$ GD TO 50

$45 \quad \underset{\operatorname{EPSXX}}{\operatorname{EPS}}\{(I)=\operatorname{ECC}(I)$ GO TO 50

$46 \operatorname{EPSX}(I)=\operatorname{ECC}(I)$ 


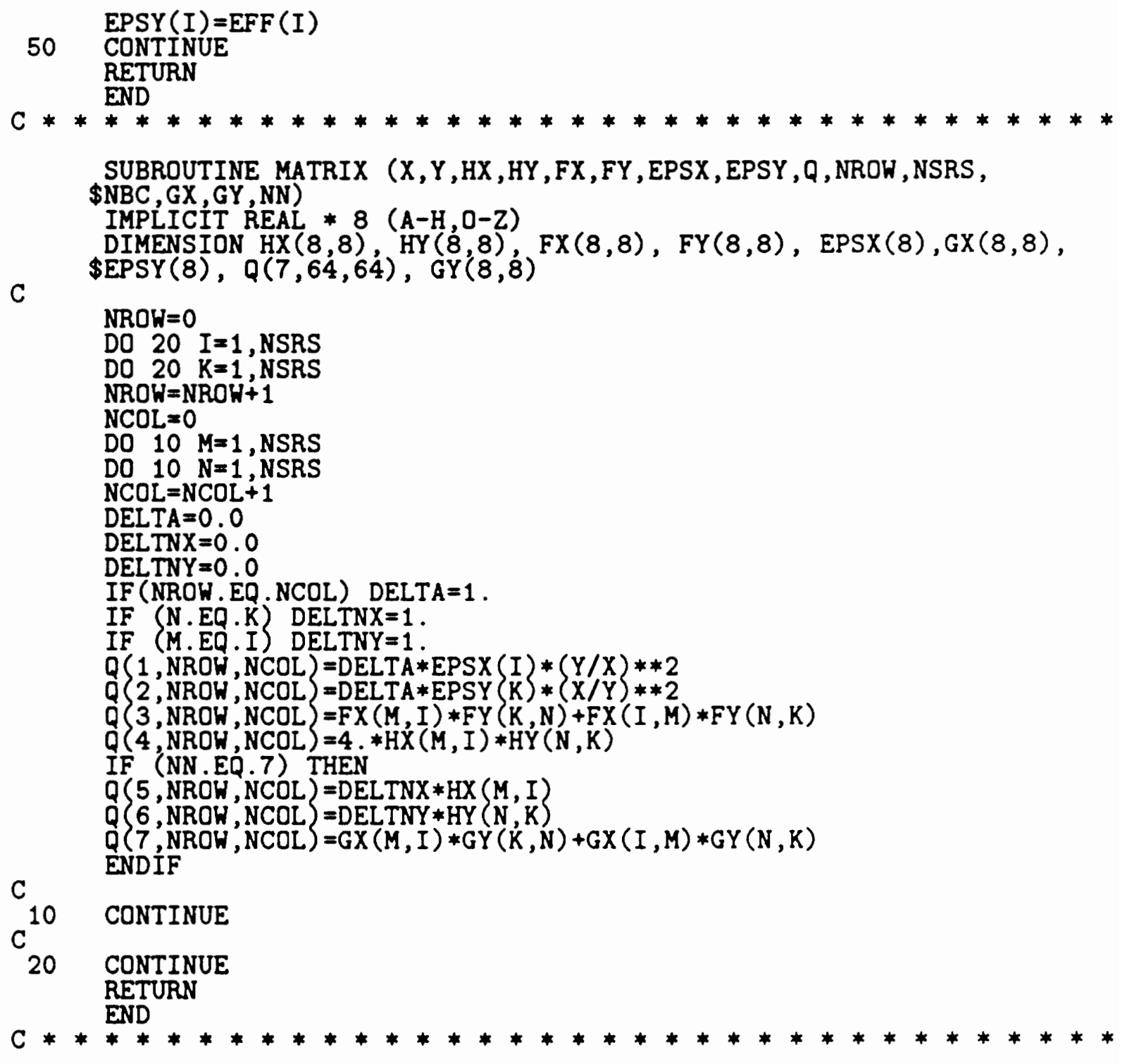




\section{Vita}

Juzer Mohsin Mohammedshah was born on November 29, 1966, in Bombay, India. After finishing High School in 1982, he entered the M.H.S.S. Polytechnic in Bombay, where he recieved his Diploma in Mechanical Engineering. Dissatisfied with that, he entered the University of Bombay for the B.S. degree in Mechanical Engineering. On completion of his B.S. in 1988, he joined the Virginia Polytechnic Institute and State University for M.S. in Mechanical Engineering.

He has decided to take a break from academia for a while and work for a design firm in Detroit, with the intention of coming back after a few years.

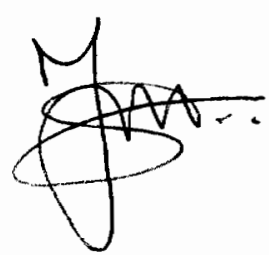

